Check for updates

Cite this: Nanoscale Horiz., 2021, 6,588

Received 8th March 2021,

Accepted 6th May 2021

DOI: $10.1039 / \mathrm{d} 1 \mathrm{nh} 00127 \mathrm{~b}$

rsc.li/nanoscale-horizons

\section{A current overview of the oxidative desulfurization of fuels utilizing heat and solar light: from materials design to catalysis for clean energy}

\author{
Xian Bin Lim (D) ab and Wee-Jun Ong (D) *abc
}

\begin{abstract}
The ceaseless increase of pollution cases due to the tremendous consumption of fossil fuels has steered the world towards an environmental crisis and necessitated urgency to curtail noxious sulfur oxide emissions. Since the world is moving toward green chemistry, a fuel desulfurization process driven by clean technology is of paramount significance in the field of environmental remediation. Among the novel desulfurization techniques, the oxidative desulfurization (ODS) process has been intensively studied and is highlighted as the rising star to effectuate sulfur-free fuels due to its mild reaction conditions and remarkable desulfurization performances in the past decade. This critical review emphasizes the latest advances in thermal catalytic ODS and photocatalytic ODS related to the design and synthesis routes of myriad materials. This encompasses the engineering of metal oxides, ionic liquids, deep eutectic solvents, polyoxometalates, metal-organic frameworks, metal-free materials and their hybrids in the customization of advantageous properties in terms of morphology, topography, composition and electronic states. The essential connection between catalyst characteristics and performances in ODS will be critically discussed along with corresponding reaction mechanisms to provide thorough insight for shaping future research directions. The impacts of oxidant type, solvent type, temperature and other pivotal factors on the effectiveness of ODS are outlined. Finally, a summary of confronted challenges and future outlooks in the journey to ODS application is presented.
\end{abstract}

\section{Introduction}

Moving into the 21st century, meteoric population growth and industrialization have kindled the incessant proliferation of global energy demand. As the paramount energy source under current technologies, fossil fuels have been substantially consumed for energy production and transportation, leading to the colossal release of hazardous gases, including sulfur oxides $\left(\mathrm{SO}_{x}\right)$, nitrogen oxides $\left(\mathrm{NO}_{x}\right)$ and carbon oxides, into the atmosphere. Such increased emissions have signaled the advent of an environmental crisis, eliciting the attention of the global community. Currently, $\mathrm{SO}_{x}$ emission is a terrifying environmental issue because of its contribution to acid rain and particle pollution, which engender unceasing and deleterious impacts on the entire ecosystem and human health. ${ }^{1-3}$ In catalysis,

\footnotetext{
${ }^{a}$ School of Energy and Chemical Engineering, Xiamen University Malaysia, Selangor Darul Ehsan 43900, Malaysia. E-mail: weejun.ong@xmu.edu.my

${ }^{b}$ Center of Excellence for NaNo Energy \& Catalysis Technology (CONNECT), Xiamen University Malaysia, Selangor Darul Ehsan 43900, Malaysia ${ }^{c}$ College of Chemistry and Chemical Engineering, Xiamen University, Xiamen 361005, China
}

the existence of sulfur contaminants in fossil fuels also triggers the deactivation of valuable metallic catalysts such as nickel and palladium that are typically utilized in automobile exhaust purification and the catalytic reforming process, thereby causing poor catalytic performance as well as enormous financial damage. ${ }^{4}$ More significantly, the combustion of heavy fuel (e.g. diesel with a higher degree of sulfur content) greatly aggravates these impacts on the world. ${ }^{5}$ Embracing the preservation of biodiversity as well as the health and welfare of human communities, developed countries like the United States and European Union members have gradually tightened environmental regulations to control the sulfur content in diesel fuels and gasolines and enforce the utilization of ultra-low-sulfur fuels $(\leq 10 \mathrm{ppm})$ in transportation and industry. ${ }^{6}$ To safeguard the vitality of our planet and future generations and fulfill stringent regulations, an efficacious desulfurization technology is mandatory in the oil refinery industry to curb the sulfur level in fuels.

Over the past few decades, hydrodesulfurization (HDS) has been extensively applied to attenuate environmental stress and the effect of sulfur poisoning on oil processing. ${ }^{7,8}$ In the HDS of gasoline, the organosulfur constituents such as thiols, sulfides and disulfides are fully converted into hydrocarbons and 
hydrogen sulfide $\left(\mathrm{H}_{2} \mathrm{~S}\right)$ gas by interacting with $\mathrm{H}_{2}$ gases over transition metal catalysts at $300-450{ }^{\circ} \mathrm{C}$ and $10-250$ atm. ${ }^{9,10}$ However, in the case of diesel fuel, a lower HDS efficiency is obtained due to the emergence of refractory sulfur compounds, namely thiophene (Th), benzothiophene (BT), dibenzothiophene (DBT) and other thiophene derivatives, which possess outstanding stability in their aromatic chemical structure as well as strong steric hindrance effects on the active sites of the catalyst. ${ }^{11}$ Accordingly, the removal of these aromatic sulfur compounds from heavy fuels through HDS necessitates harsher reaction conditions and a more active catalyst to overcome the strong $\mathrm{C}-\mathrm{S}$ bond energy. The reactivity order of various sulfur compounds in fuels is presented in Fig. 1. Obviously, the harsh operational conditions and the release of hazardous $\mathrm{H}_{2} \mathrm{~S}$ gas in HDS have limited its prospects in sustainable chemistry. Also, the mediocre efficiency of sulfur removal, the immense energy expenses and investment capital required and the dangerous process have set a firm barrier against the industrial production of ultra-low-sulfur diesels via HDS. Therefore, a productive, economical, streamlined and low-risk desulfurization method is continually being pursued to replace HDS at an industrial scale.

Benefitting from the arduous efforts of researchers, several potential fuel desulfurization technologies have been discovered, paving the way toward a pollution-free Earth. The alternative desulfurization methods are adsorptive desulfurization (ADS) ${ }^{15-17}$ biodesulfurization (BDS), ${ }^{18}$ extractive desulfurization (EDS) ${ }^{19,20}$ and oxidative desulfurization (ODS), ${ }^{21}$ which have been thoroughly reviewed in the literature to date. Among the frontline desulfurization routes, ODS has recently become a research hotspot, attributed to its attractive advantages such as moderate operating conditions, magnificent selectivity, utilization of safe and low-priced oxidant and prominent efficiency in removing aromatic sulfur constituents from diesel fuels. ${ }^{22-24}$ For instance, scientists showed that the utilization of ODS to purify diesel fuel achieved up to $92 \%$ sulfur removal, which was far superior to the EDS method which attained only $45 \% .^{25}$ In addition to the appealing merits, the burgeoning market demand for ultra-low-sulfur fuels due to strict environmental regulations and the limitations of the ultra-deep HDS process have ignited an abrupt surge of research interest in the ODS of fuels, especially in the past 10 years. This can be seen in the Web of Science database with a search keyword of "oxidative desulfurization". As depicted in Fig. 2, the number of publications on ODS has progressively grown from 2011 to 2020. The citations of ODS works have also increased drastically since 2012. It is anticipated that the soaring trend of ODS research will persist in the future. This has also unambiguously highlighted the significance of ODS and the rising urgency for more environmentallyfriendly and sustainable desulfurization technologies in the field of environmental remediation. However, there is still progress to be made to commercialize ODS given the limited understanding of the modification strategies to revamp the intrinsic features of ODS catalysts to achieve maximum catalytic activity. Additionally, several drawbacks, such as the transient stability and life cycles of catalysts, lengthy reaction time and high consumption of oxidant, have markedly hindered the progress of ODS commercialization. In this context, additional studies on ODS are urgently needed to alleviate these issues and create a more sustainable ODS process.

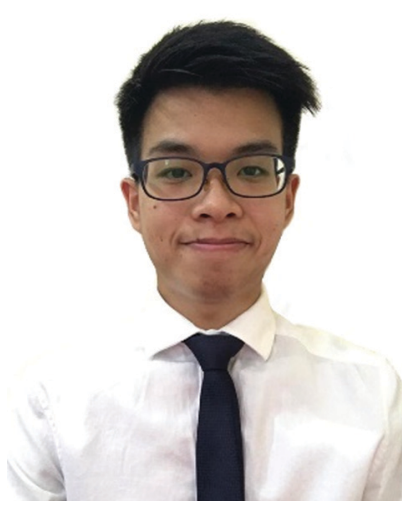

Xian Bin Lim
Xian Bin Lim is currently a research student at the School of Energy and Chemical Engineering at Xiamen University, Malaysia under the supervision of Assoc. Prof. Dr Wee-Jun Ong. His current research interests include the design of catalysts for oxidative desulfurization, photocatalysis and energy conversion.

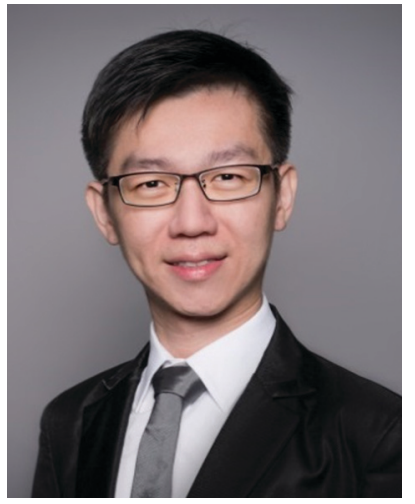

Wee-Jun Ong

Wee-Jun Ong received his BEng and $P h D$ in Chemical Engineering from Monash University. He is an Associate Professor at the School of Energy and Chemical Engineering at Xiamen University, Malaysia. In 2021, he became a Director of "CONNECT" research center. Previously, he was a scientist at the Agency for Science, Technology and Research ( $\left.A^{*} S T A R\right)$, Singapore. In 2019, he was a visiting scientist at Technische Universität, Dresden and a visiting professor at Lawrence Berkeley National Laboratory. At present, he serves as the Chief Editor of Frontiers in Nanotechnology, Associate Editor of Frontiers in Chemistry, Beilstein Journal of Nanotechnology and Engineering Reports, and Board Member of Materials Horizons, Nano Research, Langmuir, Chinese Journal of Catalysis, Scientific Reports and Nanotechnology. His research interests include nanomaterials for advanced oxidative reactions, photocatalytic, photoelectrocatalytic and electrochemical processes, and energy storage devices. For more details, refer to https://sites.google.com/site/ wjongresearch/. 


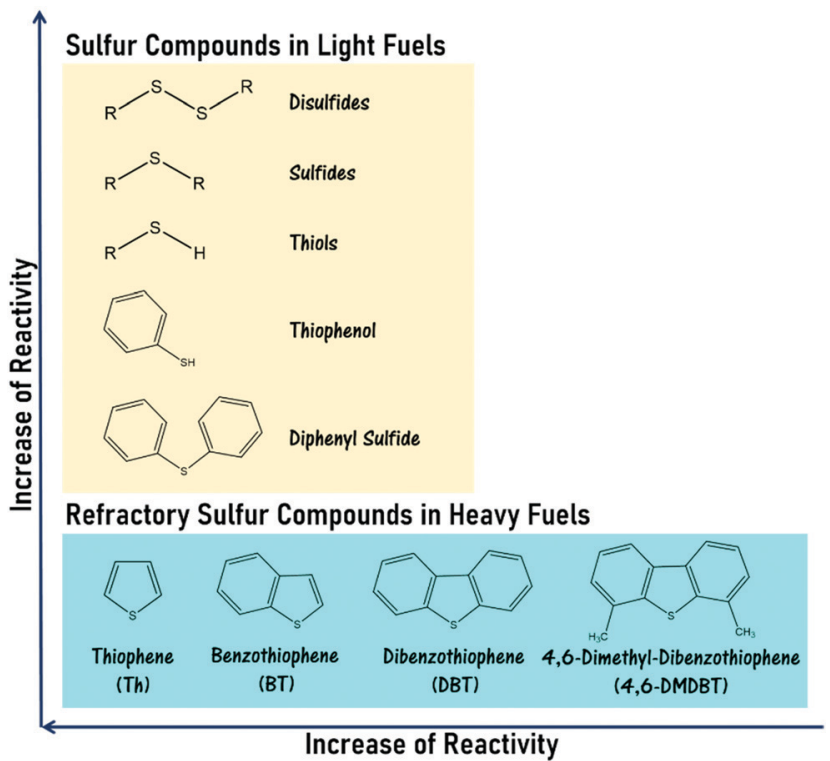

Fig. 1 Sulfur compounds and refractory sulfur compounds, which are found in light fuels and heavy fuels, respectively, in the order of reactivity in HDS. ${ }^{12-14}$

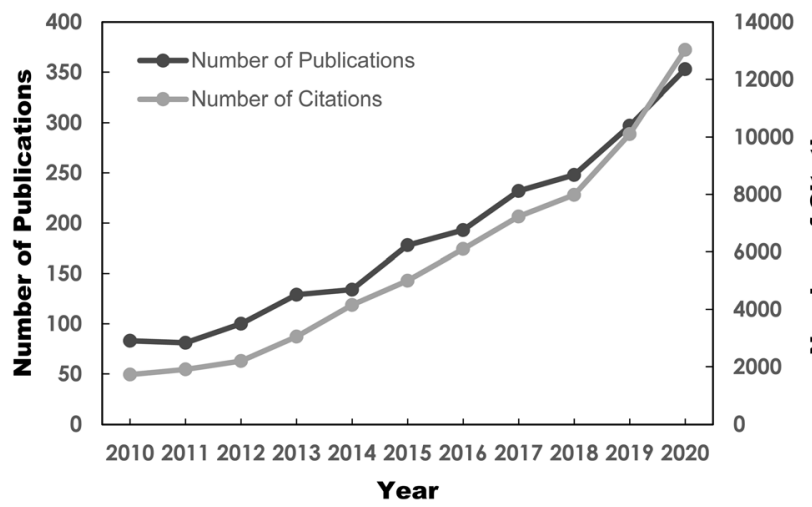

Fig. 2 Number of published reports and citations on ODS from 2010 to 2020, sourced from Web of Science database with the topic keyword "oxidative desulfurization" on 3rd May 2021.

The fact that catalysts have been denoted as the pivotal factor in accomplishing an efficient ODS process has caused scholars in catalytic science to dive deep into the intrinsic properties of myriad materials to seek prospective materials with outstanding catalytic activity in ODS. To date, copious review papers have been published to provide mechanistic insights into the application of different materials in ODS driven by thermal or light energy. Rajendran et al. systematically described the significant relationships between the catalysts, operating parameters and reaction mechanisms in ODS under different classifications. ${ }^{26}$ In the work of Zhou and co-workers, the salient challenges in photocatalytic ODS, including rapid charge carrier recombination rate and deficient light absorption capability, along with the countermeasures were reported to guide the future development of photocatalytic ODS. $^{27}$ The catalytic performances of various homogeneous and heterogeneous ODS catalysts have also been critically discussed and compared in several reports. ${ }^{28-30}$ The applications of ionic liquids (ILs), ${ }^{31-33}$ polyoxometalates (POMs), ${ }^{34}$ metalorganic frameworks (MOFs) ${ }^{35,36}$ and graphene ${ }^{11}$ in ODS have also been individually reviewed. Although these scientific reviews have encapsulated a wide panorama of the innumerable ODS applications, the structure-activity connection of multiple materials, which is of vital importance to direct material engineering for shaping catalysts with extraordinary catalytic activity and stability in ODS, has not yet been completely unraveled. To the best of our knowledge, an encyclopedic summary of the synergistic effect on ODS performance from the hybridization of many materials with unique characteristics has not been published in the literature of ODS.

Additionally, a limited review article targets the configuration of the catalyst for ODS. To develop a pragmatic and effective ODS process for industrial application, rational design of the catalyst is a crucial piece of the puzzle. The reaction parameters in a synthesis approach have a huge impact on the physico-chemical properties of catalysts and further influence their catalytic performance in ODS. None of the previous scholars have covered thermal-driven and light-driven ODS in a single review paper. This is very useful to lay a substantial knowledge foundation on light-driven ODS, contributing a groundbreaking reference for designing versatile catalysts which are applicable for both thermal-driven and light-driven ODS processes. More importantly, the incorporation of inexhaustible photon energy in various applications, especially in the realms of environmental protection and energy production, was reported as one of the future trending research directions in the World Economic Forum 2020. ${ }^{37}$ These knowledge gaps have greatly invigorated us to compose another useful ODS review.

In this review, the core theories and fundamental mechanisms of thermal-driven and light-driven ODS are first spotlighted to create an overall picture of ODS. In the subsequent sections, the focal point is the influences of synthesis pathways and modification strategies toward ameliorated physico-chemical properties, including the morphologies, compositions, topographies and optical properties of myriad catalysts together with their corresponding catalytic performances in ODS. The ODS catalysts are categorized according to their species as metal oxides, ILs, deep eutectic solvents (DESs), POMs, MOFs, metalfree nanomaterials and their hybrid heterostructured composites, which will be thoroughly discussed in their respective sections. Moreover, theoretical insights into the reaction mechanisms of different materials in thermal-driven and light-driven ODS will be elucidated to explore the structureactivity connection. This current review concludes with a concise summary, an overview of the encountered challenges in ODS based on the research works, accompanied by a number of constructive recommendations and viewpoints to proffer fruitful guidance which will be conducive to the commercialization of ODS in years to come. In short, the predominant objectives of this critical review are to recount the ongoing innovations in ODS in the topics of synthesis approach, catalyst design, 


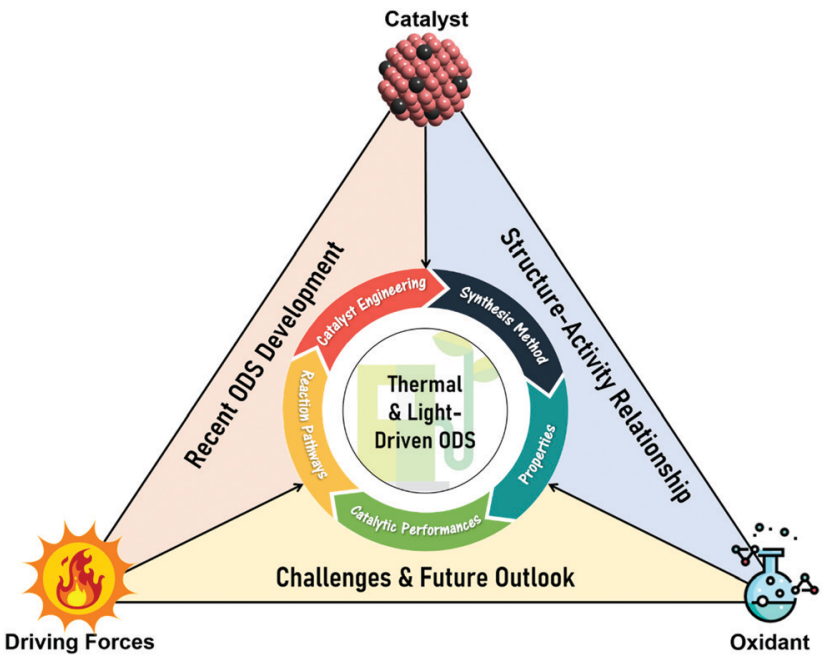

Fig. 3 Graphical synopsis of the five predominant focal points, including engineering, synthesis, properties, catalytic performance and reaction mechanisms of catalysts, in contributing insights into recent ODS advancements, the structure-activity relationship of catalysts and the challenges and future outlook in thermal and light-driven ODS systems.

properties, reaction pathways and catalytic performance, and to serve as a useful scaffold for future research directions on ODS (Fig. 3).

\section{Oxidative desulfurization (ODS) process}

ODS is a two-step process that begins with the oxidation of aromatic sulfur compounds (Fig. 4) in the presence of an appropriate oxidizing agent such as $\mathrm{H}_{2} \mathrm{O}_{2}$ and $\mathrm{O}_{2}$, followed by the separation of the oxidized sulfur species from the fuels through solvent extraction or distillation. ${ }^{29}$ Owing to the sluggish oxidation rate, catalysis is typically integrated into ODS to boost the reaction kinetics by lowering the requisite activation energy for the conversion of the oxidant into the corresponding reactive oxygen species. The theory of ODS involves the chemical transformation of sulfur compounds into sulfones, which have an easily removable structure, by modifying their chemical properties. ODS endows increased polarity and reduced boiling point to sulfur compounds by attaching $\mathrm{O}_{2}$ at the $\mathrm{S}$ atom. ${ }^{38}$ This can greatly enhance the miscibility of sulfur compounds in polar solvents and increase the boiling point difference between hydrocarbons and sulfur compounds, thereby facilitating the downstream separation process to yield ultra-low-sulfur fuels. After the incorporation of oxidizing agents and catalysts, the driving force both initiates and accelerates the ODS process. Ascribed to their superiority in accessibility, economy and environmental friendliness, thermal and light energies are the front-runners and are capable of offering abundant dynamism to drive the ODS process under current technology. Additionally, different operational parameters, such as reaction temperature, dosage of catalyst and amount of oxidant, impact the efficiency of ODS and the quality of the purified fuels. The fundamental concepts of thermal-driven ODS and photo-driven ODS are discussed in the next sections.

\subsection{Thermal-driven ODS}

During thermal-driven ODS, heat energy is incorporated into the ODS process as the source of activation energy to propel the reaction. To summarize the overall idea of thermal-driven ODS, the mechanism for the oxidation of DBT using $\mathrm{O}_{2}$ as an example oxidant is illustrated in Fig. 5a. Following kinetic molecular theory, the kinetic energies of oxidants, sulfur compounds and catalyst are intensified after absorbing thermal energy from the surroundings, which further stimulates effective collisions between particles. The rapid particle collisions and ample supply of activation energy (1) prompt the adsorption of $\mathrm{O}_{2}$ on the surface of the catalyst (2), leading to the conversion of $\mathrm{O}_{2}$ into highly reactive oxygen species. Due to the vigorous affinity of the sulfur atom towards oxygen, DBT is then activated by the active oxygen groups on the surface of catalyst to form S-O bonding, creating DBT sulfoxide (3). As DBT sulfoxide is thermodynamically unstable, it reacts with another active oxygen species to yield DBT sulfone as the final product (4). Lastly, DBT sulfone is desorbed from the catalyst's surface. As mentioned previously, the resulting fuels undergo a specific downstream purification process to eliminate the oxidized sulfur compounds. In comparison with other desulfurization techniques, the reaction temperature of thermal-driven ODS prevalently stays in the range of 35 to $90{ }^{\circ} \mathrm{C},{ }^{38}$ which is much lower than those in the conventional HDS $\left(300-360{ }^{\circ} \mathrm{C}\right)^{39-41}$ and
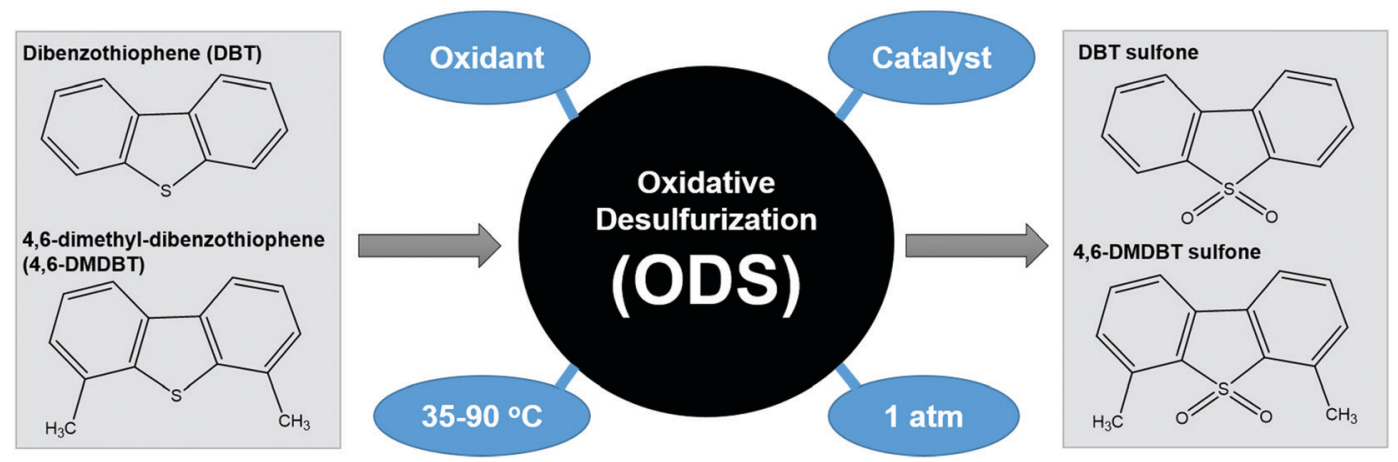

Fig. 4 Typical reaction route for ODS of DBT and 4,6-DMDBT. 
ADS approaches $\left(\sim 350{ }^{\circ} \mathrm{C}\right) .^{42}$ The energy efficiency of thermaldriven ODS tends to preserve operational cost and minimize the safety considerations for the desulfurization process, opening a prospective door to future industrial application.

\subsection{Light-driven ODS}

In general, light-driven ODS can be described as a combination of photocatalysis and conventional ODS. Certainly, knowledge of photocatalysis is indispensable to unravel the mechanistic insights on light-driven ODS. To build an explicit understanding, the operation of light-driven ODS of DBT with $\mathrm{O}_{2}$ as the oxidant is depicted in Fig. 5b. To commence photocatalysis, a material with light-harvesting property is demanded. Moreover, the photon energy in the incoming light must be equivalent to or higher than the band gap of the photocatalyst to initiate photocatalysis. ${ }^{43}$ Once the above criteria are fulfilled, light absorption by the photocatalyst takes place (1) upon the illumination of solar light. After the stable electrons in the valence band $(\mathrm{VB})$ receive enough energy from the photons, they are excited and lifted to the conduction band (CB) at a higher energy level (2). ${ }^{44,45}$ Under this circumstance, electronhole pairs are momentarily induced and move from the bulk of photocatalyst to the surface to generate electron-rich and

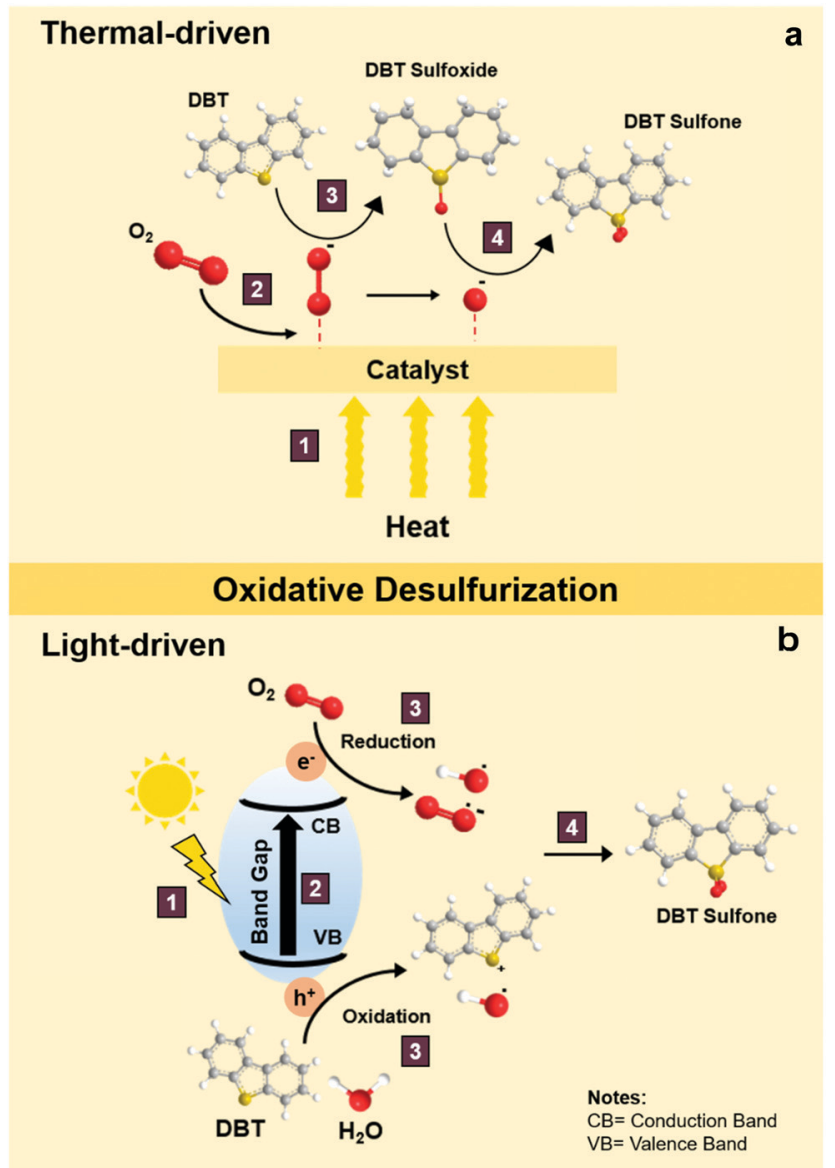

Fig. 5 Reaction mechanisms of sulfur removal by DBT via (a) thermaldriven ODS and (b) light-driven ODS. hole-rich sites. At the same time, the reactants in the bulk liquid phase diffuse and absorb onto the surface of the photocatalyst. ${ }^{46,47}$ The adsorbed DBT and $\mathrm{H}_{2} \mathrm{O}$ molecules readily react with a hole in the $\mathrm{VB}$ and form reactive intermediates composed of a radical cation and hydroxyl radicals $\left({ }^{\bullet} \mathrm{OH}\right)$, respectively, through the oxidation process (3). ${ }^{27}$ Meanwhile, $\mathrm{O}_{2}$ undergoes a reduction process in the CB (3) and transforms into energetic oxygen species including superoxide radicals $\left({ }^{\bullet} \mathrm{O}_{2}{ }^{-}\right)$and ${ }^{\bullet} \mathrm{OH}$ radicals (3). ${ }^{48-52}$ Consequently, the redox reaction is accomplished, followed by the desorption of the products from the surface of the photocatalyst. Ultimately, a reaction between the DBT reactive intermediate and oxygen radicals occurs to produce DBT sulfoxide which is subsequently converted to DBT sulfone (4).

In contrast to thermal-driven ODS, light-driven ODS employs photon energy to energize the catalyst in order to carry out redox reactions. Over the last decade, attention has turned to light-driven ODS which is presumed to be the leading edge of desulfurization technology and a viable replacement for conventional desulfurization techniques because of its benefits in economy, sustainability and safety. ${ }^{53,54}$ Nevertheless, the emergence of several difficult challenges, such as rapid electron-hole recombination, a narrow light absorption range and sluggish light response, has hampered the industrialization of photo-driven ODS. In a later section, the strenuous efforts by previous researchers to tackle these handicaps will be critically discussed.

\section{Catalyst design and mechanisms for thermal-driven ODS}

To date, impressive progress and outcomes have been gained by adopting the thermal-driven ODS process with a variety of catalysts to desulfurize fuels. Generally, the application of a heterogeneous catalyst in thermal-driven ODS is more favorable than a homogenous catalyst such as acetic acid ${ }^{55}$ and phosphotungstic acid ${ }^{56,57}$ due to the remarkable trait of easing the downstream separation process, which reduces the overall capital expenditure for the ODS process. Even so, homogeneous catalysts cannot be neglected completely as they can constitute an extensive mass transfer phase for the ODS reaction, thereby accelerating the rate of reaction. Interestingly, every catalyst exhibits different competence in ODS, which is attributed to differences in natural characteristics and reaction mechanisms. The synthesis approaches, structure-activity relationships and reaction pathways of various catalysts in thermaldriven ODS will be evaluated extensively in the following sections.

\subsection{Application of metal oxides in ODS}

In the field of catalysis, metal oxides with a Lewis acid characteristic are prominent and inveterate catalysts that speed up most important reactions, such as oxidation and acid-base reactions, compensating for the drawback of poor selectivity. ${ }^{58,59}$ Significantly, metal oxides have been advocated to replace precious 
metals such as $\mathrm{Pt}^{60}$ and $\mathrm{Au}^{61}$ in performing ODS to counter the high price and restricted availability that are stumbling blocks to their industrial application. In line with previous research, various relatively economical metal oxides, such as $\mathrm{MoO}_{3}, \mathrm{WO}_{3}, \mathrm{Co}_{3} \mathrm{O}_{4}$, $\mathrm{MnO}_{2}$ and so on, have been highlighted as promising candidates for fuel purification via ODS. ${ }^{62-71}$

For the synthesis of metal oxide catalysts, the calcination method has been broadly adopted because of its facile and controllable steps. ${ }^{72}$ Basically, the formulation of metal oxide catalysts via calcination can be referred to as the activation of metal precursors in the presence of oxygen or air under elevated temperature, resulting in the oxidation of the metal. Due to the variations in metal precursors, other synthesis techniques, such as solvothermal and hydrothermal methods, have been utilized to shape certain metal oxide catalysts, like $\mathrm{WO}_{3}$-based catalysts. ${ }^{66,70}$ In contrast to the calcination method, the solvothermal and hydrothermal routes exhibit comparably intricate processes but are carried out under lower temperatures. In these synthesis routes, the heating temperature and duration play decisive roles in controlling the nucleation and growth of metallic nanoparticles that crucially affect the morphologies of the resulting metal oxide catalysts. As revealed by Thalgaspitiya et al., $\mathrm{WO}_{3}$ fabricated at a higher calcination temperature and shorter reaction time exhibited a smaller specific surface area because of sintering. ${ }^{73}$ Eventually, the decrement of active sites brings about lower catalytic activity in ODS. Recently, Zhang et al. impregnated $\mathrm{W}$ precursors in the structure of poly(methyl methacrylate) and performed calcination to eliminate the template and oxidize the $\mathrm{W}$ to engineer $3 \mathrm{D}$ nanoporous $\mathrm{WO}_{3}$ with oxygen defects $\left(3 \mathrm{DOM} \mathrm{WO}_{x}\right){ }^{74}$ The $3 \mathrm{DOM} \mathrm{WO}_{x}$ fabricated at different calcination temperatures demonstrated different rates of 4,6-DMDBT oxidation owing to morphology variations. As seen in the SEM images (Fig. 6a and b), 3DOM $\mathrm{WO}_{x}$ calcined at $500{ }^{\circ} \mathrm{C}\left(3 \mathrm{DOM} \mathrm{WO} \mathrm{WO}_{x}-500\right)$ possessed a more disordered porous structure compared with that calcined at $400{ }^{\circ} \mathrm{C}\left(3 \mathrm{DOM} \mathrm{WO}_{x}-400\right)$ due to the breakdown of the structure from overheating. This led to a lower pore volume and reduced the number of available active sites for ODS. The mass diffusion of sulfur compounds toward the active sites was also restricted. As a result, $3 \mathrm{DOM} \mathrm{WO}_{x}-400$, with greater morphological benefits, achieved $99 \%$ oxidation of 4,6-DMDBT in $4 \mathrm{~h}$ with the continuous injection of air at $120{ }^{\circ} \mathrm{C}$ (Fig. 6c). Accordingly, optimization of the calcination temperature is imperative to preserve the advantageous textual properties of metal oxide catalysts and attain outstanding desulfurization activity in ODS.

3.1.1 Mixed metal oxides. In view of the catalyst morphology's impact on ODS activity, a few recent studies have signified that nanorod and nanosheet mixed metallic oxide catalysts are potentially the key to ODS advancement. ${ }^{75-77}$ However, the decision on whether nanosheet catalysts perform better than nanorod catalysts in ODS is still under debate. To clarify this, Co-Mo-O nanorods and nanosheets were fabricated by the co-precipitation method prior to calcination (Fig. 6d) in the works of Zhang et al. and Dong et al. ${ }^{75,77}$ As seen in Fig. 6e and f, the thickness of the Co-Mo-O nanosheet was around $2-3 \mathrm{~nm}$, which was thinner than the
Co-Mo-O nanorod with a $80-120 \mathrm{~nm}$ width. With a relatively lower thickness, the Co-Mo-O nanosheets showed complete conversion of DBT after $4 \mathrm{~h}$ using $\mathrm{O}_{2}$, whereas the Co-Mo-O nanorods achieved merely 46\% DBT conversion after $6 \mathrm{~h}$. The significant discrepancy in DBT conversion underscores the impact of catalyst morphology on the catalytic activity in ODS, as the thinner material was able to offer a larger specific surface area as well as many more surface active sites. Undoubtedly, the nanosheet catalyst has a higher surface area to volume ratio than the nanorod catalyst and provides an excellent platform for ODS. In the research of Liu et al., a hierarchical hollow $\mathrm{Co}-\mathrm{Ni}-\mathrm{Mo}-\mathrm{O}$ nanotube was constructed by growing $\mathrm{CoMoO}_{4} /$ $\mathrm{NiMoO}_{4}$ ultrathin nanosheets on the surface of $\mathrm{MoO}_{3}$ nanotubes via hydrothermal method (Fig. 6i). ${ }^{76}$ The $\mathrm{Co}-\mathrm{Ni}-\mathrm{Mo}-\mathrm{O}$ catalyst exhibited the best performance in converting DBT to DBT sulfone among the other catalysts ( $\mathrm{Ni}-\mathrm{Mo}-\mathrm{O}$, Co-Mo-O and $\mathrm{MoO}_{3}$ nanotubes) due to the increase in surface electron density after the immobilization of the $\mathrm{Co}$ and $\mathrm{Ni}$ species. In detail, the migration of electrons from $\mathrm{Ni}$ and $\mathrm{Co}$ to $\mathrm{Mo}$ magnified the capability of Mo to activate $\mathrm{O}_{2}$ for DBT oxidation (Fig. 6h). Collectively, this research demonstrates the importance of adopting a suitable dopant as the electron density promoter to enhance ODS activity. Fascinatingly, contention emerged in the mechanism of Co-Mo-O oxidizing DBT (Fig. 6g) proposed by Zhang et al., in which $\mathrm{O}_{2}$ was initially energized by Co instead of Mo and reacted with Mo to form the Mo-O-O active species. ${ }^{75}$ As an explanation for this circumstance, Co possesses a lower electronegativity than Mo in the absence of $\mathrm{Ni}$ which made Co more susceptible to donating electrons to $\mathrm{O}_{2}$ due to the lower attraction force from the metal center. However, the effect of coupling different metal oxide species on the reaction pathway in ODS is still ambiguous: will activation of the oxidant be carried out at electron-rich sites or low electronegativity sites? This knowledge gap would be an interesting research topic to establish a better mechanistic understanding of the ODS of fuels using mixed metallic oxide catalysts. Despite mixed metal oxide nanosheets realizing the goal of zero-sulfur fuels, there is still limited information on their application in the ODS of real fuels, which is crucial to determine their viability for industrialization.

3.1.2 Metal oxides on various supports. Despite their remarkable activity in ODS, metal oxide nanoparticles with high surface energy are susceptible to agglomeration, which is the highest hurdle to their practical application. The formation of metal oxide clusters with smaller surface areas results in a low density of active sites, which substantially restricts catalytic activity in ODS. To ameliorate this disadvantage, metal oxides are commonly dispersed on a suitable support with very large surface area to increase the exposure of active sites and achieve higher catalytic activity in ODS. Generally, the incipient wetness impregnation method (IWI) with calcination has been extensively used to fabricate heterogeneous catalysts, including metal oxide composites. For instance, Abu Bakar et al. prepared $\mathrm{MoO}_{3} / \mathrm{Al}_{2} \mathrm{O}_{3}$ catalyst via IWI by incorporating the Mo precursor solution with the aluminum precursor and proceeded to calcination in air at 

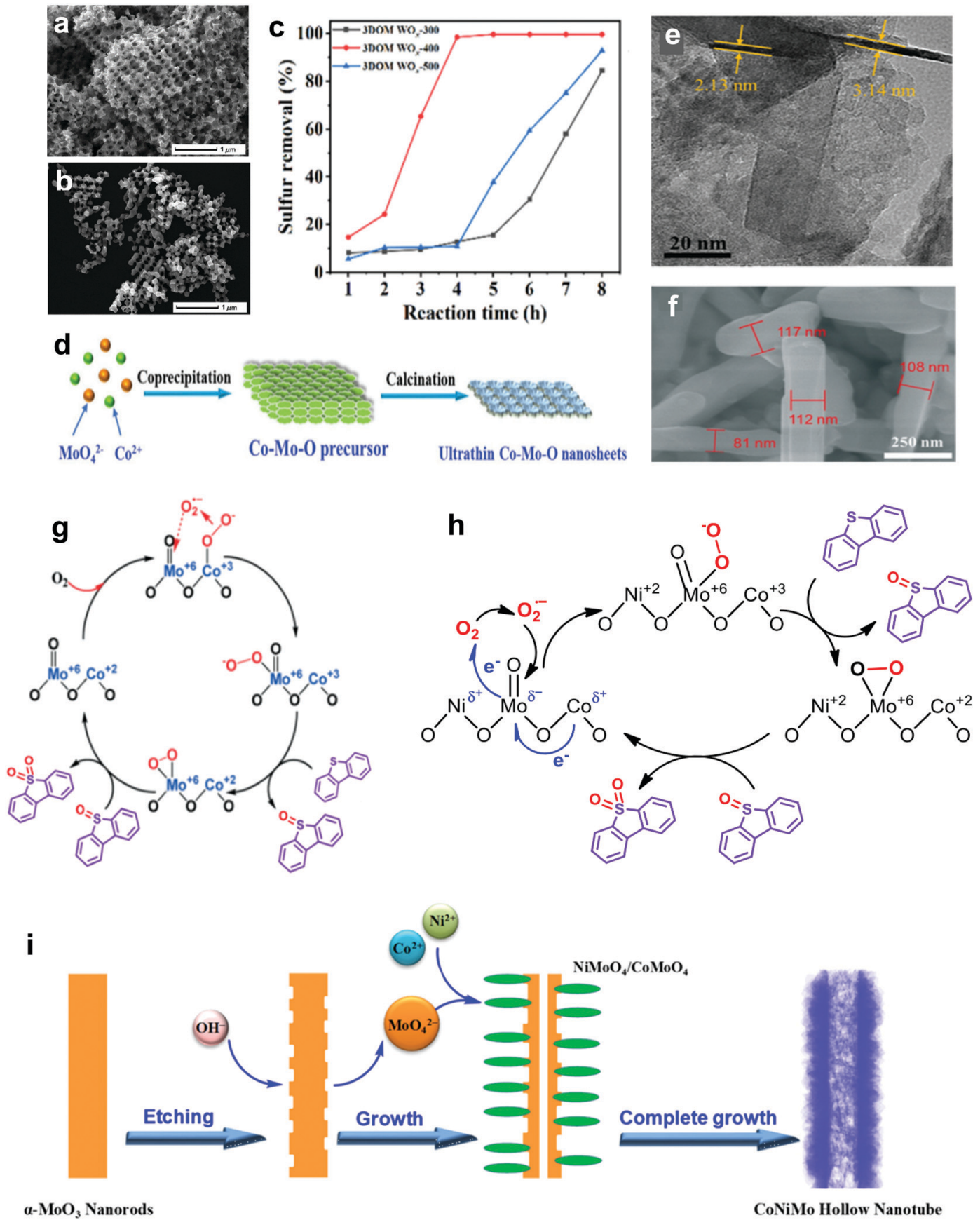

Fig. 6 SEM images of (a) 3DOM WO ${ }_{x}-400$ and (b) 3DOM WO -500 . (c) Removal efficiencies of 4,6-DMDBT using $\mathrm{O}_{2}$ at $120{ }^{\circ} \mathrm{C}$ over $3 \mathrm{DOM} \mathrm{WO} \mathrm{O}_{x}-300$, 3DOM WO -400 and $3 \mathrm{DOM} \mathrm{WO}_{x}-500$, synthesized at calcination temperatures of 300,400 and $500{ }^{\circ} \mathrm{C}$, respectively. Reprinted with permission. ${ }^{74}$ Copyright 2021. American Chemical Society. (d) Synthesis mechanism and (e) TEM image of Co-Mo-O nanosheet. Reprinted with permission. ${ }^{77}$ Copyright 2019, Royal Society of Chemistry. (f) SEM image of Co-Mo-O nanorod and (g) its proposed reaction pathway in the ODS of DBT. Reprinted with permission. ${ }^{75}$ Copyright 2019, Royal Society of Chemistry. (h) Plausible reaction mechanism for ODS of DBT by Co-Ni-Mo-O nanotube and (i) its fabrication route. Reprinted with permission. ${ }^{76}$ Copyright 2020, American Chemical Society.

$500{ }^{\circ} \mathrm{C}$ to activate the catalyst. ${ }^{62}$ In addition to the previous report, there is much literature discussing the employment of IWI in the synthesis of $\mathrm{MoO}_{3} / \mathrm{Al}_{2} \mathrm{O}_{3}$ catalysts. ${ }^{63,67,78,79}$ Besides $\mathrm{MoO}_{3} / \mathrm{Al}_{2} \mathrm{O}_{3}$, Abdalla and his co-workers embedded $\mathrm{Na}_{2} \mathrm{WO}_{4}$ into $\mathrm{Al}_{2} \mathrm{O}_{3}$ through a similar synthesis method but at a slightly higher calcination temperature $\left(540{ }^{\circ} \mathrm{C}\right) \cdot{ }^{80}$ Likewise, in the work of Sampathar et al., the IWI technique was employed to impregnate $\mathrm{Co}_{3} \mathrm{O}_{4}$ and $\mathrm{MnO}_{2}$ into $\mathrm{Al}_{2} \mathrm{O}_{3}$ with an ancillary rolling step prior to the aging and drying stage to achieve uniform dispersion of metal oxide particles. ${ }^{71}$ In summary, the combination of the IWI method and calcination has dominated the arena of metal oxide composite preparation because of its technical simplicity, potential for commercialization and widespread applicability for most common metal oxides. 
3.1.2.1 Aluminum oxide supported metal oxides. In 2011, Jia's group reported the complete oxidation of DBT by $\mathrm{MoO}_{3} / \gamma-\mathrm{Al}_{2} \mathrm{O}_{3}$ in merely $15 \mathrm{~min}$ at $60{ }^{\circ} \mathrm{C} .{ }^{78}$ In their findings, the utilization of solvents like acetonitrile and methanol crucially reduced the oxidation of DBT (Fig. 7a) due to the existence of adsorption competition between the solvent molecules and DBT on the active sites of $\mathrm{MoO}_{3} / \gamma-\mathrm{Al}_{2} \mathrm{O}_{3}$. From the outlook of sustainability, the omission of solvent in ODS is also helpful in cutting down the production of chemical waste and alleviating pollution risk. Thus, Akbari et al. studied the viability of using ultrasound for a similar function as solvent in ODS to enhance the accessibility of the catalyst to the sulfur reactants. ${ }^{63}$ Impressively, above $98 \%$ DBT oxidation was attained using $\mathrm{MoO}_{3} / \mathrm{Al}_{2} \mathrm{O}_{3}$ and $\mathrm{H}_{2} \mathrm{O}_{2}$ in the system. Also, the stability of $\mathrm{MoO}_{3} / \mathrm{Al}_{2} \mathrm{O}_{3}$ in the ultrasound system ( $>6$ runs) was higher than that in a conventional stirring system ( $<3$ runs). This could be imputed to the elimination of impurities from the surface of $\mathrm{MoO}_{3} / \mathrm{Al}_{2} \mathrm{O}_{3}$ by the ultrasound, thus inhibiting deactivation of the catalyst due to pore blockage.

Returning to the work of Abu Bakar et al., the ODS activities of various metal oxides, including Mo, Mn, Sn, Fe, Co and $\mathrm{Zn}$, supported on $\mathrm{Al}_{2} \mathrm{O}_{3}$ were examined. ${ }^{62}$ Among all the prepared catalysts, $\mathrm{MoO}_{3} / \mathrm{Al}_{2} \mathrm{O}_{3}$ was the best catalyst in ODS with the highest ODS activity in the presence of tert-butyl hydroperoxide (TBHP) at $60{ }^{\circ} \mathrm{C}$ (Fig. 7b). Likewise, $\mathrm{MoO}_{3} / \mathrm{Al}_{2} \mathrm{O}_{3}$ also attained the highest DBT conversion with TBHP compared with other metal oxides at $110{ }^{\circ} \mathrm{C}$ in the report of Wang et al. ${ }^{81}$ The marvelous performance of $\mathrm{MoO}_{3} / \mathrm{Al}_{2} \mathrm{O}_{3}$ in ODS stems from its superior Lewis acidity and lower oxidation potential in the highest oxidation state of Mo compared to other metal oxides, facilitating the conversion of $\mathrm{H}_{2} \mathrm{O}_{2}$ and resulting in abundant active oxygen species for ODS. ${ }^{82}$ Taking $\mathrm{O}_{2}$ as an example, the stronger Lewis acid feature allows rapid interaction between the $\mathrm{Mo}$ and $\mathrm{O}$ atoms, leading to partial dissociation of the $\mathrm{O}=\mathrm{O}$ bond and accelerating the rate of ODS. Therefore, $\mathrm{MoO}_{3}$ can be labelled the most competent metal oxide catalyst for desulfurizing fuels, attributed to its impressive strength in catalyzing the activation of oxidants which is conducive to the oxidation of aromatic sulfur compounds.

In order to develop a breakthrough in ODS activity, several attempts have been made to dope $\mathrm{TiO}_{2}, \mathrm{~V}_{2} \mathrm{O}_{5}$ and $\mathrm{WO}_{3}$ onto $\mathrm{MoO}_{3} / \mathrm{Al}_{2} \mathrm{O}_{3} \cdot{ }^{62,79,83}$ Among these dopants, only $\mathrm{WO}_{3}$ enhanced
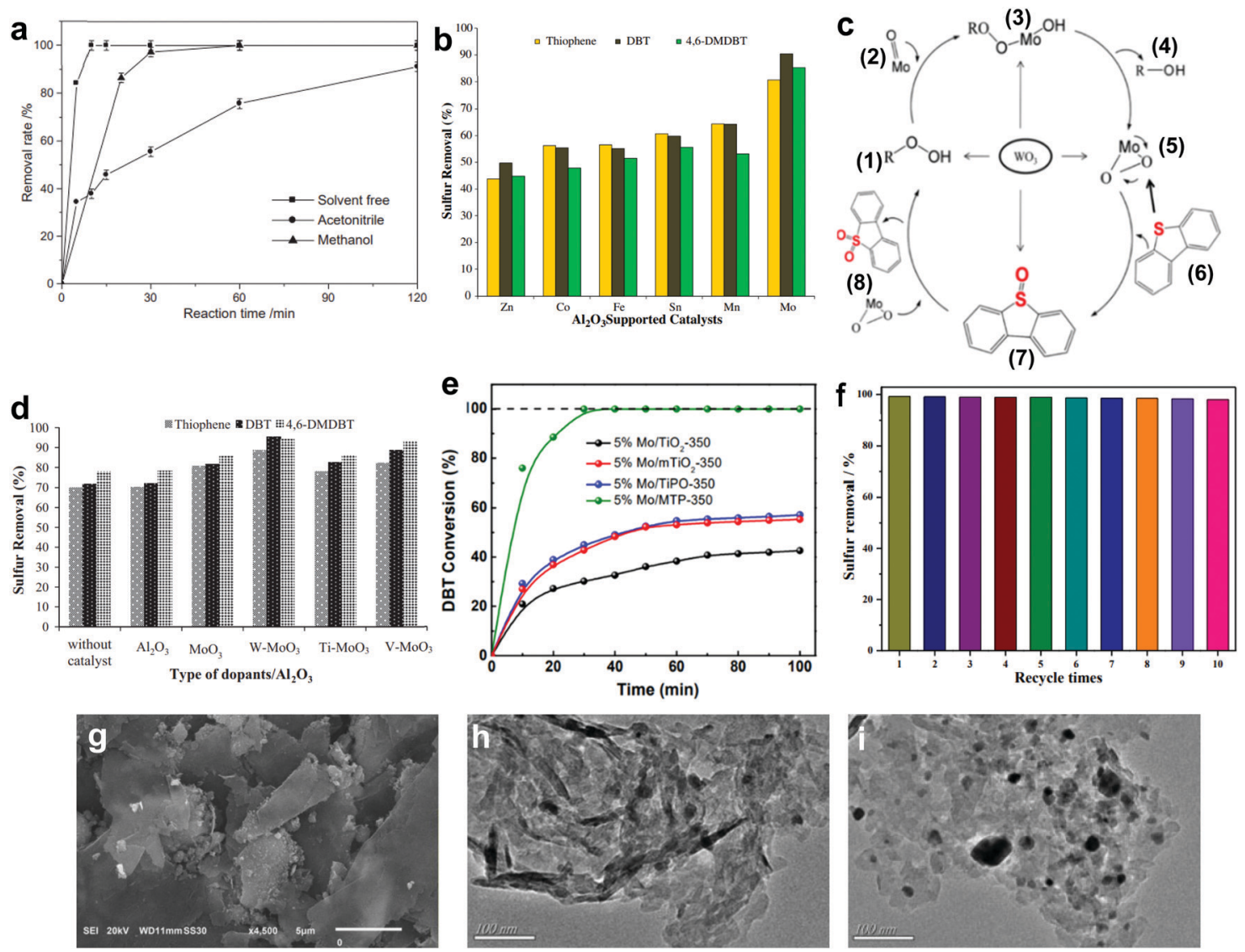

Fig. 7 (a) Effect of different solvents on the removal rate of $\mathrm{DBT}$ over $\mathrm{MoO}_{3} / \gamma-\mathrm{Al}_{2} \mathrm{O}_{3}$ utilizing $\mathrm{H}_{2} \mathrm{O}_{2}$ at $60{ }^{\circ} \mathrm{C}$. Reprinted with permission. ${ }^{78} \mathrm{Copyright}$ 2011, Elsevier B.V. (b) Sulfur removal rate in ODS using various metal oxides supported on $\mathrm{Al}_{2} \mathrm{O}_{3}$ catalysts at $60{ }^{\circ} \mathrm{C}$ in the presence of TBHP. (c) ODS mechanism of DBT for $\mathrm{WO}_{3} / \mathrm{MoO}_{3} / \mathrm{Al}_{2} \mathrm{O}_{3}$ catalyst. Reprinted with permission. ${ }^{62}$ Copyright 2012, Elsevier B.V. (d) Sulfur removal efficiency of different dopants on $\mathrm{MoO}_{3} / \mathrm{Al}_{2} \mathrm{O}_{3}$ catalyst at $60{ }^{\circ} \mathrm{C}$ in the presence of TBHP. Reprinted with permission. ${ }^{79}$ Copyright 2018, Elsevier B.V. (e) Conversion of DBT using $\mathrm{MoO}_{3}$ with different supports as catalyst in the presence of TBHP at $40{ }^{\circ} \mathrm{C}$. Reprinted with permission. ${ }^{86}$ Copyright 2021 , Elsevier Inc. (f) DBT removal for ten runs, at $1 \mathrm{~h}$ per run, using $\mathrm{TiO}_{2} / \mathrm{GC}$ with $\mathrm{H}_{2} \mathrm{O}_{2}$ at $50{ }^{\circ} \mathrm{C}$ and $(\mathrm{g})$ the corresponding SEM image. Reprinted with permission. ${ }^{87} \mathrm{Copyright} 2020$, American Chemical Society. TEM images of $\mathrm{WO}_{3}$ on (h) bulk g- $\mathrm{C}_{3} \mathrm{~N}_{4}$ and (i) layered g- $\mathrm{C}_{3} \mathrm{~N}_{4}$. Reprinted with permission. ${ }^{89}$ Copyright 2019 , Elsevier B.V. 
the sulfur removal in $\mathrm{MoO}_{3} / \mathrm{Al}_{2} \mathrm{O}_{3}$, which was about $10 \%$ higher than that of the pure $\mathrm{MoO}_{3} / \mathrm{Al}_{2} \mathrm{O}_{3}$ under the same operating conditions (Fig. 7d). This can be explained by the transfer of electrons from $\mathrm{WO}_{3}$ to $\mathrm{MoO}_{3}$ strengthening the nucleophilicity of $\mathrm{MoO}_{3}{ }^{62,79}$ From the perspective of catalyst structure, $\mathrm{WO}_{3} /$ $\mathrm{MoO}_{3} / \mathrm{Al}_{2} \mathrm{O}_{3}$, with a smaller particle size than $\mathrm{MoO}_{3} / \mathrm{Al}_{2} \mathrm{O}_{3}$, possessed a greater proportion of $\mathrm{MoO}_{3}$ particles on the $\mathrm{Al}_{2} \mathrm{O}_{3}$ surface which developed robust active sites for ODS. With respect to the reaction mechanism (Fig. 7c), the enhancement of active sites and nucleophilic property promoted the transformation of molybdate (2) to the peroxomolybdate species (5) after the nucleophilic attack of TBHP (1). With this rich active oxygen species, the DBT (6) in diesel fuel was readily oxidized to DBT sulfoxide (7) and DBT sulfone (8), resulting in a higher rate of oxidation. In other words, selecting an appropriate dopant, which is beneficial to improving the nucleophilicity and morphology of pure metal oxides, is pivotal for efficient ODS.

3.1.2.2 Zirconium oxide supported metal oxides. Instead of applying conventional $\mathrm{Al}_{2} \mathrm{O}_{3}$ as the support, Muñoz et al. immobilized $\mathrm{WO}_{3}$ on $\mathrm{ZrO}_{2}$ by applying the equilibrium adsorption method and examined the performance of the prepared catalyst in ODS. ${ }^{84}$ During the catalyst synthesis process, the $\mathrm{pH}$ of the solution was well controlled to create a charge difference on the surfaces of $\mathrm{WO}_{3}$ and $\mathrm{ZrO}_{2}$ to facilitate the formation of chemical bonds and the entire adsorption process. The introduction of $\mathrm{WO}_{3}$ on $\mathrm{ZrO}_{2}$ tremendously improved the conversion of diphenyl sulfide into diphenyl sulfone, from $45 \%$ to $100 \%$, with $\mathrm{H}_{2} \mathrm{O}_{2}$. This impressive enhancement manifested the paramount role of surface acidity in governing the catalytic activity in ODS, as $\mathrm{WO}_{3}$ possesses a higher acid strength. In the report of Xun et al., a hydrothermal and calcination approach was adopted to support $\mathrm{WO}_{3}$ on $\mathrm{ZrO}_{2}$ to catalyze the ODS of model diesel. This work revealed that the increase of calcination temperature constructed a more mesoporous structure in $\mathrm{WO}_{3} / \mathrm{ZrO}_{2}$, resulting in the increment of active sites for ODS and the subsequent enhancement of sulfur removal. ${ }^{70}$ On the downside, the structure of $\mathrm{WO}_{3} / \mathrm{ZrO}_{2}$ suffered collapse at extreme calcination temperatures $\left(800{ }^{\circ} \mathrm{C}\right)$ because the excessive thermal energy broke the molecular bonding between the particles. As a consequence, the porosity advantage of $\mathrm{WO}_{3}$ / $\mathrm{ZrO}_{2}$ was forfeited, leading to a lower ODS performance.

3.1.2.3 Metal phosphonate supported metal oxides. As an emerging porous nanomaterial, metal phosphonate has attracted enormous research interest in the area of catalysis owing to its tailorable structure, vast surface area and beneficial surface properties. ${ }^{85}$ The propitious properties of metal phosphonate inspired Chen et al. to support $\mathrm{MoO}_{3}$ with mesoporous titanium phosphonates (MTP) via a simple hydrothermal process to enhance the dispersion of $\mathrm{MoO}_{3}$ and guarantee its catalytic activity in ODS. ${ }^{86}$ Interestingly, the organophosphonic ligands in MTP served as essential coordinators for anchoring $\mathrm{MoO}_{3}$ nanoparticles to form a uniform dispersion. In comparison with other Ti-based supports, $\mathrm{MoO}_{3} / \mathrm{MTP}$ achieved the highest DBT conversion rate in the presence of TBHP at $40{ }^{\circ} \mathrm{C}$ (Fig. 7e). This was attributed to the valuable substrate-support interaction, which was created by organophosphonic ligands, prevented the agglomeration of $\mathrm{MoO}_{3}$ and simultaneously generated smaller $\mathrm{MoO}_{3}$ nanoparticles with a higher exposure of catalytic sites for ODS. This work not only highlights the importance of substratesupport interactions on the ODS activity of metal oxide-based catalysts but also proposes a novel support for metal oxides.

3.1.2.4 Metal-free nanomaterial supported metal oxides. Xun et al. decorated $\mathrm{TiO}_{2}$ nanoparticles on graphitic carbon (GC) via annealing and calcination. ${ }^{87}$ From the view of morphology, $\mathrm{TiO}_{2}$ was uniformly anchored on the surface of 2D layered GC (Fig. 7g). Impressively, the activity of $\mathrm{TiO}_{2} / \mathrm{GC}$ in oxidizing DBT with $\mathrm{H}_{2} \mathrm{O}_{2}$ remained at above $98 \%$ (Fig. $7 \mathrm{f}$ ) for ten consecutive runs. This suggests the capability of GC to stabilize or grasp $\mathrm{TiO}_{2}$ nanoparticles firmly through strong chemical interactions, thereby hindering the aggregation of particles and ensuring durability in ODS. Zhao et al. deposited $\mathrm{WO}_{3}$ nanoparticles on $\mathrm{g}-\mathrm{C}_{3} \mathrm{~N}_{4}$ through the calcination method to address the active site shortage in $\mathrm{WO}_{3}$ and applied the prepared composite in ODS. ${ }^{88}$ Unfortunately, the occurrence of severe $\mathrm{WO}_{3}$ aggregation on the surface of $\mathrm{g}-\mathrm{C}_{3} \mathrm{~N}_{4}$ led to a low specific surface area and limited number of surface active sites. In ODS, $\mathrm{WO}_{3} / \mathrm{g}-\mathrm{C}_{3} \mathrm{~N}_{4}$ took $3 \mathrm{~h}$ to achieve $91.2 \%$ DBT removal with $\mathrm{H}_{2} \mathrm{O}_{2}$ at $60{ }^{\circ} \mathrm{C}$. To further enlarge the specific surface area, Ma and co-workers developed a layered $\mathrm{g}-\mathrm{C}_{3} \mathrm{~N}_{4}$ by thermal decomposition to support $\mathrm{WO}_{3}$ in ODS. ${ }^{89}$ Compared with the morphology of bulk $\mathrm{g}-\mathrm{C}_{3} \mathrm{~N}_{4}$ (Fig. 7h), a relatively minor agglomeration of $\mathrm{WO}_{3}$ nanoparticles occurred on layered $\mathrm{g}-\mathrm{C}_{3} \mathrm{~N}_{4}$ (Fig. 7i) as a result of the beneficial 2D morphology that offers innumerable anchor sites for $\mathrm{WO}_{3}$. Evidently, $\mathrm{WO}_{3}$ /layered $\mathrm{g}-\mathrm{C}_{3} \mathrm{~N}_{4}$ showed a higher specific surface area $\left(186.32 \mathrm{~m}^{2} \mathrm{~g}^{-1}\right)$ than $\mathrm{WO}_{3} /$ bulk $\mathrm{g}-\mathrm{C}_{3} \mathrm{~N}_{4}\left(129.71 \mathrm{~m}^{2} \mathrm{~g}^{-1}\right)$. Consequently, $\mathrm{WO}_{3} /$ layered $\mathrm{g}-\mathrm{C}_{3} \mathrm{~N}_{4}$, with a greater number of active sites, achieved a higher DBT conversion (100\%) with $\mathrm{H}_{2} \mathrm{O}_{2}$ at $50{ }^{\circ} \mathrm{C}$ in 40 min than did $\mathrm{WO}_{3} /$ bulk g- $\mathrm{C}_{3} \mathrm{~N}_{4}$ (91\%). Recently, Wang et al. constructed $2 \mathrm{D} / 2 \mathrm{D}$ $\mathrm{V}_{2} \mathrm{O}_{5} / \mathrm{BN}$ nanosheets through the solvothermal method. ${ }^{90}$ Owing to the high surface to volume ratio in 2D morphology, the $\mathrm{V}_{2} \mathrm{O}_{5}$ nanosheets were well-dispersed on the BN nanosheets, which contributed to the increment of surface active sites. The $\mathrm{V}_{2} \mathrm{O}_{5} / \mathrm{BN}$ nanosheet attained higher DBT oxidation (99.6\%) than did $\mathrm{V}_{2} \mathrm{O}_{5} /$ bulk $\mathrm{BN}(62.3 \%)$. The large contact area between $\mathrm{V}_{2} \mathrm{O}_{5}$ and $\mathrm{BN}$ also established strong $2 \mathrm{D} / 2 \mathrm{D}$ chemical interactions, inhibiting the deactivation of the catalyst due to catalyst loss during ODS. Indeed, the fabrication of ultrathin 2D nanomaterials, especially the assembly of $2 \mathrm{D} / 2 \mathrm{D}$ nanocomposites, is a rational and effective strategy for improving catalytic activity and stability in ODS.

Support introduction and metal oxide doping are promising strategies for intensifying the catalytic activity of metal oxides in ODS by elevating the exposure of active sites as well as the electron density. Moreover, the operating conditions of the synthesis method play a vital role in controlling the morphology of metal oxides. Hence, metal oxide characteristics should be well tuned to engineer a metal oxide with excellent ODS catalytic performance. Table 1 summarizes the performances of 
Table 1 Representative summary of the performances of metal oxide-based catalysts in ODS

\begin{tabular}{|c|c|c|c|c|c|c|c|}
\hline \multirow[b]{2}{*}{ Catalysts } & \multirow[b]{2}{*}{$\begin{array}{l}\text { Reaction } \\
\text { temperature }\left({ }^{\circ} \mathrm{C}\right)\end{array}$} & \multirow[b]{2}{*}{ Oxidant } & \multirow[b]{2}{*}{ Extractant } & \multicolumn{3}{|l|}{ Performances } & \multirow[b]{2}{*}{ Ref. } \\
\hline & & & & $\begin{array}{l}\text { Sulfur removal } \\
\text { (reactant) }\end{array}$ & $\begin{array}{l}\text { Reaction } \\
\text { time }(\mathrm{h})\end{array}$ & $\begin{array}{l}\text { Stability } \\
\text { (h) }\end{array}$ & \\
\hline $\mathrm{WO}_{3} / \mathrm{MoO}_{3} / \mathrm{Al}_{2} \mathrm{O}_{3}$ & 60 & TBHP (70 wt\%) & $\mathrm{DMF}$ & $100 \%(\mathrm{DBT})$ & 1 & $>150$ & 62 \\
\hline $\mathrm{MoO}_{3} / \mathrm{Al}_{2} \mathrm{O}_{3}$ & 110 & TBHP (70 wt\%) & $\mathrm{N} / \mathrm{A}$ & 86.13\% (DBT) & 3 & $\mathrm{~N} / \mathrm{A}$ & 81 \\
\hline $\mathrm{WO}_{3} / \mathrm{Al}_{2} \mathrm{O}_{3}$ & & & & 78.76\% (DBT) & & & \\
\hline $\mathrm{CrO}_{3} / \mathrm{Al}_{2} \mathrm{O}_{3}$ & & & & $3.47 \%$ (DBT) & & & \\
\hline $\mathrm{V}_{2} \mathrm{O}_{5} / \mathrm{Al}_{2} \mathrm{O}_{3}$ & & & & $53.34 \%(\mathrm{DBT})$ & & & \\
\hline $\mathrm{Nb}_{2} \mathrm{O}_{5} / \mathrm{Al}_{2} \mathrm{O}_{3}$ & & & & $43.42 \%$ (DBT) & & & \\
\hline $\mathrm{ZrO}_{2} / \mathrm{Al}_{2} \mathrm{O}_{3}$ & & & & $33.87 \%$ (DBT) & & & \\
\hline $\mathrm{MoO}_{3} / \mathrm{Al}_{2} \mathrm{O}_{3}$ & 45 & $\mathrm{H}_{2} \mathrm{O}_{2}(30 \mathrm{wt} \%)$ & N/A & 98\% (DBT) & 0.5 & $>3$ & 63 \\
\hline $\mathrm{MoO}_{3} / \mathrm{Al}_{2} \mathrm{O}_{3}$ & 70 & $\mathrm{H}_{2} \mathrm{O}_{2}(30 \mathrm{wt} \%)$ & Acetonitrile & 〜 80\% (DBT) & 2.5 & N/A & 91 \\
\hline $\mathrm{WO}_{3} / \mathrm{TiO}_{2}$ & 50 & $\mathrm{H}_{2} \mathrm{O}_{2}(30 \mathrm{wt} \%)$ & $\mathrm{N} / \mathrm{A}$ & $100 \%(\mathrm{DBT})$ & 1 & $>7$ & 92 \\
\hline $\mathrm{V}_{2} \mathrm{O}_{5} / \mathrm{TiO}_{2}$ & 60 & $\mathrm{H}_{2} \mathrm{O}_{2}(30 \mathrm{wt} \%)$ & Acetonitrile & 99.5\% (DBT) & 0.5 & N/A & 64 \\
\hline $\mathrm{V}_{2} \mathrm{O}_{5} / \mathrm{Al}_{2} \mathrm{O}_{3}-\mathrm{TiO}_{2}$ & & & & 97.9\% (DBT) & & & \\
\hline $\mathrm{V}_{2} \mathrm{O}_{5} / \mathrm{SiO}_{2}$ & & & & $59.8 \%$ (DBT) & & & \\
\hline $\mathrm{V}_{2} \mathrm{O}_{5} / \mathrm{Nb}_{2} \mathrm{O}_{5}$ & & & & 97.7\% (DBT) & & & \\
\hline $\mathrm{Ni}-\mathrm{MoO}_{3}$ & 70 & $\mathrm{H}_{2} \mathrm{O}_{2}(30 \mathrm{wt} \%)$ & Acetonitrile & 99.8\% (DBT) & 2 & $<8$ & 93 \\
\hline $\mathrm{Mo}-\mathrm{Ni}-\mathrm{Cu}-\mathrm{Zn}-\mathrm{Co}-\mathrm{O}_{X}$ & 120 & $\mathrm{O}_{2}$ & $\mathrm{~N} / \mathrm{A}$ & $100 \%(\mathrm{DBT})$ & 3 & $>18$ & 65 \\
\hline $\mathrm{WO}_{x}-\mathrm{OAm}$ & 60 & $\mathrm{H}_{2} \mathrm{O}_{2}(30 \mathrm{wt} \%)$ & N/A & $58.8 \%(\mathrm{DBT})$ & 0.67 & $>10$ & 66 \\
\hline $\mathrm{WO}_{x}-\mathrm{OAm} / \mathrm{HCl}$ & & & & $100 \%(\mathrm{DBT})$ & & N/A & \\
\hline $\mathrm{WO}_{x}-\mathrm{Et}$ & & & & $9.9 \%(\mathrm{DBT})$ & & N/A & \\
\hline $\mathrm{WO}_{x}-\mathrm{Et} / \mathrm{HCl}$ & & & & 35.1\% (DBT) & & N/A & \\
\hline $\mathrm{Ca} / \mathrm{MoO}_{3} / \mathrm{Al}_{2} \mathrm{O}_{3}$ & 55 & $\mathrm{H}_{2} \mathrm{O}_{2}(30 w t \%)$ & N/A & 〜 100\% (DBT) & 0.13 & $<1.07$ & 67 \\
\hline $\mathrm{SnO}_{2}$ & 60 & $\mathrm{H}_{2} \mathrm{O}_{2}(30 w t \%)$ & Methanol & 100\% (DBT) & 2 & $>28$ & 68 \\
\hline $\mathrm{C}_{16}-\mathrm{WO}_{3} / \mathrm{ZrO}_{2}$ & 50 & $\mathrm{H}_{2} \mathrm{O}_{2}(30 \mathrm{wt} \%)$ & Acetonitrile & $100 \%(\mathrm{DBT})$ & 1 & $>10$ & 70 \\
\hline $\mathrm{MnO}_{2} / \mathrm{Al}_{2} \mathrm{O}_{3}$ & 150 & $\mathrm{O}_{2}$ & $\begin{array}{l}\text { DMF } \\
\text { Acetonitrile } \\
\text { NMP } \\
\text { Methanol }\end{array}$ & $\sim 80 \%(\mathrm{DBT})$ & 8 & N/A & 71 \\
\hline $\mathrm{Na}_{2} \mathrm{WO}_{4} / \mathrm{Al}_{2} \mathrm{O}_{3}$ & 70 & $\mathrm{H}_{2} \mathrm{O}_{2}(30 \mathrm{wt} \%)$ & Acetonitrile & $\sim 82 \%(\mathrm{DBT})$ & 3 & N/A & 80 \\
\hline $\mathrm{Na}_{2} \mathrm{WO}_{4} \mathrm{P}_{1.5} / \mathrm{Al}_{2} \mathrm{O}_{3}$ & & & & 〜98\% (DBT) & & $<12$ & \\
\hline $\mathrm{V} / \mathrm{W} / \mathrm{MoO}_{3} / \mathrm{Al}_{2} \mathrm{O}_{3}$ & 60 & TBHP (70 wt\%) & DMF & $100 \%(\mathrm{DBT})$ & 0.5 & $>2.5$ & 79 \\
\hline $\mathrm{Ti} / \mathrm{W} / \mathrm{MoO}_{3} / \mathrm{Al}_{2} \mathrm{O}_{3}$ & & & & $94.2 \%(\mathrm{DBT})$ & & N/A & \\
\hline $\mathrm{W} / \mathrm{MoO}_{3} / \mathrm{Al}_{2} \mathrm{O}_{3}$ & & & & 95.6\% (DBT) & & N/A & \\
\hline $\mathrm{MoO}_{3} / \mathrm{Al}_{2} \mathrm{O}_{3}$ & & & & $84.7 \%(\mathrm{DBT})$ & & N/A & \\
\hline $\mathrm{MoO}_{3} / \gamma-\mathrm{Al}_{2} \mathrm{O}_{3}$ & 60 & $\mathrm{H}_{2} \mathrm{O}_{2}(30 w \mathrm{t} \%)$ & N/A & $100 \%(\mathrm{DBT})$ & 0.25 & $<4.5$ & 78 \\
\hline $\mathrm{V}_{2} \mathrm{O}_{5}-\mathrm{MoO}_{3} / \mathrm{Al}_{2} \mathrm{O}_{3}$ & 60 & TBHP (70 wt\%) & Acetonitrile & 〜 25\% (DBT) & 1 & N/A & 83 \\
\hline $3 \mathrm{DOM} \mathrm{WO}_{x}$ & 120 & $\mathrm{O}_{2}$ & N/A & $99 \%(4,6-\mathrm{DMDBT})$ & 4 & $>20$ & 74 \\
\hline $\mathrm{MoO}_{3} / \mathrm{MTP}$ & 40 & TBHP (70 wt\%) & N/A & $100 \%(\mathrm{DBT})$ & 0.5 & $>5$ & 86 \\
\hline $\mathrm{ZrO}_{2}$ & 75 & $\mathrm{H}_{2} \mathrm{O}_{2}(30 \mathrm{wt} \%)$ & $\mathrm{N} / \mathrm{A}$ & 70\% (diphenyl sulfide) & 1 & N/A & 84 \\
\hline $\mathrm{WO}_{3} / \mathrm{ZrO}_{2}$ & & & & 100\% (diphenyl sulfide) & & $>2$ & \\
\hline $\mathrm{Co}_{2}-\mathrm{Mo}-\mathrm{O}$ & 120 & $\mathrm{O}_{2}$ & N/A & $100 \%(\mathrm{DBT})$ & 3 & $>15$ & 75 \\
\hline $\mathrm{Co}_{2}-\mathrm{Mo}-\mathrm{O}$ & 100 & & & $83 \%(\mathrm{DBT})$ & 6 & $\mathrm{~N} / \mathrm{A}$ & \\
\hline Co-Mo-O & 100 & & & 46\% (DBT) & 6 & N/A & \\
\hline $\mathrm{Co}-\mathrm{Mo}_{2}-\mathrm{O}$ & 100 & & & 29\% (DBT) & 6 & N/A & \\
\hline Co-Ni-Mo-O & 110 & $\mathrm{O}_{2}$ & N/A & $100 \%(\mathrm{DBT})$ & 2 & $>14$ & 76 \\
\hline Co-Ni-Mo-O & 100 & & & $100 \%(\mathrm{DBT})$ & 4 & N/A & \\
\hline Ni-Mo-O & 100 & & & 〜 16\% (DBT) & 4 & N/A & \\
\hline Co-Mo-O & 100 & & & 〜 65\% (DBT) & 4 & N/A & \\
\hline Co-Mo-O (nanosheet) & 100 & $\mathrm{O}_{2}$ & $\mathrm{~N} / \mathrm{A}$ & $100 \%(\mathrm{DBT})$ & 4 & $>18$ & 77 \\
\hline Co-Mo-O (bulk) & & & & $21.5 \%$ (DBT) & & N/A & \\
\hline $\mathrm{Co}-\mathrm{O}$ & & & & $59.3 \%$ (DBT) & & N/A & \\
\hline $\mathrm{TiO}_{2}$ /graphitic carbon & 50 & $\mathrm{H}_{2} \mathrm{O}_{2}(30 w t \%)$ & N/A & $100 \%(\mathrm{DBT})$ & 1 & $>10$ & 87 \\
\hline $\mathrm{Pt} /$ bulk $\mathrm{V}_{2} \mathrm{O}_{5}$ & 110 & $\mathrm{O}_{2}$ & N/A & 19.7\% (DBT) & 5 & N/A & 94 \\
\hline $\mathrm{Pt} / \mathrm{V}_{2} \mathrm{O}_{5}$ nanosheet & & & & $99.2 \%(\mathrm{DBT})$ & & $>45$ & \\
\hline $2 \mathrm{D} \mathrm{V}_{2} \mathrm{O}_{5} /$ bulk BN & 120 & $\mathrm{O}_{2}$ & N/A & $62.3 \%(\mathrm{DBT})$ & 4 & N/A & 90 \\
\hline $2 \mathrm{D} / 2 \mathrm{D} \mathrm{V}_{2} \mathrm{O}_{5} / \mathrm{BN}$ nanosheet & & & & 99.6\% (DBT) & & $>32$ & \\
\hline $\mathrm{WO}_{3} / \mathrm{CNTs}$ & 50 & $\mathrm{H}_{2} \mathrm{O}_{2}(30 \mathrm{wt} \%)$ & Acetonitrile & $90.73 \%(\mathrm{DBT})$ & 1 & $<5$ & 95 \\
\hline $\mathrm{WO}_{3} / \mathrm{g}-\mathrm{C}_{3} \mathrm{~N}_{4}$ & 60 & $\mathrm{H}_{2} \mathrm{O}_{2}(30 \mathrm{wt} \%)$ & Ionic liquids & $91.2 \%(\mathrm{DBT})$ & 3 & $>15$ & 88 \\
\hline $\mathrm{WO}_{3} /$ bulk g- $\mathrm{C}_{3} \mathrm{~N}_{4}$ & 50 & $\mathrm{H}_{2} \mathrm{O}_{2}(30 \mathrm{wt} \%)$ & $\mathrm{N} / \mathrm{A}$ & 91\% (DBT) & 0.67 & $\mathrm{~N} / \mathrm{A}$ & 89 \\
\hline $\mathrm{WO}_{3} /$ layered g- $\mathrm{C}_{3} \mathrm{~N}_{4}$ & & & & $100 \%(\mathrm{DBT})$ & & $>4$ & \\
\hline $\mathrm{MoO}_{3} / \mathrm{MOF}-199$ & 50 & $\mathrm{O}_{2}$ & N/A & $94.8 \%(\mathrm{DBT})$ & 2 & N/A & 96 \\
\hline $\mathrm{Fe}_{3} \mathrm{O}_{4}-\mathrm{MoO}_{3} / \mathrm{MOF}-199$ (spherical $\mathrm{MoO}_{3}$ ) & & & & 95.1\% (DBT) & 1 & N/A & \\
\hline $\mathrm{Fe}_{3} \mathrm{O}_{4}-\mathrm{MoO}_{3} / \mathrm{MOF}-199$ (clubbed $\mathrm{MoO}_{3}$ ) & & & & 98.9\% (DBT) & 0.75 & N/A & \\
\hline $\mathrm{Fe}_{3} \mathrm{O}_{4}-\mathrm{MoO}_{3} / \mathrm{MOF}-199$ (fibroid $\mathrm{MoO}_{3}$ ) & & & & $100 \%(\mathrm{DBT})$ & 0.75 & $<9$ & \\
\hline $\mathrm{MoO}_{3}-\mathrm{TiO}_{2} / \mathrm{MCM}-22$ & 100 & CHYPO (50 wt\%) & N/A & 99.96\% (DBT) & 0.25 & $>2$ & 97 \\
\hline $\mathrm{MoO}_{2} / \mathrm{C}$ & 55 & $\mathrm{H}_{2} \mathrm{O}_{2}(30 \mathrm{wt} \%)$ & Acetonitrile & $56 \%(\mathrm{DBT})$ & 1 & $<1$ & 98 \\
\hline $\mathrm{N}-\mathrm{MoO}_{3} / \mathrm{SiC}$ & & & & 99.9\% (DBT) & & $<4$ & \\
\hline $\mathrm{MoO}_{3} / \mathrm{MOF}-199$ & 40 & $\mathrm{O}_{2}$ & {$[\mathrm{Bmim}] \mathrm{BF}_{4}$} & $76.7 \%(\mathrm{DBT})$ & 1 & N/A & 99 \\
\hline
\end{tabular}




\begin{tabular}{|c|c|c|c|c|c|c|c|}
\hline \multirow[b]{2}{*}{ Catalysts } & \multirow[b]{2}{*}{$\begin{array}{l}\text { Reaction } \\
\text { temperature }\left({ }^{\circ} \mathrm{C}\right)\end{array}$} & \multirow[b]{2}{*}{ Oxidant } & \multirow[b]{2}{*}{ Extractant } & \multicolumn{3}{|l|}{$\underline{\text { Performances }}$} & \multirow[b]{2}{*}{ Ref. } \\
\hline & & & & $\begin{array}{l}\text { Sulfur removal } \\
\text { (reactant) }\end{array}$ & $\begin{array}{l}\text { Reaction } \\
\text { time (h) }\end{array}$ & $\begin{array}{l}\text { Stability } \\
\text { (h) }\end{array}$ & \\
\hline \multirow{2}{*}{\multicolumn{4}{|c|}{$\begin{array}{l}\mathrm{W}-\mathrm{MoO}_{3} / \mathrm{MOF}-199 \\
\mathrm{Fe}_{3} \mathrm{O}_{4}-\mathrm{W}-\mathrm{MoO}_{3} / \mathrm{MOF}-199\end{array}$}} & $100 \%(\mathrm{DBT})$ & \multirow{2}{*}{\multicolumn{3}{|c|}{$\begin{array}{l}\text { N/A } \\
<20\end{array}$}} \\
\hline & & & & $100 \%(\mathrm{DBT})$ & & & \\
\hline
\end{tabular}

various metal oxide-based catalysts in ODS and the operating parameters.

\subsection{Application of ionic liquids (ILs) in ODS}

Ionic liquids (ILs) are defined as liquids built up from a cation and an anion through ionic bonding with a melting point not exceeding $100{ }^{\circ} \mathrm{C} .{ }^{100}$ Since Bösmann and co-workers discovered the superior ability of ILs to remove aromatic sulfur compounds from model diesel in $2011,{ }^{101}$ there has been growing attention on the application of ILs in ODS. Crucially, their valuable intrinsic properties, including non-volatility, robust thermal stability, notable catalytic activity and high polarity, have contributed to the low-hazard and effortlessly recyclable features of ILs. ${ }^{102}$ With increasing interest in multifunctional materials, ILs have been proposed to play the roles of both catalyst and extractive solvent in ODS systems.

3.2.1 Homogeneous ILs. Metal chloride ILs with considerable Lewis acidity have been extensively employed in ODS. The importance of Lewis acidity for the desulfurization efficiency of metal chloride ILs in ODS was validated by Chen et al. ${ }^{103}$ In their work, $[\mathrm{Hnmp}] \mathrm{Cl} / \mathrm{ZnCl}_{2}$ was synthesized through a two-step reaction and applied in an ODS system containing $\mathrm{H}_{2} \mathrm{O}_{2}$. It is noteworthy that the decrement of the [ $\left.\mathrm{Hnmp}\right] \mathrm{Cl}$ to $\mathrm{ZnCl}_{2}$ molar ratio led to the improvement of DBT conversion (Fig. 8a). This phenomenon stemmed from the fact that the increase of $\mathrm{ZnCl}_{2}$ concentration elevated the Lewis acidity of $[\mathrm{Hnmp}] \mathrm{Cl} / \mathrm{ZnCl}_{2}$, which facilitated the activation of $\mathrm{H}_{2} \mathrm{O}_{2}$ to generate more reactive oxygen species, thus accelerating the reaction rate of ODS. However, $[\mathrm{Hnmp}] \mathrm{Cl} / \mathrm{ZnCl}_{2}$ demonstrated poor desulfurization efficiency (about 20.5\%) in ODS of commercial diesel under the same reaction conditions owing to the emergence of myriad sulfur compounds and complex hydrocarbons. In this context, future study of the effect of different sulfur compounds and hydrocarbons in real fuels on the ODS activity of ILs is imperative to understand the practicality of ILS on an industrial scale.

Guo et al. developed a task-specific IL, namely $\left[\mathrm{C}_{5} \mathrm{~min}\right]_{2}\left[\mathrm{~S}_{2} \mathrm{O}_{8}\right]$ as the oxidant for ODS via metathesis reaction. ${ }^{104}$ The application of $\left[\mathrm{C}_{5} \mathrm{~min}\right]_{2}\left[\mathrm{~S}_{2} \mathrm{O}_{8}\right]$ in the ODS of model diesel with $\left[\mathrm{C}_{5}\right.$ minCl $]\left[\mathrm{CoCl}_{2}\right]$ as the catalyst and extractant achieved 98.7\% DBT removal, better than that achieved utilizing pure $\mathrm{K}_{2} \mathrm{~S}_{2} \mathrm{O}_{8}$ (36\%). This revealed that the substitution of 1-pentyl-3methylimidazolium for potassium successfully lowered the activation barrier of $\left[\mathrm{C}_{5} \mathrm{~min}\right]_{2}\left[\mathrm{~S}_{2} \mathrm{O}_{8}\right]$ and promoted the supply of reactive oxygen species for ODS. In addition to $\left[\mathrm{C}_{5} \mathrm{minCl}\right]\left[\mathrm{CoCl}_{2}\right]$, the researchers also investigated the catalytic activity of other metal chloride ILs, including $\left[\mathrm{C}_{5} \mathrm{minCl}\right]\left[\mathrm{FeCl}_{3}\right],\left[\mathrm{C}_{5} \mathrm{minCl}\right]\left[\mathrm{ZnCl}_{2}\right]$ and $\left[\mathrm{C}_{5} \mathrm{minCl}\right][\mathrm{CuCl}]$, in identical ODS systems. The results showed that $\left[\mathrm{C}_{5} \mathrm{minCl}\right]\left[\mathrm{CoCl}_{2}\right]$ exhibited the highest DBT removal due to its stronger ability to activate $\left[\mathrm{C}_{5} \mathrm{~min}\right]_{2}\left[\mathrm{~S}_{2} \mathrm{O}_{8}\right]$ (Fig. $8 \mathrm{~b}$ ). The reaction pathway for the ODS process using $\left[\mathrm{C}_{5} \mathrm{~min}\right]_{2}\left[\mathrm{~S}_{2} \mathrm{O}_{8}\right]$ remains obscure, but is of vital significance for mechanistic understanding of the activation of $\left[\mathrm{C}_{5} \mathrm{~min}\right]_{2}\left[\mathrm{~S}_{2} \mathrm{O}_{8}\right]$. This could substantially help in widening the application of $\left[\mathrm{C}_{5} \mathrm{~min}\right]_{2}\left[\mathrm{~S}_{2} \mathrm{O}_{8}\right]$ in ODS, as it possesses higher oxidative ability than other conventional oxidants like $\mathrm{H}_{2} \mathrm{O}_{2}$ and $\mathrm{O}_{2}$. Similar to $\left[\mathrm{C}_{5} \mathrm{~min}\right]_{2}\left[\mathrm{~S}_{2} \mathrm{O}_{8}\right],[\mathrm{OMIM}]_{2}\left[\mathrm{~S}_{2} \mathrm{O}_{8}\right]$ was also adopted as a bi-functional IL in extractive ODS and achieved remarkable performance in oxidizing and extracting aromatic sulfur compounds from fuel. ${ }^{105}$

Although the employment of task-specific ILs in ODS can eliminate the need for external oxidants and extractants, taskspecific ILs are non-reusable after the ODS reaction, which is an uneconomical and unsustainable approach to industrial application. To address this, Elwan et al. recently produced a pyridinium-based IL, [BMPy] $\left[\left(\mathrm{C}_{6} \mathrm{H}_{5}\right) \mathrm{COO}\right]$, for the ODS of model diesel in the presence of $\mathrm{H}_{2} \mathrm{O}_{2} \cdot{ }^{106}$ Because of the nature of the pyridinium cation, aromatic sulfur compounds were extracted into the IL phase for oxidation by strong $\pi-\pi$ interactions between the pyridinium ring of [BMPy $]\left[\left(\mathrm{C}_{6} \mathrm{H}_{5}\right) \mathrm{COO}\right]$ and sulfur compounds. The prominent extraction capability of [BMPy]$\left[\left(\mathrm{C}_{6} \mathrm{H}_{5}\right) \mathrm{COO}\right]$ brought about $98.9 \%$ DBT removal at $60{ }^{\circ} \mathrm{C}$ within $90 \mathrm{~min}$. However, the DBT removal efficiency began to drop significantly after the fifth run (Fig. 8c) due to an irreversible accumulation of DBT sulfone in [BMPy] $\left.\left(\mathrm{C}_{6} \mathrm{H}_{5}\right) \mathrm{COO}\right]$ that hindered the extraction of DBT. Therefore, a novel modification strategy is demanded to ameliorate the chemical properties of ILs and increase their stability in ODS applications in the future. Furthermore, Zhang et al. synthesized a POM-based IL, $\left[\mathrm{C}_{4} \mathrm{VIM}\right] \mathrm{PMoV}_{2}$, by ion-exchange method and unveiled the influence of the $\mathrm{V}$ number to its catalytic activity in ODS. ${ }^{107}$ As seen in the cyclic voltammetry curves (Fig. 8d), [C $\left.{ }_{4} \mathrm{VIM}\right]$ $\mathrm{PMoV}_{2}$ exhibited a greater positive potential than $\left[\mathrm{C}_{4} \mathrm{VIM}\right] \mathrm{PMoV}$ and $\left[\mathrm{C}_{4} \mathrm{VIM}\right] \mathrm{PMoV}_{3}$, which revealed the presence of higher electrophilicity in $\left[\mathrm{C}_{4} \mathrm{VIM}\right] \mathrm{PMoV}_{2}$. As a result, $\left[\mathrm{C}_{4} \mathrm{VIM}\right] \mathrm{PMoV}_{2}$ activated $\mathrm{O}_{2}$ more efficaciously, leading to increased generation of oxygen radicals for the ODS of sulfur compounds. [ $\mathrm{C}_{4} \mathrm{VIM}$ ]$\mathrm{PMoV}_{2}$ achieved the highest DBT conversion (98.9\%) after $5 \mathrm{~h}$ at $120{ }^{\circ} \mathrm{C}$. 

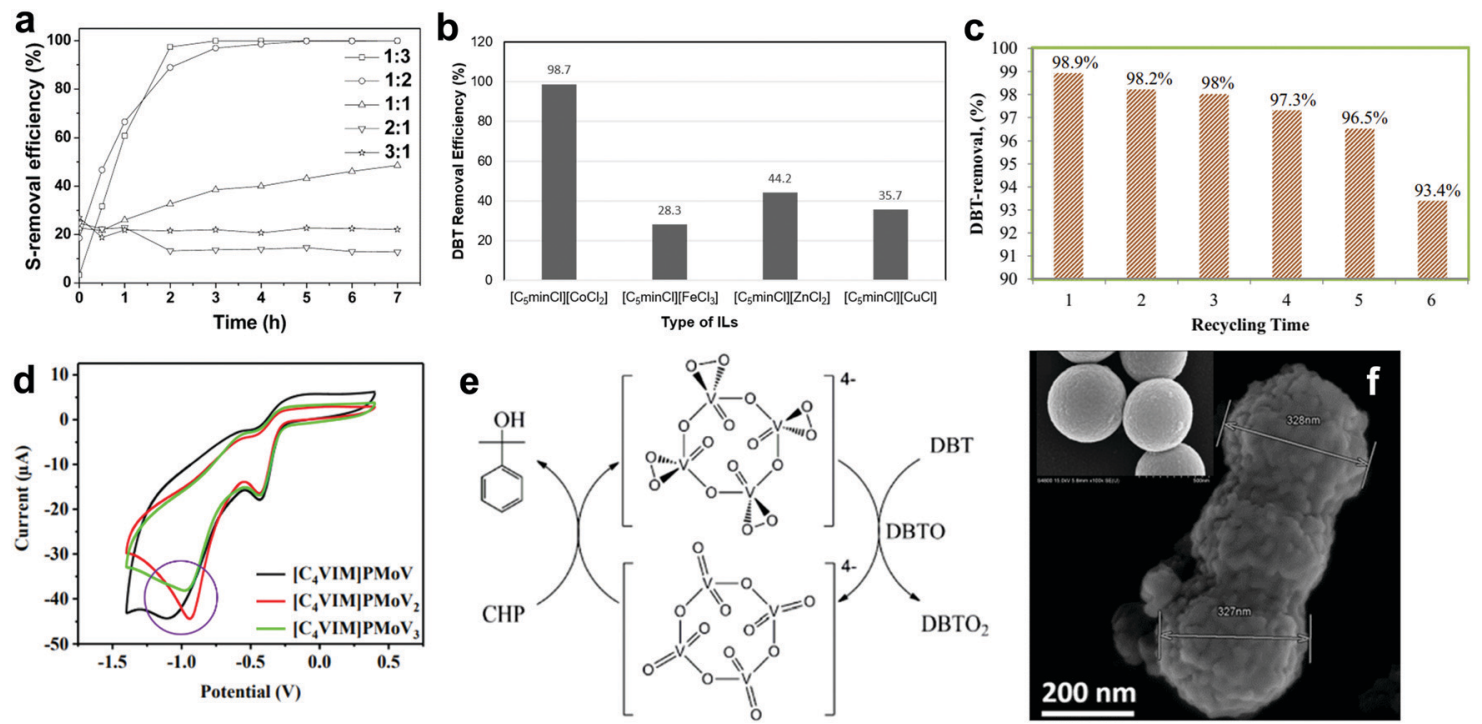

Fig. 8 (a) Effect of $[\mathrm{Hnmp}] \mathrm{Cl}$ to $\mathrm{ZnCl}_{2}$ molar ratio on the DBT removal efficiency in the presence of $\mathrm{H}_{2} \mathrm{O}_{2}$ at $30{ }^{\circ} \mathrm{C}$. Reprinted with permission. ${ }^{103}$ Copyright 2015, American Chemical Society. (b) ODS activity of different metal chloride ILs at $30{ }^{\circ} \mathrm{C}$ in the presence of $\left[\mathrm{C}_{5} \mathrm{~min}\right]_{2}\left[\mathrm{~S}_{2} \mathrm{O}_{8}\right]$ after 65 min. Redrawn with permission. ${ }^{104}$ Copyright 2019. American Chemical Society. (c) DBT removal efficiency of [BMPy][( $\left.{ }_{6} \mathrm{H}_{5}\right) \mathrm{COO}$ ] for six successive cycles at 90 min per cycle and $60{ }^{\circ} \mathrm{C}$ using $\mathrm{H}_{2} \mathrm{O}_{2}$ as oxidant. Reprinted with permission. ${ }^{106}$ Copyright 2020, Elsevier B.V. (d) Cyclic voltammetry curves of oxygen reduction reaction on different types of POM-based IL in $0.1 \mathrm{M}$ oxygen-saturated $\mathrm{KOH}$ solution. Reproduced with permission. ${ }^{107} \mathrm{Copyright} 2020$, Elsevier B.V. (e) Reaction mechanism for ODS of DBT using V-PIL and CHP. Reprinted with permission. ${ }^{109}$ Copyright 2016, American Chemical Society. (f) SEM image of $\left[\left(\mathrm{C}_{8} \mathrm{H}_{17}\right)_{3} \mathrm{NCH}_{3}\right]_{3} \mathrm{PMO}_{12} \mathrm{O}_{40}$ on the rough-surfaced MMS and the smooth-surfaced MMS (inset). Reproduced with permission. ${ }^{111}$ Copyright 2019 , Elsevier B.V.

Despite the fact that ILs are capable of remarkable ODS activity, the oxidation of sulfur compounds entails considerable reaction time. In order to boost the reaction rate, ultrasound irradiation was integrated into an ODS system with a Brønsted acidic IL, [Omin $]\left[\mathrm{H}_{2} \mathrm{SO}_{4}\right]$, as the catalyst and extractant. ${ }^{108}$ With ultrasound, the reaction time for $[\mathrm{Omin}]\left[\mathrm{H}_{2} \mathrm{SO}_{4}\right]$ to attain $100 \%$ DBT oxidation was shortened from $70 \mathrm{~min}$ to $3 \mathrm{~min}$ under the same operating conditions. This was ascribed to the intense mixing that enhanced the mass transfer of sulfur compounds into the IL phase and propelled the interactions between catalyst and reactants. However, additional settling time after the ODS reaction was unavoidable to ensure complete phase separation for removing the IL and the oxidized sulfur compounds from the fuel. This report suggested a constructive method for developing a rapid and efficient ODS process with the aid of ultrasonication.

3.2.2 Heterogeneous ILs. To reduce waste generation and the risk of fuel contamination, interest in the application of ILs in ODS has gradually switched from homogeneous ILs to heterogeneous ILs. For example, Chen et al. prepared a vanadate-based poly-IL (V-PIL) with mesoporous structure as the catalyst and absorbent in ODS. ${ }^{109}$ Owing to its immense specific surface area, V-PIL possesses a high number of exposed catalytic sites for ODS, resulting in $98 \%$ DBT conversion in the presence of cumene hydroperoxide (CHP) within $1 \mathrm{~h}$ at $50{ }^{\circ} \mathrm{C}$. Interestingly, the ODS reaction mechanism of V-PIL was distinct from those of other catalysts. As illustrated in Fig. 8e, the oxidation of DBT was first carried out by reaction with peroxy vanadate, accompanied by the oxidation of V-PIL by CHP to recover the lost oxygen atom in the ionic framework. Moreover, the extraordinary porosity created numerous capture sites which were able to undergo vigorous interactions with DBT sulfone. Therefore, DBT sulfone was confined in the structure of V-PIL and could be easily eliminated with V-PIL through a simple filtration process.

Anchoring ILs on porous materials is also a common and efficient strategy to heterogenize ILs, enhance their catalytic activity and reduce their usage amounts in catalysis. In the report of Xun et al., a POM-based IL, $\left[\left(\mathrm{C}_{8} \mathrm{H}_{17}\right)_{3} \mathrm{NCH}_{3}\right]_{3} \mathrm{PMo}_{12} \mathrm{O}_{40}$, was immobilized on a magnetic mesoporous silica nanosphere (MMS), $\mathrm{Fe}_{3} \mathrm{O}_{4}-\mathrm{SiO}_{2}$-mesoporous $\mathrm{SiO}_{2}$, to enlarge the specific surface area of IL and facilitate the separation process in ODS. ${ }^{110}$ In the ODS experiment, $100 \%$ DBT removal was achieved by $\left[\left(\mathrm{C}_{8} \mathrm{H}_{17}\right)_{3} \mathrm{NCH}_{3}\right]_{3} \mathrm{PMo}_{12} \mathrm{O}_{40} / \mathrm{MMS}$ in $5 \mathrm{~h}$ with $\mathrm{O}_{2}$ as the oxidant at $120^{\circ} \mathrm{C}$. However, only $79.5 \%$ DBT removal could be attained when non-porous $\mathrm{SiO}_{2}$ replaced the mesoporous $\mathrm{SiO}_{2}$. This indicates the significance of support porosity to the ODS activity, as the emergence of enormous pores creates more adsorption sites for the reactants, thereby promoting the oxidation of sulfur compounds. In order to further enhance the desulfurization efficiency, the same research group performed morphology modification on MMS by introducing hexane into the precursor solution to form a rough surface (Fig. 8f). ${ }^{111}$ As a result, the wettability of the catalyst to the organic phase, or hydrophobicity, was improved and contributed to a higher accessibility of the catalyst for sulfur compounds compared to the smooth-surfaced MMS. The $\left[\left(\mathrm{C}_{8} \mathrm{H}_{17}\right)_{3} \mathrm{NCH}_{3}\right]_{3} \mathrm{PMo}_{12} \mathrm{O}_{40}$ on the rough surface MMS demonstrated better DBT conversion (98.3\%) than that on the smooth surface MMS (53.1\%) after $50 \mathrm{~min}$ in an ODS system with $\mathrm{H}_{2} \mathrm{O}_{2}$ at $60{ }^{\circ} \mathrm{C}$. However, 
Table 2 Representative summary of the performances of ionic liquid-based catalysts in ODS

\begin{tabular}{|c|c|c|c|c|c|c|c|}
\hline \multirow[b]{2}{*}{ Catalysts } & \multirow{2}{*}{$\begin{array}{l}\text { Reaction } \\
\text { temperature } \\
\left({ }^{\circ} \mathrm{C}\right)\end{array}$} & \multirow[b]{2}{*}{ Oxidant } & \multirow[b]{2}{*}{ Extractant } & \multicolumn{3}{|l|}{ Performances } & \multirow[b]{2}{*}{ Ref. } \\
\hline & & & & $\begin{array}{l}\text { Sulfur removal } \\
\text { (reactant) }\end{array}$ & $\begin{array}{l}\text { Reaction } \\
\text { time (h) }\end{array}$ & $\begin{array}{l}\text { Stability } \\
\text { (h) }\end{array}$ & \\
\hline$[\mathrm{Hnmp}] \mathrm{Cl} / \mathrm{ZnCl}_{2}$ & 75 & $\mathrm{H}_{2} \mathrm{O}_{2}(30 \mathrm{wt} \%)$ & {$[\mathrm{Hnmp}] \mathrm{Cl} / \mathrm{ZnCl}_{2}$} & 99.9\% (DBT) & 0.33 & $>2.33$ & 103 \\
\hline$\left[\mathrm{C}_{5} \mathrm{minCl}\right]\left[\mathrm{FeCl}_{3}\right]$ & 30 & {$\left[\mathrm{C}_{5} \mathrm{~min}\right]_{2}\left[\mathrm{~S}_{2} \mathrm{O}_{8}\right]$} & {$\left[\mathrm{C}_{5} \mathrm{minCl}\right]\left[\mathrm{FeCl}_{3}\right]$} & $28.3 \%(\mathrm{DBT})$ & 1.08 & N/A & 104 \\
\hline$\left[\mathrm{C}_{5} \mathrm{minCl}\right]\left[\mathrm{ZnCl}_{2}\right]$ & & & {$\left[\mathrm{C}_{5} \mathrm{minCl}\right]\left[\mathrm{ZnCl}_{2}\right]$} & $44.2 \%$ (DBT) & & N/A & \\
\hline$\left[\mathrm{C}_{5} \mathrm{minCl}\right][\mathrm{CuCl}]$ & & & {$\left[\mathrm{C}_{5} \mathrm{minCl}\right][\mathrm{CuCl}]$} & $35.7 \%(\mathrm{DBT})$ & & N/A & \\
\hline$\left[\mathrm{C}_{5} \mathrm{minCl}\right]\left[\mathrm{CoCl}_{2}\right]$ & & & {$\left[\mathrm{C}_{5} \mathrm{minCl}\right]\left[\mathrm{CoCl}_{2}\right]$} & $98.7 \%(\mathrm{DBT})$ & & $>7.58$ & \\
\hline$[\mathrm{OMIM}]_{2}\left[\mathrm{~S}_{2} \mathrm{O}_{8}\right]$ & 60 & {$[\mathrm{OMIM}]_{2}\left[\mathrm{~S}_{2} \mathrm{O}_{8}\right]$} & {$[\mathrm{OMIM}]_{2}\left[\mathrm{~S}_{2} \mathrm{O}_{8}\right]$} & $97.8 \%(\mathrm{DBT})$ & 3 & N/A & 105 \\
\hline$[\mathrm{BMPy}]\left[\left(\mathrm{C}_{6} \mathrm{H}_{5}\right) \mathrm{COO}\right]$ & 60 & $\mathrm{H}_{2} \mathrm{O}_{2}(30$ wt\%) & {$[\mathrm{BMPy}]\left[\left(\mathrm{C}_{6} \mathrm{H}_{5}\right) \mathrm{COO}\right]$} & $98.9 \%(\mathrm{DBT})$ & 1.5 & $>7.5$ & 106 \\
\hline$[\mathrm{Omin}]\left[\mathrm{H}_{2} \mathrm{SO}_{4}\right]$ & 25 & $\mathrm{H}_{2} \mathrm{O}_{2}(30 \mathrm{wt} \%)$ & {$[\mathrm{Omin}]\left[\mathrm{H}_{2} \mathrm{SO}_{4}\right]$} & $100 \%(\mathrm{DBT})$ & 1.17 & $>7$ & 108 \\
\hline$[\mathrm{Omin}]\left[\mathrm{H}_{2} \mathrm{SO}_{4}\right]$ (with ultrasonic) & & & & $100 \%(\mathrm{DBT})$ & 0.05 & $>0.3$ & \\
\hline$\left[\mathrm{C}_{4} \mathrm{VIM}\right] \mathrm{PMoV}$ & 120 & $\mathrm{O}_{2}$ & {$\left[\mathrm{C}_{4} \mathrm{VIM}\right] \mathrm{PMoV}$} & $21.2 \%(\mathrm{DBT})$ & 5 & $\mathrm{~N} / \mathrm{A}$ & 107 \\
\hline$\left[\mathrm{C}_{4} \mathrm{VIM}\right] \mathrm{PMoV}_{2}$ & & & {$\left[\mathrm{C}_{4} \mathrm{VIM}\right] \mathrm{PMoV}_{2}$} & $98.9 \%(\mathrm{DBT})$ & & $>30$ & \\
\hline$\left[\mathrm{C}_{4} \mathrm{VIM}\right] \mathrm{PMoV}_{3}$ & & & {$\left[\mathrm{C}_{4} \mathrm{VIM}\right] \mathrm{PMoV}_{3}$} & $44.8 \%(\mathrm{DBT})$ & & N/A & \\
\hline V-PIL & 50 & CHP & N/A & $98.0 \%(\mathrm{DBT})$ & 1 & $>12$ & 109 \\
\hline$\left[\left(\mathrm{C}_{8} \mathrm{H}_{17}\right)_{3} \mathrm{NCH}_{3}\right]_{3} \mathrm{PMo}_{12} \mathrm{O}_{40} / \mathrm{MMS}$ & 120 & $\mathrm{O}_{2}$ & N/A & $100 \%$ (DBT) & 5 & $>20$ & 110 \\
\hline$\left[\left(\mathrm{C}_{8} \mathrm{H}_{17}\right)_{3} \mathrm{NCH}_{3}\right]_{3} \mathrm{PMo}_{12} \mathrm{O}_{40} /$ SS-MMS & 60 & $\mathrm{O}_{2}$ & N/A & $53.1 \%$ (DBT) & 0.83 & N/A & 111 \\
\hline$\left[\left(\mathrm{C}_{8} \mathrm{H}_{17}\right)_{3} \mathrm{NCH}_{3}\right]_{3} \mathrm{PMo}_{12} \mathrm{O}_{40} / \mathrm{RS}-\mathrm{MMS}$ & & & N/A & $98.2 \%(\mathrm{DBT})$ & & $>4.17$ & \\
\hline$[\mathrm{HDBN}] \mathrm{Cl} / \mathrm{ZnCl}_{2}$ & 40 & $\mathrm{H}_{2} \mathrm{O}_{2}(30 \mathrm{wt} \%)$ & {$[\mathrm{HDBN}] \mathrm{Cl} / \mathrm{ZnCl}_{2}$} & 99.9\% (DBT) & 2 & $>10$ & 112 \\
\hline
\end{tabular}

PIL: poly-ionic liquid; MMS: magnetic mesoporous silica sphere; SS-MMS: smooth surface mesoporous silica sphere; RS-MMS: rough surface mesoporous silica sphere; DBN: 1,5-diazabicyclo[4.3.0]-non-3-ene.

excessive increment of hydrophobicity could lead to the reduction of ODS activity, which was proved in the work by utilizing a strongly hydrophobic rough-surfaced MMS. Additionally, it increases the difficulty of the subsequent catalyst regeneration process. Optimal hydrophobicity should be pursued to maximize the desulfurization performance in ODS. On the whole, the porosity and morphology of the support are the predominant factors governing the catalytic activity of supported ILs in ODS.

The application of ILs in ODS has contributed numerous benefits, including high efficiency in producing ultra-low-sulfur fuels, an easy recycling process and a low temperature reaction. Nonetheless, the shortcomings of ILs, such as relatively expensive precursors, considerable toxicity, poor regeneration efficiency and high viscosity, should be resolved by screening economical and harmless anion and cation sources and enhancing their chemical properties, especially the solubility in organic media, in order to improve their industrial compatibility. Table 2 summarizes the performances of various ILs in different ODS systems.

\subsection{Application of deep eutectic solvents (DESs) in ODS}

In 2003, the discovery of deep eutectic solvents (DESs) by Abbott et al. created a new research horizon in chemistry. ${ }^{113}$ Different from ILs, DESs are generally synthesized from a hydrogen bond donor (HBD) with a hydrogen bond acceptor (HBA) or a quaternary ammonium salt through hydrogen bonding. ${ }^{114}$ Therefore, the physico-chemical properties of DESs can be facilely tuned to the application purpose by selecting the appropriate precursors or modifying the composition of DESs. Apart from having unique characteristics analogous to ILs, DESs are also biodegradable, non-toxic and comparatively cheap. ${ }^{115}$ This has attracted widespread attention from researchers to dive deep into their applications owing to the rising demand for green solvents in industry. In view of their relative advantages, DESs have been appointed as a prospective alternative to ILs in the arena of fuel desulfurization technology. ${ }^{116,117}$

Currently, the argument on whether the acidity of DESs is the most decisive factor for achieving remarkable catalytic activity in ODS has not come to a substantive conclusion. The connection between the acidity of DESs and the ODS efficiency was revealed by Yin et al. ${ }^{118}$ In their work, various acidic DESs were prepared by mixing different species of HBA and HBD for the ODS of model fuel. The experimental results disclosed that the employment of HBDs with greater acidity, like $p$-toluenesulfonic acid ( $p$-TsOH), could significantly improve the conversion of BT using $\mathrm{H}_{2} \mathrm{O}_{2}$ as oxidant (Fig. 9a). Notably, the conversion of BT remained at $99 \%$ when $p$-TsOH was coupled with different HBAs. Obviously, HBD exhibited a greater influence on the ODS activity of DESs compared with HBA. However, Hao et al. expressed their disagreement on the positive correlation between the acidity of DESs and desulfurization efficiency after examining the activity of several s-proline-based DESs in an ODS system with $\mathrm{H}_{2} \mathrm{O}_{2} \cdot{ }^{119}$ It was discovered that L-proline/ oxalic acid (OA) with the strongest acidity demonstrated the lowest DBT removal efficiency after $30 \mathrm{~min}$ at $60{ }^{\circ} \mathrm{C}$, whereas Lproline/ $p$-TsOH with a Hammett acidity function $\left(H_{0}\right)$ of 1.94 achieved 99\% DBT removal in an identical ODS system (Fig. 9b). Therefore, the effect of the acidity of DESs on ODS efficiency greatly depends on the types of HBD and HBA but is not absolutely important for all cases.

The molar ratio of HBA to HBD also has great influence on the ODS activity of DESs. Mao and co-workers investigated the ability of propionic acid-based DESs with different compositions of $\mathrm{ZnCl}_{2}$ as HBD to convert DBT into DBT sulfone in the presence of $\mathrm{H}_{2} \mathrm{O}_{2} \cdot{ }^{120}$ Interestingly, the conversion of DBT increased with the change of the $\mathrm{C}_{3} \mathrm{H}_{6} \mathrm{O}_{2}$-to- $\mathrm{ZnCl}_{2}$ molar ratio 

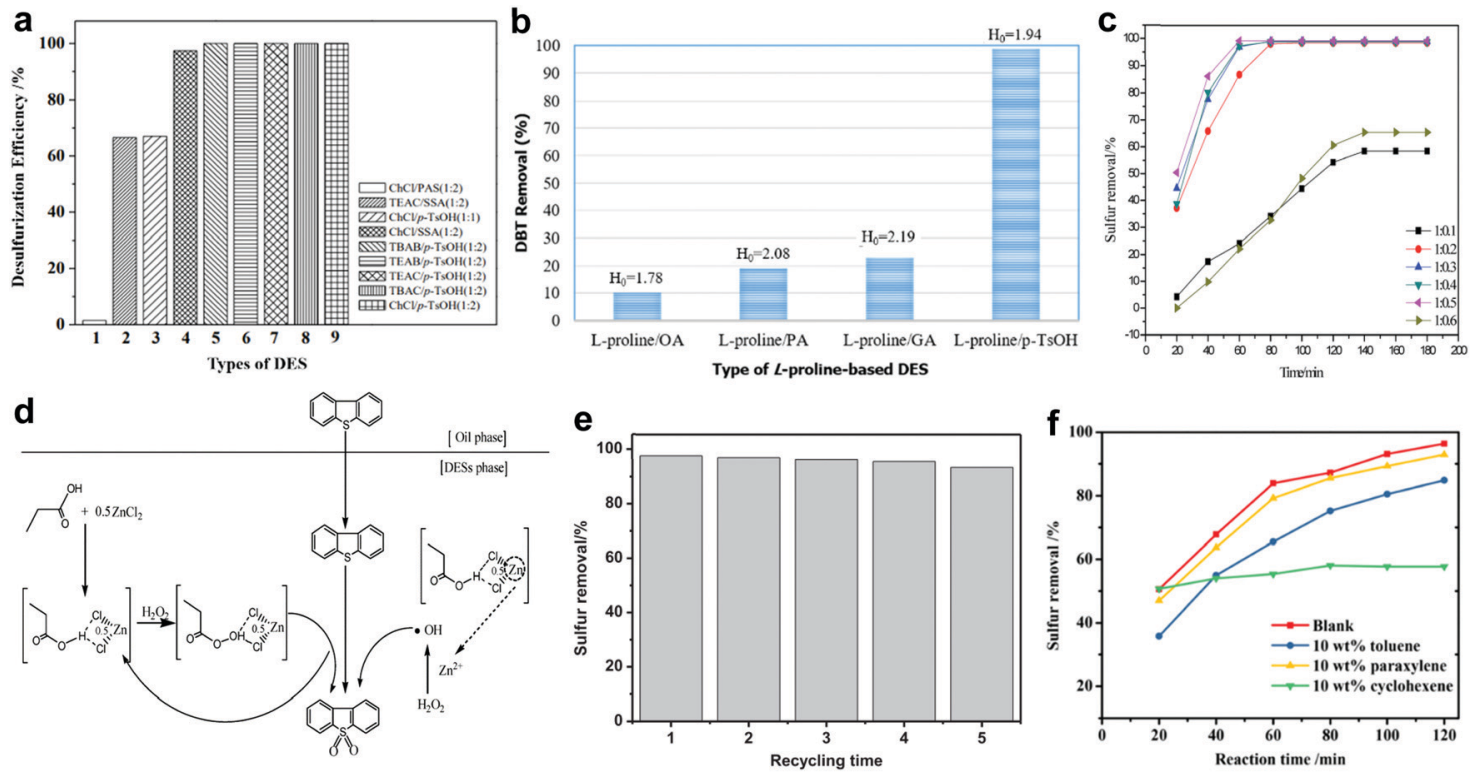

Fig. 9 (a) Catalytic activities of different DESs in oxidizing BT with $\mathrm{H}_{2} \mathrm{O}_{2}$ as oxidant at $25{ }^{\circ} \mathrm{C}$ in $1 \mathrm{~h}$. Reprinted with permission. ${ }^{118}$ Copyright 2015 , Royal Society of Chemistry. (b) DBT removal efficiency and Hammett acidity function $\left(H_{0}\right)$ of different L-proline-based DESs in ODS system with $\mathrm{H}_{2} \mathrm{O}_{2}$ at $60{ }^{\circ} \mathrm{C}$ in 30 min. Reproduced with permission. ${ }^{119}$ Copyright 2017, Elsevier B.V. (c) DBT removal efficiency using $\mathrm{C}_{3} \mathrm{H}_{6} \mathrm{O}_{2} / X \mathrm{ZnCl}_{2}(X=0.1$ to 0.6$)$ and $\mathrm{H}_{2} \mathrm{O}_{2}$ at $40{ }^{\circ} \mathrm{C}$ in $1 \mathrm{~h}$. (d) Reaction mechanism for oxidation of DBT using $\mathrm{C}_{3} \mathrm{H}_{6} \mathrm{O}_{2} / 0.5 \mathrm{ZnCl}$ as catalyst and extractant with $\mathrm{H}_{2} \mathrm{O}_{2}$ as oxidant. Reprinted with permission. ${ }^{120}$ Copyright 2017, Royal Society of Chemistry. (e) DBT oxidation for five runs, at $3 \mathrm{~h}$ per run, using [PSTEtA]Cl/OA as catalyst and extractant at $50{ }^{\circ} \mathrm{C}$ in the presence of $\mathrm{H}_{2} \mathrm{O}_{2}$. Reprinted with permission. ${ }^{123}$ Copyright 2020, Elsevier B.V. (f) Effects of toluene, paraxylene and cyclohexene on the removal of DBT in the ODS system with ChCl/PEG/BA and $\mathrm{H}_{2} \mathrm{O}_{2}$ at $60{ }^{\circ} \mathrm{C}$. Reprinted with permission. ${ }^{124}$ Copyright 2019 , Royal Society of Chemistry.

from $1: 0.1$ to $1: 0.5$, but decreased drastically when the molar ratio reached 1:0.6 (Fig. 9c). The improvement of ODS activity was attributed to the escalation of Lewis acidity, which was conducive to the acceleration of $\mathrm{H}_{2} \mathrm{O}_{2}$ activation to form more reactive oxygen species for ODS. Nevertheless, the excessive Lewis acidity could also lead to the decomposition of $\mathrm{H}_{2} \mathrm{O}_{2}$ into unreactive $\mathrm{H}_{2} \mathrm{O}$ and $\mathrm{O}_{2}$, which substantially diminished the reaction kinetics of ODS. With respect to the reaction pathway (Fig. 9d), DBT was oxidized by the hydroxyl radicals generated from the activation of $\mathrm{H}_{2} \mathrm{O}_{2}$ by DES and by the peroxy- $\mathrm{C}_{3} \mathrm{H}_{6} \mathrm{O}_{2}$ / $0.5 \mathrm{ZnCl}_{2}$ generated from the oxidation of $\mathrm{C}_{3} \mathrm{H}_{6} \mathrm{O}_{2} / 0.5 \mathrm{ZnCl}_{2}$ by $\mathrm{H}_{2} \mathrm{O}_{2}$ after the extraction of DBT from the oil phase to DES phase. In the report of Hao et al., the increase of the HBA-toHBD molar ratio from $1: 1$ to $3: 1$ in caprolactam (CPL)/OA also markedly enhanced the DBT removal efficiency from $62.6 \%$ to 98.4\% with $\mathrm{H}_{2} \mathrm{O}_{2}$ as oxidant at $60{ }^{\circ} \mathrm{C} .{ }^{121}$ This was due to the strengthening of the hydrogen bonding in CPL/OA that was essential for weakening the aromaticity of DBT by developing vigorous interactions between CPL/OA and DBT, thus boosting the activity of CPL/OA in ODS. This was supported by Lü et al. who studied the effect of the HBA-to-HBD molar ratio on the ODS performances of oxalate-based DESs. ${ }^{122}$ By and large, optimization of the HBA-to-HBD molar ratio is necessary to regulate the physico-chemical properties of DESs to maximize the ODS activity of DESs.

In 2020, Jiang et al. prepared an innovative Brønsted acidic DES with dual active sites for ODS by assembling (3-sulfopropyl)triethylammonium chloride ([PSTEtA $] \mathrm{Cl})$ and OA. ${ }^{123}$ Through DFT computations, the sulfonic group and the carboxylic group in [PSTEtA]Cl and OA, respectively, were found to be the active sites that interacted with $\mathrm{H}_{2} \mathrm{O}_{2}$ to form peroxy-intermediates for ODS. This contributed to a higher efficiency of DBT removal in the ODS system with [PSTEtA]Cl/OA (97.7\%) compared to that with tetrabutylammonium chloride (TBAC)/OA (72.9\%), which possessed only a carboxylic group as the catalytic site. Moreover, [PSTEtA]Cl/OA demonstrated outstanding stability in ODS (Fig. 9e) and could be regenerated via simple water washing owing to its hydrophilic property. In another pioneering work of Jiang et al., polyethylene glycol (PEG) and boric acid (BA) were adopted as HBDs along with choline chloride ( $\mathrm{ChCl})$ as an HBA to create a ternary DES for ODS. ${ }^{124}$ It was noteworthy that the increment of BA composition positively influenced the ODS activity of $\mathrm{ChCl} / \mathrm{PEG} / \mathrm{BA}$ but the increase of PEG composition led to the decline of ODS activity. This indicated the paramount role of $\mathrm{BA}$ in catalyzing the oxidation of sulfur compounds. Here, the replacement of ChCl with TBAC, which has a long carbon chain structure, resulted in an improved extractive ability while decreasing the catalytic activity in ODS. Apparently, the tuning of DES composition greatly affects the performances as an extractant and a catalyst in ODS due to discrepancies in the structure and properties of different HBAs and HBDs. In addition, the effect of various hydrocarbons in real diesel on the ODS performances of DES was addressed in the same report. As shown in Fig. 9f, the addition of cyclohexene into model fuel drastically reduced the DBT removal efficiency, whereas the introductions of toluene and paraxylene 
Table 3 Representative summary of the performances of deep eutectic solvent-based catalysts in ODS

\begin{tabular}{|c|c|c|c|c|c|c|c|}
\hline \multirow[b]{2}{*}{ Catalysts } & \multirow{2}{*}{$\begin{array}{l}\text { Reaction } \\
\text { temperature } \\
\left({ }^{\circ} \mathrm{C}\right)\end{array}$} & \multirow[b]{2}{*}{ Oxidant } & \multirow[b]{2}{*}{ Extractant } & \multicolumn{3}{|l|}{ Performances } & \multirow[b]{2}{*}{ Ref. } \\
\hline & & & & $\begin{array}{l}\text { Sulfur removal } \\
\text { (reactant) }\end{array}$ & $\begin{array}{l}\text { Reaction } \\
\text { time }(\mathrm{h})\end{array}$ & $\begin{array}{l}\text { Stability } \\
\text { (h) }\end{array}$ & \\
\hline TEAC/SSA & 25 & $\mathrm{H}_{2} \mathrm{O}_{2}(30 w \mathrm{t} \%)$ & TEAC/SSA & $\sim 67 \%(\mathrm{BT})$ & 1 & N/A & 118 \\
\hline $\mathrm{ChCl} / \mathrm{SSA}$ & & & $\mathrm{ChCl} / \mathrm{SSA}$ & 〜 97\% (BT) & & $\mathrm{N} / \mathrm{A}$ & \\
\hline $\mathrm{TBAB} / p-\mathrm{TsOH}$ & & & $\mathrm{TBAB} / p-\mathrm{TsOH}$ & 〜 99\% (BT) & & $\mathrm{N} / \mathrm{A}$ & \\
\hline $\mathrm{TEAB} / p$-TsOH & & & $\mathrm{TEAB} / p-\mathrm{TsOH}$ & 〜99\% (BT) & & N/A & \\
\hline $\mathrm{TEAC} / p$-TsOH & & & $\mathrm{TEAC} / p$-TsOH & 〜 99\% (BT) & & $\mathrm{N} / \mathrm{A}$ & \\
\hline $\mathrm{TBAC} / p$-TsOH & & & $\mathrm{TBAC} / p-\mathrm{TsOH}$ & 〜 99\% (BT) & & N/A & \\
\hline $\mathrm{ChCl} / p-\mathrm{TsOH}$ & & & $\mathrm{ChCl} / p-\mathrm{TsOH}$ & 〜 99\% (BT) & & $>4$ & \\
\hline L-Proline/OA & 60 & $\mathrm{H}_{2} \mathrm{O}_{2}(30 w \mathrm{wt} \%)$ & L-Proline/OA & $10 \%(\mathrm{DBT})$ & 0.5 & $\mathrm{~N} / \mathrm{A}$ & 119 \\
\hline L-Proline/PA & & & L-Proline/PA & 19\% (DBT) & & $\mathrm{N} / \mathrm{A}$ & \\
\hline L-Proline/GA & & & L-Proline/GA & $23 \%(\mathrm{DBT})$ & & $\mathrm{N} / \mathrm{A}$ & \\
\hline L-Proline $/ p$-TsOH & & & L-Proline $/ p$-TsOH & 99\% (DBT) & & $>3$ & \\
\hline $\mathrm{C}_{3} \mathrm{H}_{6} \mathrm{O}_{2} / 0.5 \mathrm{ZnCl}_{2}$ & 30 & $\mathrm{H}_{2} \mathrm{O}_{2}(30 \mathrm{wt} \%)$ & $\mathrm{C}_{3} \mathrm{H}_{6} \mathrm{O}_{2} / 0.5 \mathrm{ZnCl}_{2}$ & $99.42 \%(\mathrm{DBT})$ & 1 & $>5$ & 120 \\
\hline Caprolactam/OA & 60 & $\mathrm{H}_{2} \mathrm{O}_{2}(30 w \mathrm{t} \%)$ & Caprolactam/OA & $98.4 \%(\mathrm{DBT})$ & 0.5 & $\mathrm{~N} / \mathrm{A}$ & 121 \\
\hline TBAC/OA & 50 & $\mathrm{H}_{2} \mathrm{O}_{2}(30 w \mathrm{t} \%)$ & TBAC/OA & $91 \%(\mathrm{DBT})$ & 3 & $\mathrm{~N} / \mathrm{A}$ & 122 \\
\hline $\mathrm{ChCl} / \mathrm{OA}$ & & & $\mathrm{ChCl} / \mathrm{OA}$ & $71 \%(\mathrm{DBT})$ & & $\mathrm{N} / \mathrm{A}$ & \\
\hline TMAC/OA & & & TMAC/OA & $41 \%(\mathrm{DBT})$ & & $\mathrm{N} / \mathrm{A}$ & \\
\hline L-Pyro/TFA & 60 & $\mathrm{H}_{2} \mathrm{O}_{2}(30 w \mathrm{t} \%)$ & L-Pyro/TFA & 99.7\% (DBT) & 3 & $>4.5$ & 125 \\
\hline L-Pyro/formic acid & & & L-Pyro/formic acid & $97.0 \%(\mathrm{DBT})$ & & N/A & \\
\hline L-Proline/TFA & & & L-Proline/TFA & 99.6\% (DBT) & & N/A & \\
\hline L-Proline/formic acid & & & L-Proline/formic acid & $4.7 \%(\mathrm{DBT})$ & & $\mathrm{N} / \mathrm{A}$ & \\
\hline$[\mathrm{PSTEtA}] \mathrm{Cl} / \mathrm{OA}$ & 50 & $\mathrm{H}_{2} \mathrm{O}_{2}(30 \mathrm{wt} \%)$ & {$[$ PSTEtA $] \mathrm{Cl} / \mathrm{OA}$} & $97.7 \%(\mathrm{DBT})$ & 3 & $>15$ & 123 \\
\hline TBAC/OA & & & $\mathrm{TBAC} / \mathrm{OA}$ & $72.9 \%(\mathrm{DBT})$ & & N/A & \\
\hline [PSTEtA] Cl/AA & & & [PSTEtA]Cl/AA & $95.1 \%(\mathrm{DBT})$ & & $\mathrm{N} / \mathrm{A}$ & \\
\hline $\mathrm{ChCl} / \mathrm{BA}$ & 60 & $\mathrm{H}_{2} \mathrm{O}_{2}(30 w \mathrm{w} \%)$ & $\mathrm{ChCl} / \mathrm{BA}$ & $34.0 \%(\mathrm{DBT})$ & 2 & $\mathrm{~N} / \mathrm{A}$ & 124 \\
\hline $\mathrm{ChCl} / \mathrm{PEG}$ & & & $\mathrm{ChCl} / \mathrm{PEG}$ & $27.4 \%(\mathrm{DBT})$ & & $\mathrm{N} / \mathrm{A}$ & \\
\hline $\mathrm{ChCl} / \mathrm{PEG} / \mathrm{BA}$ & & & $\mathrm{ChCl} / \mathrm{PEG} / \mathrm{BA}$ & $96.4 \%(\mathrm{DBT})$ & & $>4$ & \\
\hline TBAC/PEG/BA & & & TBAC/PEG/BA & $56.4 \%(\mathrm{DBT})$ & & $\mathrm{N} / \mathrm{A}$ & \\
\hline 2Acetamide/GA & 60 & $\mathrm{H}_{2} \mathrm{O}_{2}(30 \mathrm{wt} \%)$ & 2Acetamide/GA & $57 \%(\mathrm{DBT})$ & 0.5 & $\mathrm{~N} / \mathrm{A}$ & 126 \\
\hline Acetamide/GA & & & Acetamide/GA & $95 \%(\mathrm{DBT})$ & & $\mathrm{N} / \mathrm{A}$ & \\
\hline Acetamide/2GA & & & Acetamide/2GA & $99 \%(\mathrm{DBT})$ & & $\mathrm{N} / \mathrm{A}$ & \\
\hline Acetamide/3GA & & & Acetamide/3GA & $95 \%(\mathrm{DBT})$ & & $\mathrm{N} / \mathrm{A}$ & \\
\hline $\mathrm{CoCl}_{2}-\mathrm{ChCl} / 2 \mathrm{PEG}$ & 20 & PMS & $\mathrm{CoCl}_{2}-\mathrm{ChCl} / 2 \mathrm{PEG}$ & 100\% (DBT) & 1 & $>6$ & 127 \\
\hline $\mathrm{CoCl}_{2}-\mathrm{ChCl} / 2 \mathrm{Pr}$ & & & $\mathrm{CoCl}_{2}-\mathrm{ChCl} / 2 \mathrm{Pr}$ & $83 \%(\mathrm{DBT})$ & & $\mathrm{N} / \mathrm{A}$ & \\
\hline $\mathrm{CoCl}_{2}-\mathrm{ChCl} / 2 \mathrm{EG}$ & & & $\mathrm{CoCl}_{2}-\mathrm{ChCl} / 2 \mathrm{EG}$ & $73 \%(\mathrm{DBT})$ & & $\mathrm{N} / \mathrm{A}$ & \\
\hline $\mathrm{CoCl}_{2}-\mathrm{ChCl} / 2$ glycerol & & & $\mathrm{CoCl}_{2}-\mathrm{ChCl} / 2$ glycerol & $55 \%(\mathrm{DBT})$ & & N/A & \\
\hline
\end{tabular}

TEAC: tetraethylammonium chloride; SSA: 5 -sulfosalicylic acid; ChCl: choline chloride; TBAB: tetrabutylammonium bromide; $p$-TsOH: $p$-toluenesulfonic acid; TEAB: tetraethylammonium bromide; TBAC: tetrabutylammonium chloride; OA: oxalic acid; PA: propanedioic acid; GA: glutaric acid; TMAC: tetramethylammonium chloride; L-Pyro: L-pyroglutamic acid; TFA: trifluoroacetic acid; [PSTEtA]Cl: (3-sulfopropyl)triethylammonium chloride; AA: acetic acid; BA: boric acid; PEG: polyethylene glycol; PMS: peroxymonosulfate; Pr: propionic acid; EG: ethylene glycol.

brought about little influence on the oxidation of DBT. This phenomenon is produced by the competitive oxidation reaction between hydrocarbons and DBT. The detrimental impact of cyclohexene on the ODS reaction was also ascertained by Liu et al., who studied the ODS system with L-pyroglutamic acid/trifluoroacetic acid. ${ }^{125}$ Therefore, further research should be performed to strengthen the selectivity towards aromatic sulfur compounds by modulating the intrinsic characteristics of DESs to secure the outstanding ODS activity of DESs in treating commercial diesel.

DESs are a promising catalyst and extractant in ODS due to their ability to achieve ultra-deep desulfurization of fuels at a relatively mild reaction temperature, which is highly desirable for future industrial applications. Proper screening of the HBA and HBD as well as alteration of their molar ratio must be performed to engineer DESs with excellent desulfurization performances in ODS. As a suggestion, additional study on the utilization of cheaper and environmentally benign $\mathrm{O}_{2}$ as the oxidant in the ODS system with DESs should be conducted to proffer valuable insights into the development of a sustainable
ODS process. Table 3 presents the performances of various DESs in different ODS systems.

\subsection{Application of polyoxometalates (POMs) in ODS}

To date, an appreciable amount of literature has been published on the ODS of diesel fuel by utilizing POMs, chosen for their tunable properties, ample exposure of active sites and exceptional performances in redox reactions. ${ }^{128-135}$ Typically, POMs are cluster form materials belonging to the metal oxide family, which is comprised of numerous transition metal oxoanions and oxygen atoms, frequently with heteroatoms. ${ }^{136}$ In regard to their structure, POMs can be classified into several types, including Anderson-Evans, ${ }^{134}$ Keggin, ${ }^{133,137-139}$ Dawson $^{140}$ and so forth, which respectively possess the coordination of a single heteroatom surrounded by 6 transition metal atoms $\left(\left[\mathrm{XM}_{6} \mathrm{O}_{24}\right]^{n-}\right),{ }^{141}$ one heteroatom surrounded by 12 transition metal atoms $\left(\left[\mathrm{XM}_{12} \mathrm{O}_{40}\right]^{n-}\right)^{140}$ and two heteroatoms surrounded by 18 transition metal atoms $\left(\left[\mathrm{X}_{2} \mathrm{M}_{18} \mathrm{O}_{62}\right]^{n-}\right) \cdot{ }^{140}$ Among the POM types, Keggin-based POMs have been popularly investigated in 
ODS by previous researchers on account of their superiority in industrial applicability, thermal resistance and simplicity of synthesis procedures. ${ }^{26,130}$ Owing to their poor miscibility in the organic phase, homogeneous POMs are invariably coupled with an extractant such as ILs, DESs or organic polar solvents to accelerate the desulfurization process by facilitating the mass diffusion of sulfur compounds in fuels with POMs. ${ }^{129,133,134,137,138,142}$

3.4.1 Homogenous POMs. In general, common homogenous Keggin-type POMs like phosphomolybdic acid $\left(\mathrm{H}_{3} \mathrm{PMo}_{12} \mathrm{O}_{40}\right)$, phosphotungstic acid $\left(\mathrm{H}_{3} \mathrm{PW}_{12} \mathrm{O}_{40}\right)$, silicotungstic acid $\left(\mathrm{H}_{4} \mathrm{SiW}_{12} \mathrm{O}_{40}\right)$ and sodium phosphotungstate $\left(\mathrm{Na}_{3} \mathrm{PW}_{12} \mathrm{O}_{40}\right)$ can be readily procured commercially. ${ }^{130,137,138,143}$ The Keggin-based POMs can be revamped through various methods to tailor their properties. The modification steps consist of the degradation of pure POMs into lacunary species with alkaline solutions to eliminate part of the original transition metal atoms, followed by filling the vacancies with the desired transition metal atoms. ${ }^{140}$ In contrast, Wang et al. employed a refluxing technique accompanied by crystallization to fabricate modified POMs, $\mathrm{H}_{3} \mathrm{PW}_{x} \mathrm{Mo}_{12-x} \mathrm{O}_{40}(x=1,3,6)$, directly from precursors instead of reshaping commercial POMs. ${ }^{132}$ Similarly, analogous synthesis procedures were conducted by Komintarachat et al. in the formation of $\left[\mathrm{PVW}_{11} \mathrm{O}_{40}\right]^{4-}$ and $\left[\mathrm{PV}_{2} \mathrm{Mo}_{10} \mathrm{O}_{40}\right]^{4-}$, but the $\mathrm{pH}$ of the precursor solution was regulated to a different value compared to the previous paper. ${ }^{142}$ It is noteworthy that the alteration of $\mathrm{pH}$ value in aqueous solution is essential to provide an ample concentration of hydrogen ions for the assembly of oxoanions in order to form the desired POM structure. ${ }^{140}$ Both methods are practicable in preparing modified POMs, but the latter technique has gained more research interest, which is accredited to the superior controllability of the structure and elemental composition of POMs.

In the past, Wang and co-workers highlighted phosphotungstic acid (HPW) as a promising POM for desulfurizing model diesel because it proficiently transformed $99.23 \%$ of DBT to DBT sulfone with the aid of $\mathrm{H}_{2} \mathrm{O}_{2}$ within $60 \mathrm{~min}$ at $60{ }^{\circ} \mathrm{C}^{132}$ This was not in agreement with the research of Trakarnpruk and Rujiraworawut, which manifested that HPW achieved merely 93\% conversion of DBT after 150 min under the identical reaction temperature. ${ }^{139}$ The performance discrepancy originated from a difference in the applied oxygen to sulfur $(\mathrm{O} / \mathrm{S})$ molar ratio, as the first report utilized 15:1 compared to $10: 1$ in the second report. In order to construct a comprehensive picture of the correlation between the $\mathrm{O} / \mathrm{S}$ ratio and ODS activity, the proposed ODS mechanism of HPW is shown in Fig. 10a. In fact, the increment of the $\mathrm{O} / \mathrm{S}$ ratio appreciably increased the ODS efficiency. The excess $\mathrm{H}_{2} \mathrm{O}_{2}$ was able to promote the generation of an unstable peroxo-HPW intermediate by accelerating the rate of nucleophilic attack towards the W atom of HPW in the aqueous phase (1). With the help of a polar extractant, DBT was transferred from the organic phase to the aqueous phase and readily reacted with the peroxo-HPW to yield DBT sulfoxide (2). Eventually, DBT sulfoxide was oxidized to DBT sulfone through the same pathway (3 and 4). Meanwhile, DBT sulfone was sealed in the aqueous phase due to the increase of polarity and was removed through a further separation process. However, Wang et al. also revealed that the $\mathrm{O} / \mathrm{S}$ ratio no longer significantly intensified the ODS activity when it was increased to $1: 18 .{ }^{132}$ Moreover, the excessive oxidants triggered the rapid oxidation of alkenes and aromatic hydrocarbons in the diesel fuel. Consequently, the yield of clean diesel fuel greatly declined, which could exacerbate the operational cost for ODS. ${ }^{57}$ Therefore, knowledge of the optimum $\mathrm{O} / \mathrm{S}$ ratio for different ODS systems is essential to economically maximize the ODS activity and bring it a step closer to industrial application.

Instead of utilizing extractant, Choi et al. applied a phase transfer agent (PTA) to perform ODS with POMs with the assistance of vigorous mixing and ultrasound. ${ }^{137,138}$ While an extractant and PTA share the same objective in promoting mass transfer between catalyst and reactant, their mechanisms in ODS were contrary. In the ODS system with PTA and HPW (Fig. 10b), the oxidation of DBT (3) arose in the organic phase rather than in aqueous phase due to the PTA conveying active peroxo-HPW. After the oxidation process, the peroxo-HPW was degraded to HPW, detached from PTA and transported back to the aqueous phase (4). At the same time, the oxidized DBT was endowed with a higher miscibility in aqueous phase, which facilitated its dissociation from the fuels.

Apart from traditional Keggin-type POMs, POMs modified by heteroatom substitution have been investigated for their catalytic activity in ODS. First, the $\left[\mathrm{PV}_{2} \mathrm{Mo}_{10} \mathrm{O}_{40}\right]^{4-}$ complex prepared by Komintarachat and Trakarnpruk achieved 86\% DBT conversion in gas oil after $5 \mathrm{~h}$, which was mainly attributed to the higher tendency of Mo-O-V species to generate a more unstable peroxo-POMs lattice after the replacement of Mo with V. ${ }^{142}$ Nevertheless, a few years later, Wang et al. reported that the replacement of Mo with $\mathrm{W}$ in phosphomolybdic acid (HPMo) demonstrated better ODS efficiency (>98\%) with $\mathrm{H}_{2} \mathrm{O}_{2}$ in $1 \mathrm{~h}^{132}$ The increase of $\mathrm{W}$ in HPMo improved the ODS activity in the order of $\mathrm{W}_{6}(99.79 \%)>\mathrm{W}_{3}(99.22 \%)>\mathrm{W}_{1}$ $(98.80 \%)$ owing to the function of the $\mathrm{W}$ atom in promoting the Brønsted acidity of HPMo. Recently, Bertleff et al. produced $\mathrm{H}_{8} \mathrm{PV}_{5} \mathrm{Mo}_{7} \mathrm{O}_{40}$ by substituting Mo with $\mathrm{V}$ in HPMo, which attained up to $99 \%$ sulfur removal with the consumption of $\mathrm{O}_{2}$ at $140{ }^{\circ} \mathrm{C}$ and 20 bar oxygen pressure within 6 h. ${ }^{131}$ Despite the harsh operating conditions and long reaction time, the hazardous and uneconomical $\mathrm{H}_{2} \mathrm{O}_{2}$ was supplanted by $\mathrm{O}_{2}$ in the study, contributing a valuable insight into environmentallyfriendly ODS. The application of a green ODS process on an industrial scale without compromising the rate and operating conditions of ODS is a momentous challenge for the future. In the above studies, the development of POMs in ODS is clearly illustrated, from improving the ODS activity and rate of reaction by attempting various heteroatom substitution to establishing an eco-friendly ODS process by utilizing safe and free ingredients.

3.4.2 Heterogeneous POMs. Despite their prodigious catalytic activity in ODS, the cumbersome catalyst recovery process and the scarcity of active sites are the primary bottlenecks to the practicality of using homogenous POMs in industrial-scale ODS. This scenario has unleashed the curiosity of the research 
a

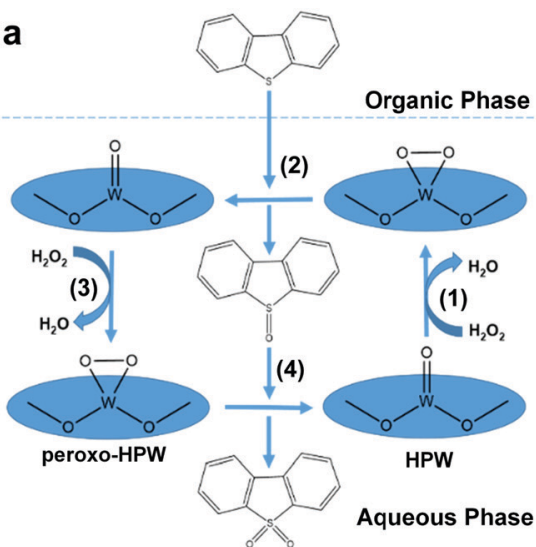

b

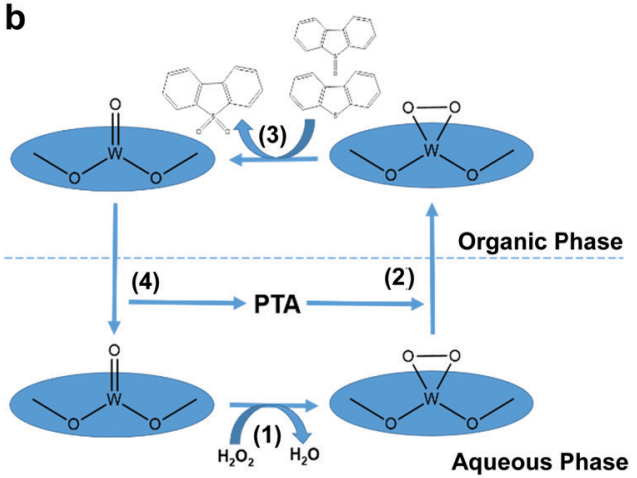

Fig. 10 ODS mechanisms of DBT over HPW POM using (a) extractant and (b) phase transfer agent (PTA).

community on the scheme of fabricating heterogeneous POMs to circumvent the shortcomings of homogenous POMs. With the aims of ease of separation and sustainability, monumental efforts have been dedicated to modification strategies for homogeneous POMs, encompassing precipitation with insoluble metal ions, immobilization on supports and encapsulation in MOFs, to enhance the heterogeneity without compromising the unprecedented catalytic performances in ODS. ${ }^{144}$

3.4.2.1 Heterogeneous POMs synthesized by precipitation. For the precipitation of POMs with insoluble cations, the protons or hydrogen atoms of POMs are replaced with large insoluble metal ions to improve the heterogeneity. Recently, Akbari et al. synthesized Cs salts of HPW (CsPW) by co-precipitation method (CP), reversed emulsion (RE) method and reversed microemulsion (RME) method and applied them in the ODS of model diesel. ${ }^{145}$ The utilization of surfactant in RME led to the attachment of the surfactant on the surface of CsPW and fostered an amphiphilic property in CsPW. The surfactant also ameliorated the total surface energy of CsPW by building up more counter ions on the surface. This weakened the van der Waals forces between CsPW particles, hampering the agglomeration of particles and generating separated particles (Fig. 11a). In contrast, the CsPW synthesized by CP agglomerated and formed a large granule (Fig. 11b) due to the absence of surfactant. As a result, the CsPW obtained via RME exhibited the highest activity (50\%) in eliminating DBT (Fig. 11c), which was attributed to the increase of active sites exposed to the sulfur reactants for ODS. In spite of that, the achieved ODS activity is still quite far from ultra-deep desulfurization and is crucially restricted by the scarcity of active sites.

In addition to Keggin-type POMs, Li's research team recently used the Anderson-Evans type POM Na $\mathrm{TeW}_{6} \mathrm{O}_{24} \cdot 22 \mathrm{H}_{2} \mathrm{O}\left(\mathrm{TeW}_{6}\right)$ in ODS. ${ }^{146}$ They also incorporated $\mathrm{Cu}$ ions into the structure of $\mathrm{TeW}_{6}$ to endow a heterogeneous feature in organic fuels. The results showed that the conversion efficiency of thioanisole over $\mathrm{Te}_{2} \mathrm{~W}_{8} \mathrm{Cu}_{2}$ attained $99 \%$ with $\mathrm{H}_{2} \mathrm{O}_{2}$ after $6 \mathrm{~h}$ at room temperature, which was slightly higher than those of $\mathrm{TeW}_{6} \mathrm{Cu}(89 \%)$ and conventional $\mathrm{TeW}_{6}$ $(89 \%)$. It was demonstrated that the introduction of $\mathrm{Cu}$ ions successfully developed new active sites for $\mathrm{TeW}_{6}$, leading to the improvement of ODS activity. Despite the sluggish ODS kinetics, this research proved that it is viable to achieve notable ODS performance without inputting external heat energy to the system.

3.4.2.2 Heterogeneous POMs synthesized by anchoring on support. Alternatively, POMs can also be impregnated into an appropriate support with a large surface area and high porosity characteristics. In this regard, Julião and coworkers fabricated a peroxophosphotungstate-based catalyst $\left(\mathrm{PW}_{4}\right)$ on trimethylammonium group-functionalized mesoporous silica (TMA-SBA-15)
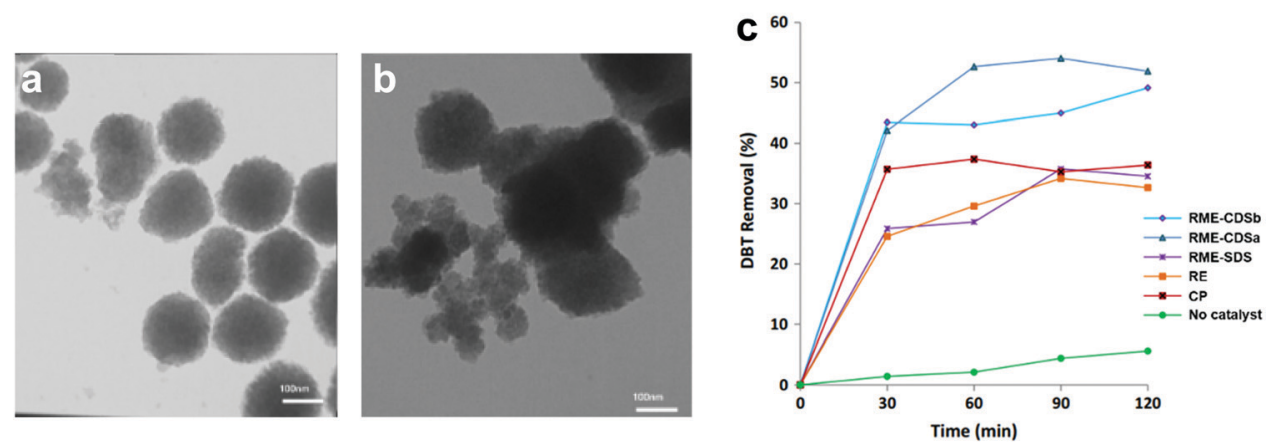

Fig. 11 TEM images of CSPW synthesized via (a) reverse microemulsion (RME) method and (b) co-precipitation (CP) method. (c) DBT removal with TBHP at $60{ }^{\circ} \mathrm{C}$ over various CsPW created by CP, reversed emulsion (RE) method and RME with sodium dodecyl sulfate (SDS) or caesium dodecyl sulfate (CDS) as surfactant. Reprinted with permission. ${ }^{145}$ Copyright 2020, Springer Nature. 
through an impregnation method and studied its activity in a biphasic ODS system with model and real diesel fuels. ${ }^{57}$ Both $\mathrm{PW}_{4}$ and $\mathrm{PW}_{4} /$ TMA-SBA-15 attained complete desulfurization in model diesel within $2 \mathrm{~h}$ under the same operating conditions, but $\mathrm{PW}_{4} /$ TMA-SBA-15 demonstrated higher stability $(>30 \mathrm{~h})$ than $\mathrm{PW}_{4}(<20 \mathrm{~h})$. The robustness of the catalyst can be observed in Fig. 12a and b, which display the unchanged morphology and structure of $\mathrm{PW}_{4} / \mathrm{TMA}-\mathrm{SBA}-15$ after catalyst recovery. This phenomenon was ascribed to the functionalization of the SBA-15 surface with TMA organic groups which resulted in stronger intermolecular bonds between $\mathrm{PW}_{4}$ and SBA-15, inhibiting the occurrence of leaching. Mirante et al. also implemented a similar strategy in functionalizing large-pore mesoporous silica nanospheres (LPMS) with TMA, which later served as the support for a sandwich-type samariumphosphomolybdic catalyst (SmPMo) through the impregnation method (Fig. 12c). ${ }^{147}$ In the FTIR analysis (Fig. 12d and e), the similar spectral profiles of initial and recovered SmPMo/TMALPMS disclosed the robust structure and outstanding stability of the catalyst which further contributed to the $100 \%$ desulfurization of model diesel for three consecutive cycles. Both studies confirmed the key role of surface functional groups, like TMA, in developing POM composites with a stable structure and prolonged lifetime in ODS.

Ribeiro and coworkers employed the amine functional group (3-aminopropyl)triethoxysilane (aptes) and the tributylammonium (TBA) functional group to functionalize the surface of SBA-15 in order to enhance the dative bonding between SBA-15 and lacunary phosphotungstic catalyst $\left(\mathrm{PW}_{11}\right) \cdot{ }^{133}$ Interestingly, the aptes-functionalized composite attained a higher desulfurization efficiency $(100 \%)$ than the composite with TBA $(80 \%)$ in $70 \mathrm{~min}$. This phenomenon stemmed from the blockage of pores in SBA-15 by TBA with its larger particle size, which immensely inhibited the interactions of reactants and active sites, thereby diminishing the catalytic performance in ODS. PW $_{11} /$ aptes-SBA-15 exhibited identical ODS activity in biphasic and monophasic systems with model diesel (Fig. 12f) due to the improvement of heterogeneity, which contributed to the good dispersion of the catalyst in the organic phase. The remarkable performance of POMs in the absence of extractive solvent can be noted as a breakthrough in ODS and a valuable insight for future industrial application.

Mojaverian Kermani's research group reported an ingenious strategy to deal with the burdensome catalyst recovery challenge in ODS systems with POMs. ${ }^{148}$ They magnetized a Keplerate-type POM, isopolyoxomolybdate $\left(\mathrm{Mo}_{132}\right)$, by embedding it into IL-functionalized magnetic silica nanoparticles (IL-MSN) to ease the recycling of the catalyst after ODS with a magnet. Moreover, IL-MSN served as a valuable dispersion platform for $\mathrm{Mo}_{132}$ to create more surface active sites for catalyzing ODS. This contributed to a tremendous enhancement of DBT conversion at $62.5{ }^{\circ} \mathrm{C}$ utilizing $\mathrm{H}_{2} \mathrm{O}_{2}$ as oxidant in $30 \mathrm{~min}$. However, light leaching of $\mathrm{Mo}_{132}$ emerged after $1 \mathrm{~h}$ of ODS owing to the poor chemical bonding between $\mathrm{Mo}_{123}$ and
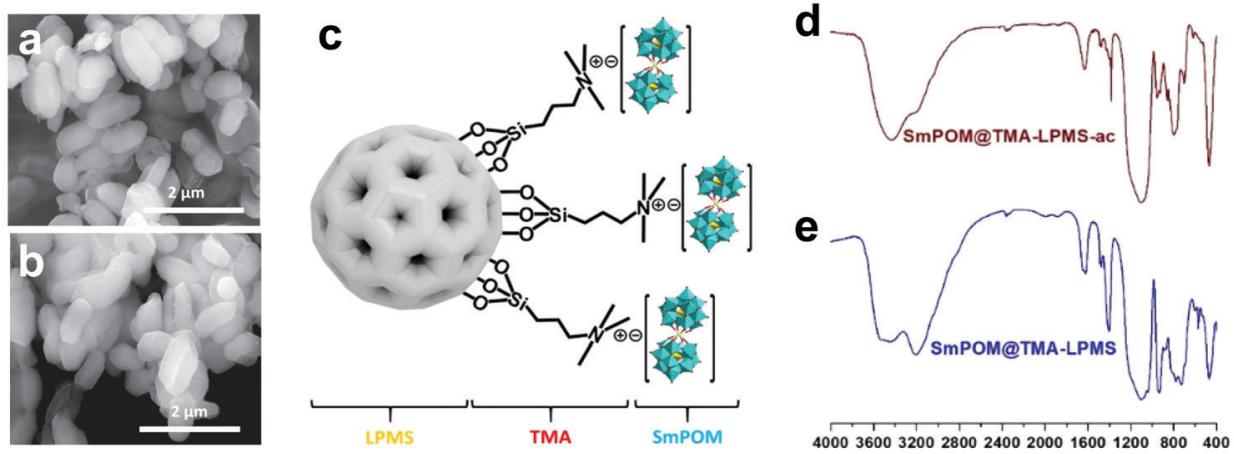

40003600320028002400200016001200800400 Wavenumber $\left(\mathrm{cm}^{-1}\right)$
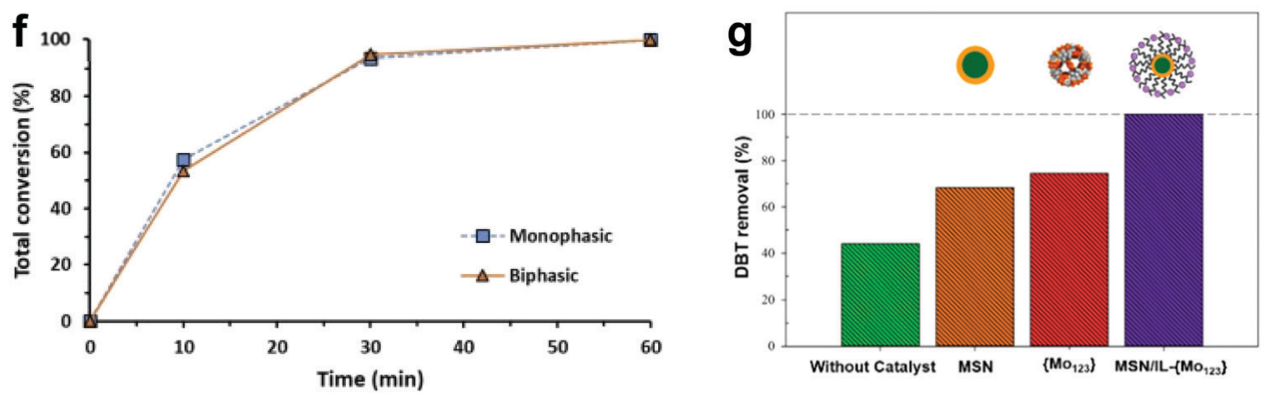

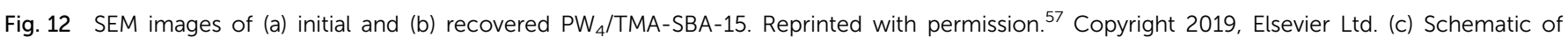

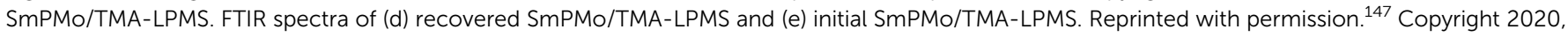

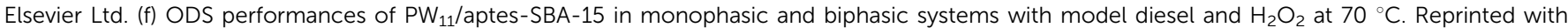

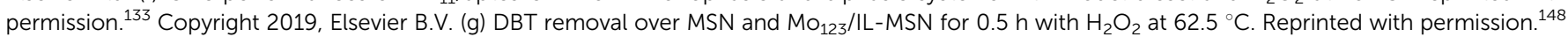
Copyright 2021, Elsevier Ltd. 
IL-MSN, resulting in significant ODS activity loss (Fig. 12g). In other words, the IL functional group on the surface of the MSN was insufficient to strongly bond $\mathrm{Mo}_{123}$ and prevent its detachment in long-time ODS. Thus, the substitution of the IL with a relatively robust functional group would prolong the lifetime and strengthen the recyclability of POMs nanocomposites in ODS.

Besides mesoporous silica-based supports, carbonaceous materials with extensive surfaces have also been nominated as supports for POMs in ODS. According to the pioneering work by Xiao et al., HPW was immobilized on activated carbon (AC) as the supporting material by wet impregnation method. ${ }^{149}$ The enlargement of the specific surface area from $10 \mathrm{~m}^{2} \mathrm{~g}^{-1}$ to $478.4 \mathrm{~m}^{2} \mathrm{~g}^{-1}$ in HPW after impregnation contributed $90 \% \mathrm{Th}$ conversion in model fuel with $\mathrm{H}_{2} \mathrm{O}_{2}$ at $90{ }^{\circ} \mathrm{C}$. However, the existence of readily oxidized hydrocarbons like xylene, octadiene and cyclohexene as competitors to Th significantly decreased the effectiveness of HPW/AC in desulfurizing real fuel. A possible explanation for this event was that hydrocarbons with particle sizes smaller than the pore size of catalyst were able to access the pore channels and occupy the active sites, further curtailing the availability of adsorption and oxidation platforms for Th. Since the long hydrocarbons in commercial diesel can vastly influence the activity of catalysts, this should be considered during ODS and countermeasures addressing this issue would be a fruitful area for further study.

Beyond the impregnation method, Liao and co-workers proposed an innovative electrochemical method to embed HPW into rGO (HPW/rGO-Ele). ${ }^{150}$ With a stronger reduction capability, the electrochemical method eliminated more oxygen-containing functional groups during the reduction process of GO into rGO. Advantageously, the aggregation problem from the strong interactions between HPW and oxygen-containing functional groups was efficaciously minimized. Hence, HPW/rGO-Ele displayed uniform dispersion (Fig. 13a), but not the agglomerated structure which could be observed in the morphology of impregnation method-prepared HPW/rGO (HPW/rGO-Imp) (Fig. 13b). As a result, HPW/rGO-Ele possessed larger specific surface area and richer surface catalytic sites. The stronger interaction forces between HPW and rGO, which stemmed from the substantial interfacial charge transfer, protected the structure of HPW/rGOEle from dissociation, giving rise to the consistent and impressive DBT removal rate for five successive runs (Fig. 13c). Although the electrochemical method exhibits more advantages in fabricating hybrid materials than the conventional chemical approach, its application in large scale production still remains uncertain because the demand for an incessant supply of electrons to drive the synthesis process is a major challenge.

In another work, different quantities of HPW were grafted onto GO to examine the effect of HPW loading on the oxidation activity of HPW/GO. ${ }^{151}$ The outcome of the study revealed that HPW/GO with higher loadings of HPW possessed better oxidation ability on DBT in the presence of $\mathrm{H}_{2} \mathrm{O}_{2}$ at $60{ }^{\circ} \mathrm{C}$ (Fig. 13d). This was ascribed to the increment of active sites for ODS. Likewise, Zhu et al. reported the positive effect of increasing the HPW loadings on $\mathrm{g}-\mathrm{C}_{3} \mathrm{~N}_{4}$ in the conversion of DBT. ${ }^{152}$
Nevertheless, the DBT conversion of $30 \mathrm{wt} \% \mathrm{HPW} / \mathrm{g}-\mathrm{C}_{3} \mathrm{~N}_{4}$ $(99.5 \%)$ was slightly lower than that of $20 \mathrm{wt} \% \mathrm{HPW}(100 \%)$ after $2.5 \mathrm{~h}$. This was attributed to saturation of the anchor sites on the surface of $\mathrm{g}-\mathrm{C}_{3} \mathrm{~N}_{4}$ which caused the blockage and overlapping of active sites by the additional HPW. Therefore, an optimum loading of catalyst is highly essential for elevating the ODS activity.

As in the previous works, the employment of methanol as a solvent in ODS can create extra expenses for separation, the recovery process and waste management due to the poisonous and flammable properties of solvents. Hence, Shokri Aghbolagh et al. adopted the relatively hazardless polyethylene glycol as the solvent in the ODS system with Keggin-type TBAPMo ${ }_{11} \mathrm{Cu}$ on $\mathrm{CuO}$, which was synthesized through the sol-gel method. ${ }^{153}$ The utilization of polyethylene glycol was conducive to the efficacy of TBAPMo ${ }_{11} \mathrm{Cu} / \mathrm{CuO}$ in oxidizing DBT and achieved the highest performance compared to ODS systems with conventional solvents including methanol, ethanol and acetonitrile (Fig. 13e). The effect of solvent on the rate of ODS is not clearly understood and would be an interesting research topic to guide the selection of ODS solvents in the future. The coupling of $\mathrm{TBAPMo}_{11} \mathrm{Cu}$ with $\mathrm{CuO}$ not only improved the heterogeneity but also enlarged the specific surface area and later developed more active sites for ODS. As a result, $\mathrm{TBAPMo}_{11} \mathrm{Cu} / \mathrm{CuO}$ attained a greater DBT oxidation (98\%) in the presence of $\mathrm{H}_{2} \mathrm{O}_{2}$ at $35{ }^{\circ} \mathrm{C}$ than did pristine TBAPMo ${ }_{11} \mathrm{Cu}(61 \%)$ after $1 \mathrm{~h}$.

Instead of applying a safer solvent, Yu et al. enhanced the amphiphilic feature of HPW by doping IL to eliminate the extractant and supported the modified $\mathrm{HPW}$ on $\mathrm{g}-\mathrm{C}_{3} \mathrm{~N}_{4}$ via solvothermal method. ${ }^{154}$ By substituting long carbon chains for the polar hydrogen atoms, the resulting $\mathrm{C}_{12} \mathrm{PW} / \mathrm{g}-\mathrm{C}_{3} \mathrm{~N}_{4}$ gained hydrophobic character. This allowed dispersion of the catalyst in the organic phase and accelerated the mass transfer of the catalyst in contact with reactant. This modification was affirmed by the wettability test (Fig. 13f), where $\mathrm{C}_{12} \mathrm{PW} / \mathrm{g}-\mathrm{C}_{3} \mathrm{~N}_{4}$ possessed a zero contact angle with model diesel. In addition, the fast electron migration from $\mathrm{g}-\mathrm{C}_{3} \mathrm{~N}_{4}$ to $\mathrm{C}_{12} \mathrm{PW}$ that promoted the activation of $\mathrm{H}_{2} \mathrm{O}_{2}$ brought about the complete oxidation of DBT in model fuel at $60{ }^{\circ} \mathrm{C}$ after $1 \mathrm{~h}$ through the ODS mechanism shown in Fig. 13g. However, safety concerns arising from the utilization of hazardous $\mathrm{H}_{2} \mathrm{O}_{2}$ in ODS prompted $\mathrm{Ma}$ and colleagues to investigate the possibility of $\mathrm{O}_{2}$ as the oxidizing agent. ${ }^{155}$ Through the bottom-up selfassembly approach, poly-IL (PIL) was a vital bridging agent, holding the POM anionic clusters and graphene (Gr) together (Fig. 13h) by creating a series of vigorous interactions composed of electrostatic force, van der Waals force, $\pi-\pi$ interaction and hydrophobic interaction. As a result, a mesoporous POM/PIL/Gr with 2D structure and large surface area was synthesized and achieved 100\% DBT conversion for $3 \mathrm{~h}$ at $100{ }^{\circ} \mathrm{C}$. Overall, these studies suggest that the hybridization of POMs with carbon materials can realize $100 \%$ desulfurization of fuels.

3.4.2.3 Heterogeneous POMs synthesized by encapsulating in MOFs. In addition to carbonaceous materials, highly porous 

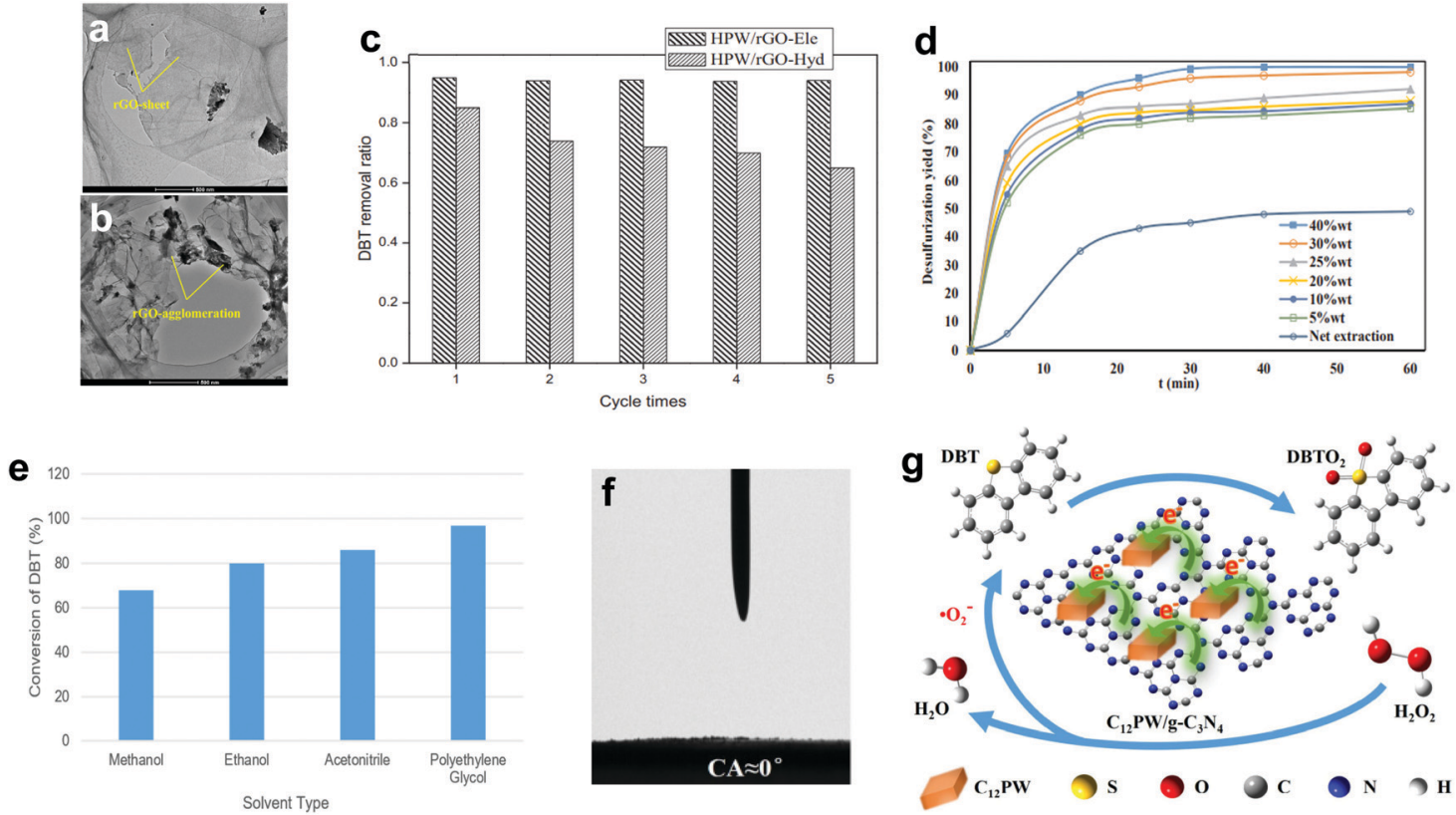

h

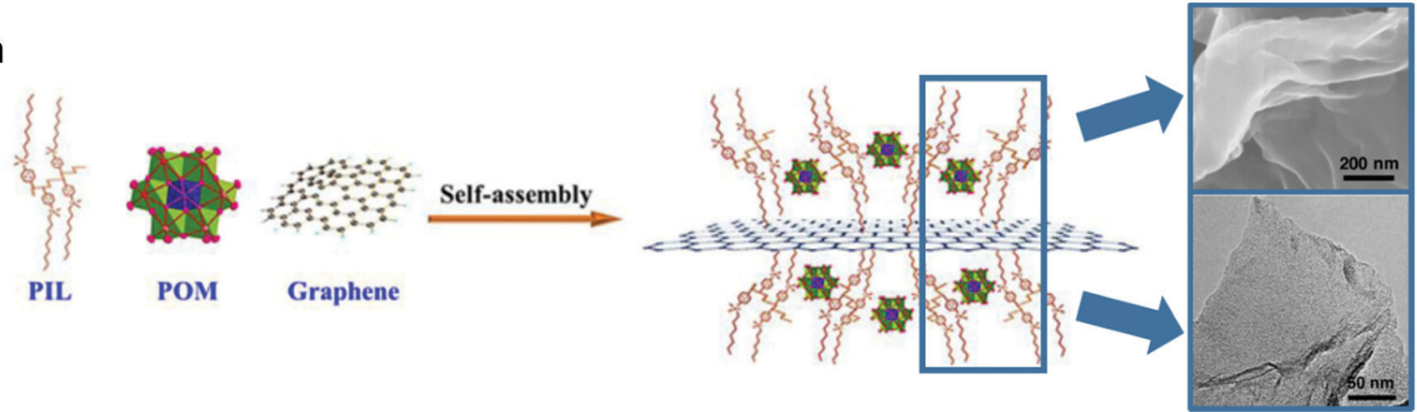

Fig. 13 TEM images of (a) HPW/rGO-Ele and (b) HPW/rGO-Imp. (c) DBT removal with $\mathrm{H}_{2} \mathrm{O}_{2}$ by $\mathrm{HPW} / \mathrm{rGO}$-Ele and HPW/rGO-Imp at $60{ }^{\circ} \mathrm{C}$ for five cycles, with $8 \mathrm{~h}$ per cycle. Reprinted with permission. ${ }^{150}$ Copyright 2019, Elsevier B.V. (d) Oxidation of DBT over HPW/GO with different HPW contents at $60{ }^{\circ} \mathrm{C}$ in the presence of $\mathrm{H}_{2} \mathrm{O}_{2}$. Reprinted with permission. ${ }^{151}$ Copyright 2019, Elsevier Ltd. (e) Conversion of DBT by applying TBAPMO ${ }_{11} \mathrm{Cu} / \mathrm{CuO}$ in ODS system with different solvents and $\mathrm{H}_{2} \mathrm{O}_{2}$ at $35{ }^{\circ} \mathrm{C}$. Redrawn with permission. ${ }^{153}$ Copyright 2020. American Chemical Society. (f) Contact angle for model oil droplet on the surface of $\mathrm{C}_{12} \mathrm{PW} / \mathrm{g}-\mathrm{C}_{3} \mathrm{~N}_{4}$. (g) Proposed ODS mechanism for $\mathrm{C}_{12} \mathrm{PW} / \mathrm{g}-\mathrm{C}_{3} \mathrm{~N}_{4}$ in the presence of $\mathrm{H}_{2} \mathrm{O}_{2}$. Reprinted with permission. ${ }^{154}$ Copyright 2020, Elsevier B.V. (h) Synthesis route for POM/PIL/Gr along with the morphology of POM/PIL/Gr in SEM (top) and TEM images (bottom). Reproduced with permission. ${ }^{155}$ Copyright 2020, Elsevier B.V.

MOFs with vast surface area and tunable morphology are expected to be a robust support for POMs to address the recycling barrier and leaching phenomenon in POMs. Peng et al. encapsulated HPW in a Zr-based MOF (UiO-67) via solvothermal method and tested its ODS activity with the addition of acetonitrile. ${ }^{156}$ In spite of HPW/UiO-67 possessing the same degree of DBT conversion as HPW (99.5\%), the narrow aperture size in UiO-67 barricaded the escape of HPW from the host, further reinforcing the robustness and recyclability of HPW/UiO-67. The absence of leaching is illustrated in Fig. 14a, in which the degree of DBT conversion remained constant at $85 \%$ after the removal of the catalyst at 30 min. Similarly, the encapsulation of HPMo in UiO-67 also showed promising catalytic activity and stability in ODS. ${ }^{157}$ To further strengthen the ODS activity, Wang and co-workers treated $\mathrm{HPMo} / \mathrm{UiO}-66$ with $\mathrm{HCl}$ to induce ligand defects in the structure. ${ }^{158}$ The removal of ligands increased the aperture size in UiO-66 and directly led to the increment of pore volume and specific surface area. In consequence, defective HPMo/UiO-66 achieved $100 \%$ DBT conversion in the presence of $\mathrm{H}_{2} \mathrm{O}_{2}$ after $1 \mathrm{~h}$, which was around $25 \%$ more than pristine HPMo/UiO-66 achieved. The remarkable ODS activity enhancement was attributed to the creation of more active sites as well as the higher accessibility of the pores of UiO-66 for sulfur compounds. In fact, the large aperture size could give rise to activity loss over time owing to the dissociation of POM from the inner surface of the MOF. Impressively, in this case, elimination of ligands did not significantly impact the stability of the catalyst in ODS as the defective HPMo/UiO-66 retained its ODS activity for ten cycles. This could be ascribed to the robust chemical interactions between HPMo and UiO-66 on the internal surface. In other work, Wei and coworkers confirmed the chemical stability of the Keggin-based POM (PMoV)/rht-MOF-1 through PXRD analysis (Fig. 14b). ${ }^{159}$ However, the ODS efficiency of PMoV/rht-MOF-1 decreased gradually over seven tests, mainly 

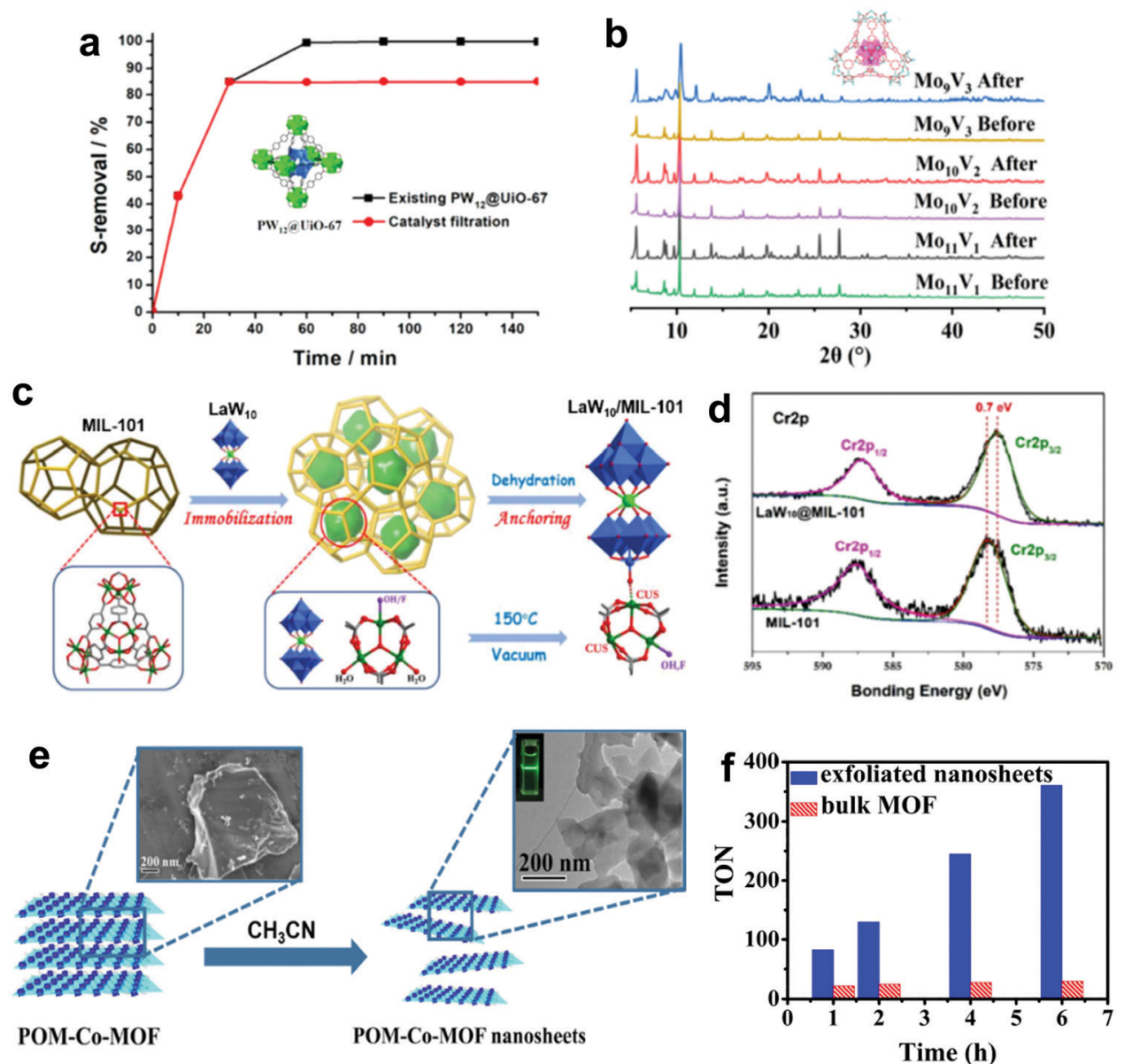

Fig. 14 (a) DBT removal with and without the elimination of $\mathrm{HPW} / \mathrm{UiO}-67$ at $70{ }^{\circ} \mathrm{C}$ in the presence of $\mathrm{H}_{2} \mathrm{O}_{2}$. Reproduced with permission. ${ }^{156} \mathrm{Copyright}$ 2018, Royal Society of Chemistry. (b) PXRD spectra of $\mathrm{Mo}_{11} \mathrm{~V}_{1}, \mathrm{Mo}_{10} \mathrm{~V}_{2}$ and $\mathrm{Mo}_{9} \mathrm{~V}_{3}$ on rht-MOF-1 before and after ODS. Reproduced with permission. ${ }^{159}$ Copyright 2020, Elsevier Ltd. (c) Fabrication route for encapsulating LaW 10 into MIL-101. (d) High-resolution Cr 2p XPS spectra of LaW $10 / M I L-101$ and MIL-101. Reprinted with permission. ${ }^{160}$ Copyright 2020, Elsevier Inc. (e) Exfoliation of POM-Co-MOF with the SEM (left) and TEM (right) images. (f) TON of DBT conversion for bulk POM/Co-MOF and POM/Co-MOF nanosheets. Reproduced with permission. ${ }^{161}$ Copyright 2018 , Wiley-VCH.

stemming from pore blockage by sulfone compounds. Lu's group reported the confinement of the Weakley-type POM $\mathrm{Na}_{7} \mathrm{H}_{2} \mathrm{LaW}_{10} \mathrm{O}_{36}\left(\mathrm{LaW}_{10}\right)$ inside mesoporous MIL-101 using the impregnation method and vacuum annealing (Fig. 14c). ${ }^{160}$ The strong interactions between LaW $_{10}$ and MIL-101 through the $\mathrm{W}=\mathrm{O}-\mathrm{Cr}$ bond coordinated $\mathrm{LaW}_{10}$ in the cavity of MIL-101, as indicated by the peak shift of $\mathrm{Cr} 2 \mathrm{p}_{3 / 2}$ to a lower bonding energy due to the electron transfer (Fig. 14d). This endowed LaW $_{10} /$ MIL-101 with excellent stability and it further achieved above 96\% DBT conversion with $\mathrm{H}_{2} \mathrm{O}_{2}$ at $60{ }^{\circ} \mathrm{C}$ for 7 runs. Generally speaking, the window size of MOFs and the bonding between POMs and MOFs are the crucial factors affecting the stability and activity of POM/MOF catalysts in ODS.

As is well known, the catalytic activity of a heterogeneous bulk catalyst is substantially restricted by its weak mass transfer in the liquid phase, which is detrimental to interactions with reactants. To address the mass transfer barrier, Xu et al. used a wet ball-milling and sonication-assisted top-down exfoliation approach with acetonitrile to delaminate the layerstructured POM/Co-MOF $\left(\left[\mathrm{Co}_{2}\left(\mathrm{H}_{2} \mathrm{O}\right)_{4}(\mathrm{BTX})_{3}\right]\left[\mathrm{PMo}_{12} \mathrm{O}_{40}\right]\right)$ into ultrathin nanosheets (Fig. 14e). ${ }^{161}$ The turnover number (TON) of the nanosheet structure oxidizing DBT using $\mathrm{H}_{2} \mathrm{O}_{2}$ as the oxidant was far beyond that of the bulk structure (Fig. 14f). The fabulous ODS performance of POM/Co-MOF nanosheets in model oil was attributed to the comparably large surface area promoting the development of surface active sites and accelerating the interactions between catalyst and reactant. However, the application of sonication during the exfoliation process would be unfeasible in industrial scale production due to its enormous energy consumption. The preparation of POM/ Co-MOF nanosheets via bottom-up approach can overcome this stumbling block but requires profound investigations from researchers in this fast-moving field.

Interestingly, there are also studies relating to the confinement of POM/MOF composites inside another MOF with a larger cage size to increase the heterogeneity and mobility of the catalyst. Li et al. immobilized $\mathrm{PMo}_{6} \mathrm{~W}_{6} \mathrm{O}_{40}$ (PMW)/copper-based MOF (MOF-199) inside the cavities of mesoporous MCM-41 through a one-pot self-assembly hydrothermal process to further enhance the durability of the catalyst in ODS. ${ }^{162}$ The extensive 
surface of MCM-41 supplied numerous anchor sites for immobilization of PMW/MOF-199. Hence, PMW/MOF-199/MCM-41 with rich catalytic sites retained $98.5 \%$ DBT oxidation in the presence of $\mathrm{O}_{2}$ for five cycles without any activity degradation. Subsequently, researchers employed MCM-41 as the host for surfactant-modified PMW/MOF-199 ${ }^{163}$ and cesium-doped PMW/MOF-199, ${ }^{164}$ obtaining drastic recyclability enhancements in ODS research. These findings provide an instructive insight into the encapsulation of POM/ MOF in MCM-41, which is a useful tactic for enhancing the stability and reusability of catalysts in ODS.

On the whole, incorporation of a support, such as mesoporous silica and metal-free nanomaterials with robust surface areas, as well as encapsulation in MOFs are relatively effective to heterogenize POMs and preserve the excellent catalytic activity in ODS compared with the precipitation approach. Nonetheless, more studies should focus on strengthening the substrate-support interactions of POM-based catalysts to avoid activity loss due to leaching to improve the recyclability in ODS and the industrial practicality. Table 4 summarizes the performances of various POMs in different ODS systems.

\subsection{Application of metal-organic frameworks (MOFs) in ODS}

As an arising class of porous and flexible materials, MOFs has been widely explored for numerous applications, especially catalysis, gas processing and storage. ${ }^{169}$ MOFs are crystalline network structure complexes comprised of inorganic metalcontaining units, or secondary building units (SBUs), and rigid organic ligands which act as coordination centers and the significant backbone that links all the SBUs together, respectively. ${ }^{170}$ By assembling different SBUs and organic ligands, a target MOF with unique topographies and properties in accordance with its functionality for specific chemical reactions can be facilely fabricated. The resulting cage-like structure material is endowed with several auspicious properties, including an abundant surface area, exceptional porosity, unique structural diversity and tailorable morphology, which offer remarkable potential for its integration in the ODS of fuels. $^{170-172}$

Solvothermal method is commonly applied to construct MOFs by heating a mixture of organic solvent, metal precursors and organic ligands to above the boiling point of the solvent in an autoclave under autogenous pressure to stimulate the nucleation and growth of nanoparticles. ${ }^{173}$ Before application, the generated MOFs undergo thermal activation to remove the guest solvent molecules in the internal pores of the MOFs in order to generate Lewis acid sites for the catalytic reaction. ${ }^{174}$ By adjusting the synthesis parameters, including temperature, reaction time and so forth, the textural properties and sizes of MOFs can be shaped precisely according to the interest of the creator. Despite the outstanding simplicity of the solvothermal method, its lengthy reaction time, huge demand for relatively expensive solvent and generation of tremendous solvent waste have become a bottleneck for industrial scale production. These arduous challenges have inspired the search for alternative synthesis routes like microwave heating, electrochemical, mechanochemical and sonochemical methods to fabricate MOFs with the desired properties. ${ }^{175}$ Currently, the alternative synthesis techniques are still not ready for industrial application due to limitations such as high energy consumption, complicated procedures and restricted application. Therefore, extensive research is essential to lay a foundation for manufacturing MOFs through a facile, economical, time-saving and commercially feasible synthesis route.

Drawn by the valuable catalytic properties, Kim and co-workers studied the activity of a titanium-based MOF, MIL125, and amine-functionalized MIL-125 ( $\mathrm{NH}_{2}$-MIL-125) in desulfurizing model fuels in the presence of cumene hydroperoxide (CHP) as the oxidant. ${ }^{176}$ Both catalysts were prepared by solvothermal method and microwave heating method before activation under vacuum for $12 \mathrm{~h}$ at $150{ }^{\circ} \mathrm{C}$. Owing to their microporous features, the performances of MIL-125 and $\mathrm{NH}_{2}$-MIL-125 in DBT conversion were merely $36 \%$ and $9 \%$, respectively, as the molecular size of DBT is much larger than the pores of the catalysts. The narrow pores immensely hindered the diffusion of DBT into the internal surfaces of this catalyst with plentiful defect Ti-sites and markedly decreased the interaction between DBT and the active sites. In contrast to $\mathrm{NH}_{2}$-MIL-125, the pore dimensions in MIL-125 were comparably large, which contributed to its higher activity in DBT conversion. Additionally, the functionalization of amine groups on MIL-125 led to the enlargement of particle size, diminishing the amount of vacant active sites on the external surface for ODS and causing the drop in catalytic activity. The inefficient functionalization of the $\mathrm{NH}_{2}$ group was also shown in the work of Valles-Garcia et al. ${ }^{177}$ It was reported that $\mathrm{NH}_{2}-\mathrm{MIL}-101(\mathrm{Cr})$ offered similar thiophenol (Thl) conversion (30\%) as the parent MIL-101(Cr) in a solvent-free ODS system using $\mathrm{O}_{2}$ as the oxidant. In the same work, the functionalization of the $\mathrm{NO}_{2}$ group on MIL-101(Cr) remarkably enhanced the Thl conversion to about three times greater than pristine MIL-101(Cr). The magnificent enhancement of ODS activity was ascribed to the greater electron-withdrawing property of the $\mathrm{NO}_{2}$ group which drew the electrons of Thl to form the Thl radical. Likewise, Liao et al. discovered that $\mathrm{NO}_{2}$-UiO-66 exhibited the highest DBT oxidation (97\%) compared to UiO-66 with $\mathrm{Br}(\sim 77 \%)$ and $\mathrm{NH}_{2}(\sim 38 \%)$ functional groups. ${ }^{178}$ The functionalization of an electron acceptor group $\left(\mathrm{NO}_{2}\right)$ in MOFs is preferred over an electron donor group $\left(\mathrm{NH}_{2}\right)$ to escalate the ODS activity by modifying the Lewis acidity of the parental MOFs.

The poor ODS activity of MIL-125 also motivated Zhang's team to alter its morphology by varying the molar amount of $\mathrm{Ti}$ precursors in the solvothermal synthesis. ${ }^{179}$ The increase of $\mathrm{Ti}$ precursors led to excessive $\mathrm{Ti}$ cations in solution which accelerated the nucleation of particles, thereby suppressing the coalescence of particles to form larger granules. The MIL125 with highest molar amount of Ti precursors (MIL-125-S) possessed the smallest particle size. In contrast with other materials, the increase of the surface area in MIL-125 by reduction of particle size failed to significantly intensify the removal of DBT and BT (Fig. 15a). This implies that the microsized pores greatly restricted the accessibility of the active sites for the aromatic sulfur constituents. In fact, most of the active 
Table 4 Representative summary of the performances of POM-based catalysts in thermal-driven ODS

\begin{tabular}{|c|c|c|c|c|c|c|c|}
\hline \multirow[b]{2}{*}{ Catalysts } & \multirow{2}{*}{$\begin{array}{l}\text { Reaction } \\
\text { temperature } \\
\left({ }^{\circ} \mathrm{C}\right)\end{array}$} & \multirow[b]{2}{*}{ Oxidant } & \multirow[b]{2}{*}{ Extractant } & \multicolumn{3}{|l|}{ Performances } & \multirow[b]{2}{*}{ Ref. } \\
\hline & & & & $\begin{array}{l}\text { Sulfur removal } \\
\text { (reactant) }\end{array}$ & $\begin{array}{l}\text { Reaction } \\
\text { time (h) }\end{array}$ & $\begin{array}{l}\text { Stability } \\
\text { (h) }\end{array}$ & \\
\hline$\left[\mathrm{C}_{16} \mathrm{mim}\right]_{2} \mathrm{Mo}_{2} \mathrm{O}_{11}$ & 50 & $\mathrm{H}_{2} \mathrm{O}_{2}(30 w \mathrm{t} \%)$ & N/A & $98.4 \%(\mathrm{DBT})$ & 1 & $>6$ & 128 \\
\hline$[\text { PSTEtA }]_{3} \mathrm{PW}_{12} \mathrm{O}_{40}$ & 40 & $\mathrm{H}_{2} \mathrm{O}_{2}(30 w \mathrm{t} \%)$ & $\mathrm{ChCl} / 2 \mathrm{Ac}$ & $100 \%(\mathrm{DBT})$ & 2.5 & N/A & 129 \\
\hline $\mathrm{H}_{3} \mathrm{PMo}_{12} \mathrm{O}_{40}$ & 50 & $\mathrm{H}_{2} \mathrm{O}_{2}(30 w \mathrm{t} \%)$ & {$[\mathrm{BMIM}] \mathrm{PF}_{6}$} & $95 \%(\mathrm{DBT})$ & 2 & N/A & 130 \\
\hline \multicolumn{8}{|l|}{$\mathrm{ODA}-\mathrm{PMO}_{12} \mathrm{O}_{40}$} \\
\hline $\mathrm{H}_{8} \mathrm{PV}_{5} \mathrm{Mo}_{7} \mathrm{O}_{40}$ & 120 & $\begin{array}{l}\mathrm{O}_{2} \\
\text { (20 bar oxygen pressure) }\end{array}$ & $\mathrm{H}_{2} \mathrm{O}$ & $99 \%(\mathrm{BT})$ & 6 & $>24$ & 131 \\
\hline $\begin{array}{l}\mathrm{H}_{3} \mathrm{PW}_{x} \mathrm{Mo}_{12-x} \mathrm{O}_{40} \\
(x=1,3,6)\end{array}$ & 60 & $\mathrm{H}_{2} \mathrm{O}_{2}(30 \mathrm{wt} \%)$ & Acetonitrile & $>98 \%(\mathrm{DBT})$ & 1 & $\mathrm{~N} / \mathrm{A}$ & 132 \\
\hline $\mathrm{PW}_{11} /$ aptes-SBA-15 & 70 & $\mathrm{H}_{2} \mathrm{O}_{2}(30 w t \%)$ & Acetonitrile & $100 \%(\mathrm{DBT})$ & 1 & $>8$ & 133 \\
\hline $\mathrm{Na}_{3} \mathrm{PW}_{12} \mathrm{O}_{40}$ & 70 & $\mathrm{H}_{2} \mathrm{O}_{2}(30 w \mathrm{t} \%)$ & N/A & $100 \%(\mathrm{DBT})$ & 0.5 & $\mathrm{~N} / \mathrm{A}$ & 137 \\
\hline $\mathrm{H}_{3} \mathrm{PW}_{12} \mathrm{O}_{40}$ & & & & $100 \%(\mathrm{DBT})$ & & & \\
\hline $\mathrm{H}_{3} \mathrm{PMo}_{12} \mathrm{O}_{40}$ & & & & $\sim 80 \%(\mathrm{DBT})$ & & & \\
\hline $\mathrm{H}_{4} \mathrm{SiW}_{12} \mathrm{O}_{40}$ & & & & $\sim 20 \%(\mathrm{DBT})$ & & & \\
\hline $\mathrm{H}_{3} \mathrm{PW}_{12} \mathrm{O}_{40}$ & 70 & $\mathrm{H}_{2} \mathrm{O}_{2}(30 w \mathrm{t} \%)$ & $\mathrm{C}_{32} \mathrm{H}_{68} \mathrm{BrN}$ & $100 \%(\mathrm{DBT})$ & 0.5 & N/A & 138 \\
\hline $\mathrm{H}_{3} \mathrm{PMo}_{12} \mathrm{O}_{40}$ & & & & $\sim 90 \%(\mathrm{DBT})$ & & & \\
\hline $\mathrm{H}_{4} \mathrm{SiW}_{12} \mathrm{O}_{40}$ & & & & $\sim 28 \%(\mathrm{DBT})$ & & & \\
\hline $\mathrm{Na}_{2} \mathrm{HPW}_{12} \mathrm{O}_{40}$ & 60 & $\mathrm{H}_{2} \mathrm{O}_{2}(30 w \mathrm{t} \%)$ & Acetic acid & $98 \%(\mathrm{DBT})$ & 2.5 & N/A & 139 \\
\hline$\left[\mathrm{V}\left(\mathrm{VW}_{11}\right) \mathrm{O}_{40}\right]^{4-}$ & 60 & $\mathrm{H}_{2} \mathrm{O}_{2}(30 w t \%)$ & DMF & $99 \%(\mathrm{DBT})$ & 5 & N/A & 142 \\
\hline$\left[\mathrm{PVW}_{11} \mathrm{O}_{40}\right]^{4-}$ & & & & $88 \%(\mathrm{DBT})$ & & & \\
\hline$\left[\mathrm{W}_{6} \mathrm{O}_{19}\right]^{2-}$ & & & & 87\% (DBT) & & & \\
\hline$\left[\mathrm{PV}_{2} \mathrm{Mo}_{10} \mathrm{O}_{40}\right]^{4-}$ & & & & $86 \%(\mathrm{DBT})$ & & & \\
\hline PIL- $\mathrm{H}_{2} \mathrm{~W}_{12} \mathrm{O}_{42}{ }^{10-}$ & 30 & $\mathrm{H}_{2} \mathrm{O}_{2}(30 w \mathrm{t} \%)$ & $\mathrm{N} / \mathrm{A}$ & $95.5 \%(\mathrm{DBT})$ & 1.5 & $>8$ & 165 \\
\hline $\mathrm{PW}_{4}$ & 70 & $\mathrm{H}_{2} \mathrm{O}_{2}(30 w \mathrm{t} \%)$ & Acetonitrile & $100 \%$ & 2 & $<20$ & 57 \\
\hline $\mathrm{PW}_{4} / \mathrm{TMA}-\mathrm{SBA}-15$ & & & & $100 \%$ & & $>30$ & \\
\hline $\mathrm{TeW}_{6}$ & Ambient & $\mathrm{H}_{2} \mathrm{O}_{2}(30 w \mathrm{t} \%)$ & Acetonitrile & $89 \%$ (thioanisole) & 6 & $>30$ & 146 \\
\hline $\mathrm{TeW}_{6} \mathrm{Cu}$ & & & Ethanol & $89 \%$ (thioanisole) & & $<30$ & \\
\hline $\mathrm{Te}_{2} \mathrm{~W}_{8} \mathrm{Cu}_{2}$ & & & & $99 \%$ (thioanisole) & & $<30$ & \\
\hline $\mathrm{CsPW}_{12} \mathrm{O}_{40}$ & 60 & TBHP (70 wt\%) & $\mathrm{N} / \mathrm{A}$ & $50 \%$ & 2 & $<12$ & 145 \\
\hline SmPMo/TMA-LPMS & 70 & $\mathrm{H}_{2} \mathrm{O}_{2}(30 \mathrm{wt} \%)$ & {$[\mathrm{BMIM}] \mathrm{PF}_{6}$} & $100 \%$ & 1 & $>4.5$ & 147 \\
\hline $\begin{array}{l}\mathrm{H}_{3} \mathrm{PMo}_{12} \mathrm{O}_{40} / \mathrm{SiO}_{2}-\mathrm{C} \\
\text { nanospheres }\end{array}$ & 40 & $\mathrm{H}_{2} \mathrm{O}_{2}(30 w \mathrm{t} \%)$ & Acetonitrile & 99\% (DBT) & 3 & $>15$ & 166 \\
\hline HPW/AC & 90 & $\mathrm{H}_{2} \mathrm{O}_{2}(30 w \mathrm{t} \%)$ & N/A & $\sim 90 \%(\mathrm{Th})$ & 2 & N/A & 149 \\
\hline $\begin{array}{l}\text { HPW/rGO (electro-chemical } \\
\text { method) }\end{array}$ & 60 & $\mathrm{H}_{2} \mathrm{O}_{2}(30 w \mathrm{t} \%)$ & Methanol & $95 \%(\mathrm{DBT})$ & 8 & $>40$ & 150 \\
\hline $\begin{array}{l}\text { HPW/rGO (chemical reduced } \\
\text { method) }\end{array}$ & & & & $85 \%(\mathrm{DBT})$ & & $<16$ & \\
\hline HPW/GO & 60 & $\mathrm{H}_{2} \mathrm{O}_{2}(30 w \mathrm{t} \%)$ & Acetonitrile & $100 \%(\mathrm{DBT})$ & 0.5 & $>8$ & 151 \\
\hline $\mathrm{HPW} / \mathrm{mpg}^{-} \mathrm{C}_{3} \mathrm{~N}_{4}$ & 60 & $\mathrm{H}_{2} \mathrm{O}_{2}(30 w \mathrm{t} \%)$ & Methanol & $100 \%(\mathrm{DBT})$ & 1 & $>37.5$ & 152 \\
\hline $\mathrm{TBAPMo}_{11} \mathrm{Cu} / \mathrm{CuO}$ & 35 & $\mathrm{H}_{2} \mathrm{O}_{2}(30 \mathrm{wt} \%)$ & $\begin{array}{l}\text { Polyethylene } \\
\text { glycol }\end{array}$ & $98 \%(\mathrm{DBT})$ & 1 & $>5$ & 153 \\
\hline $\mathrm{C}_{12} \mathrm{PW} / \mathrm{g}-\mathrm{C}_{3} \mathrm{~N}_{4}$ & 60 & $\mathrm{H}_{2} \mathrm{O}_{2}(30 w \mathrm{t} \%)$ & N/A & $100 \%(\mathrm{DBT})$ & 1 & $>5$ & 154 \\
\hline $\begin{array}{l}\mathrm{Ag} / \mathrm{HPW} \text { single-walled } \\
\text { nanotubes }\end{array}$ & 20 & $\mathrm{H}_{2} \mathrm{O}_{2}(30 w \mathrm{t} \%)$ & N/A & $\begin{array}{l}98 \% \text { (diphenyl } \\
\text { sulfide) }\end{array}$ & 1 & $>5$ & 167 \\
\hline $\mathrm{POM} / \mathrm{PIL}$ & 100 & $\mathrm{O}_{2}$ & $\mathrm{~N} / \mathrm{A}$ & $66.88 \%(\mathrm{DBT})$ & 3 & $\mathrm{~N} / \mathrm{A}$ & 155 \\
\hline POM/PIL/graphene & & & & $100 \%(\mathrm{DBT})$ & & $>18$ & \\
\hline HPW/UiO-67 & 70 & $\mathrm{H}_{2} \mathrm{O}_{2}(30 w \mathrm{t} \%)$ & Acetonitrile & $99.5 \%(\mathrm{DBT})$ & 1 & $<8$ & 156 \\
\hline HPMo/UiO-67 & 50 & $\mathrm{H}_{2} \mathrm{O}_{2}(30 w \mathrm{t} \%)$ & Acetonitrile & $99.5 \%(\mathrm{DBT})$ & 0.5 & $>2.5$ & 157 \\
\hline HPW/UiO-66 & Ambient & $\mathrm{H}_{2} \mathrm{O}_{2}(30 w \mathrm{t} \%)$ & Acetonitrile & $99.7 \%(\mathrm{DBT})$ & 0.42 & $>1.67$ & 168 \\
\hline Defective HPMo/UiO-66 & 60 & $\mathrm{H}_{2} \mathrm{O}_{2}(30 w \mathrm{t} \%)$ & Acetonitrile & $100 \%(\mathrm{DBT})$ & 1 & $>15$ & 158 \\
\hline $\mathrm{PMo}_{11} \mathrm{~V}_{1} /$ rht-MOF-1 & 70 & $\mathrm{H}_{2} \mathrm{O}_{2}(30 w \mathrm{t} \%)$ & Acetonitrile & $90 \%(\mathrm{DBT})$ & 0.83 & $>5.83$ & 159 \\
\hline $\mathrm{PMo}_{10} \mathrm{~V}_{2} /$ rht-MOF-1 & & & & $92 \%(\mathrm{DBT})$ & & $>5.83$ & \\
\hline $\mathrm{PMo}_{9} \mathrm{~V}_{3} /$ rht-MOF-1 & & & & $96 \%(\mathrm{DBT})$ & & $>5.83$ & \\
\hline POM/MOF-199 & 85 & $\mathrm{O}_{2}$ & $\mathrm{~N} / \mathrm{A}$ & $61.4 \%(\mathrm{DBT})$ & 3 & $<9$ & 162 \\
\hline POM/MCM-41 & & & & $42.2 \%(\mathrm{DBT})$ & & $<9$ & \\
\hline POM/MOF-199/MCM-41 & & & & $98.5 \%(\mathrm{DBT})$ & & $<24$ & \\
\hline MOF-199/MCM-41 & 60 & $\mathrm{O}_{2}$ & {$[\mathrm{Bmim}] \mathrm{BF}_{4}$} & $20.2 \%(\mathrm{DBT})$ & 2.5 & $\mathrm{~N} / \mathrm{A}$ & 163 \\
\hline SRL-POM/MCM-41 & & & & $45.1 \%(\mathrm{DBT})$ & & $\mathrm{N} / \mathrm{A}$ & \\
\hline SRL-POM/MOF-199 & & & & $64.9 \%(\mathrm{DBT})$ & & N/A & \\
\hline SRL-POM/MOF-199/MCM-41 & & & & $100 \%(\mathrm{DBT})$ & & $<37.5$ & \\
\hline Cs-POM/MOF-199/MCM-41 & 80 & $\mathrm{O}_{2}$ & $\mathrm{~N} / \mathrm{A}$ & $99.6 \%(\mathrm{DBT})$ & 3 & $<45$ & 164 \\
\hline $\mathrm{LaW}_{10} / \mathrm{MIL}-101$ & 60 & $\mathrm{H}_{2} \mathrm{O}_{2}(30 w \mathrm{t} \%)$ & Acetonitrile & $99.1 \%(\mathrm{DBT})$ & 3 & $>14$ & 160 \\
\hline Bulk POM/Co-MOF & 80 & $\mathrm{H}_{2} \mathrm{O}_{2}(30 w \mathrm{t} \%)$ & Acetonitrile & $100 \%(\mathrm{DBT})$ & 4 & $>20$ & 161 \\
\hline Exfoliated POM/Co-MOF & & & & $50 \%(\mathrm{DBT})$ & & $>20$ & \\
\hline
\end{tabular}




\begin{tabular}{|c|c|c|c|c|c|c|c|}
\hline \multirow[b]{2}{*}{ Catalysts } & \multirow{2}{*}{$\begin{array}{l}\text { Reaction } \\
\text { temperature } \\
\left({ }^{\circ} \mathrm{C}\right)\end{array}$} & \multirow[b]{2}{*}{ Oxidant } & \multirow[b]{2}{*}{ Extractant } & \multicolumn{3}{|l|}{ Performances } & \multirow[b]{2}{*}{ Ref. } \\
\hline & & & & $\begin{array}{l}\text { Sulfur removal } \\
\text { (reactant) }\end{array}$ & $\begin{array}{l}\text { Reaction } \\
\text { time (h) }\end{array}$ & $\begin{array}{l}\text { Stability } \\
\text { (h) }\end{array}$ & \\
\hline $\begin{array}{l}\mathrm{Mo}_{123} \\
\mathrm{Mo}_{123} / \mathrm{IL}-\text { functionalized magnetic } \\
\text { silica nanoparticles }\end{array}$ & 62.5 & $\mathrm{H}_{2} \mathrm{O}_{2}(30 w t \%)$ & Acetonitrile & $\begin{array}{l}\text { 75\% (DBT) } \\
99.97 \% \text { (DBT) }\end{array}$ & 0.5 & $\begin{array}{c}\mathrm{N} / \mathrm{A} \\
>2\end{array}$ & 148 \\
\hline \multicolumn{8}{|c|}{ 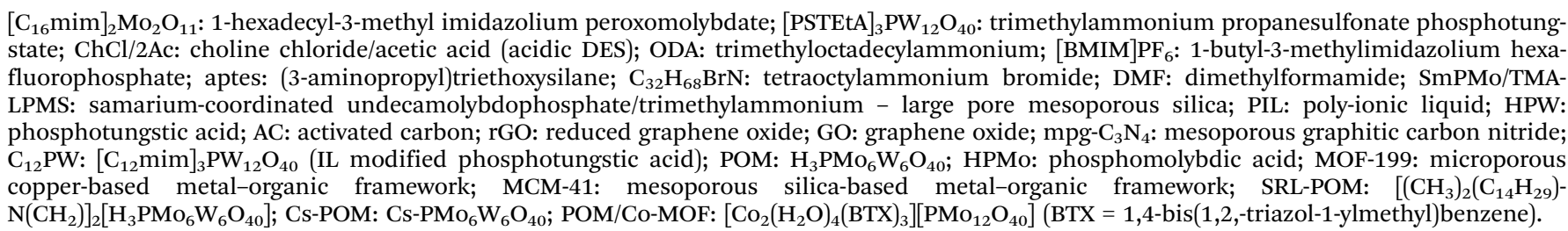 } \\
\hline
\end{tabular}

sites in MOFs are concentrated on the internal surface, not on the external surface.

Recently, Yang et al. modified the morphology of MIL-125 (Fig. 15b) through a coordination modulation technique. ${ }^{180}$ MIL-125 with a truncated octahedral structure (MIL-125-TRO) (Fig. 15c) was created after modulation with butyric acid. The construction of a (101) facet in MIL-125-TRO strengthened its activity in ODS compared to pristine MIL-125 (Fig. 15d). This phenomenon signified a facet-dependence feature of MIL-125 which could significantly affect its ODS activity. Instead of butyric acid, Ye et al. introduced acetic acid in the preparation of titanium terephthalate (Ti-BDC) to modulate the structure. ${ }^{181}$ Notably, acetic acid created defect sites on Ti-BDC and also played a role in limiting Ti-BDC growth during the solvothermal process. As a result, the improved accessibility of active sites helped Ti-BDC attain complete oxidation of DBT in $10 \mathrm{~min}$ at room temperature. While catalyzing ODS, Ti-BDC also acted as the adsorption panel to trap polar sulfone. This is greatly conducive to practical applications because it eliminates the necessity of a further extraction stage to remove sulfone products. The incorporation of an appropriate acid in the synthesis of MOFs can tailor the structure by constructing defect sites, controlling the growth, and removing some organic ligands from the framework of MOFs, thus eventually increasing the exposure of active sites and the catalytic performance in ODS.

In a different work, Masoomi et al. utilized solvothermal method to derive two cobalt-based MOFs, TMU-10 from 4,4'oxybisbenzoic acid (oba) and TMU-12 from oba and pyrazine organic ligands. ${ }^{182}$ Impressively, TMU-12 (Fig. 15e) demonstrated a larger void space and window size compared to TMU-10 (Fig. 15f). This further facilitated the passage of aromatic sulfur compounds to the unsaturated active sites near the Co center through the pores. Benefiting from the higher exposure of active sites, TMU-12 achieved better performance in DBT removal (75.2\%) after $8 \mathrm{~h}$ than TMU-10 (40.5\%) in the presence of TBHP. In the research work of Ma et al., hierarchical Ti-beta zeolite was constructed from siliceous FAU zeolite as a catalyst for ODS through interzeolite transformation. ${ }^{183}$ The application of $\mathrm{CTAB}$ as the directing agent to control the crystal growth during the synthesis process contributed to larger crystal sizes and pores in the resulting catalyst. Owing to the presence of innumerable mesopores, the diffusion limitation of sulfur compounds into the inner surface of Ti-beta zeolite was addressed, causing a substantial enhancement of DBT oxidation within $30 \mathrm{~min}$ from $34.2 \%$ to $98.5 \%$. Despite the unprecedented ODS activity, Ti-beta zeolite underwent severe deactivation after two ODS cycles and required calcination to fully regenerate its catalytic activity (Fig. 15g). Significantly, in order to maximize the ODS activity of MOFs, the expansion of aperture size is necessary to allow the diffusion of sulfur compounds into the interior space, thus facilitating the interactions between sulfur compounds and unoccupied active sites.

Very recently, the application of the microwave-assisted heating method to fabricate MOFs has attracted considerable attention because of its rapid synthesis time and ability to modify the morphologies of MOFs. As reported in the work of Viana et al., Zr-based MOFs (UiO-66) prepared by conventional solvothermal method (UiO-66-S) and microwave-assisted heating method (UiO-66-MW) exhibited dissimilar performances as a result of their structural morphologies. ${ }^{184}$ Owing to the swift reaction in the microwave-assisted method, the growth of nanoparticles was inhibited, while nucleation was accelerated. Consequently, a smaller particle size was found in UiO-66-MW (Fig. 15i) than in UiO-66-S (Fig. 15h). An identical situation occurred in the research of Kim et al., signifying that the particle dimensions of $\mathrm{NH}_{2}$-MIL-125 synthesized by microwave heating method were smaller than those synthesized by solvothermal method. ${ }^{176}$ With a larger surface area, UiO-66-MW exhibited significant catalytic activity in ODS $(>85 \%)$ for three consecutive cycles, whereas the activity of UiO-66-S experienced a sharp decline after the second cycle due to catalyst deactivation. This was because UiO-66-MW provided more active sites for ODS than UiO-66-S did, which contributed to the superior recyclability without serious activity degradation. Furthermore, the shorter synthesis time performed a vital role in generating more defects on the surface of UiO-66 and explicitly boosted the ODS activity. This behavior was revealed in the ODS mechanism (Fig. 15j). The increase of defects in UiO-66, which was the significant factor in liberating unsaturated $\mathrm{Zr}$ cation sites with Lewis acidity, contributed to the increment of electron 

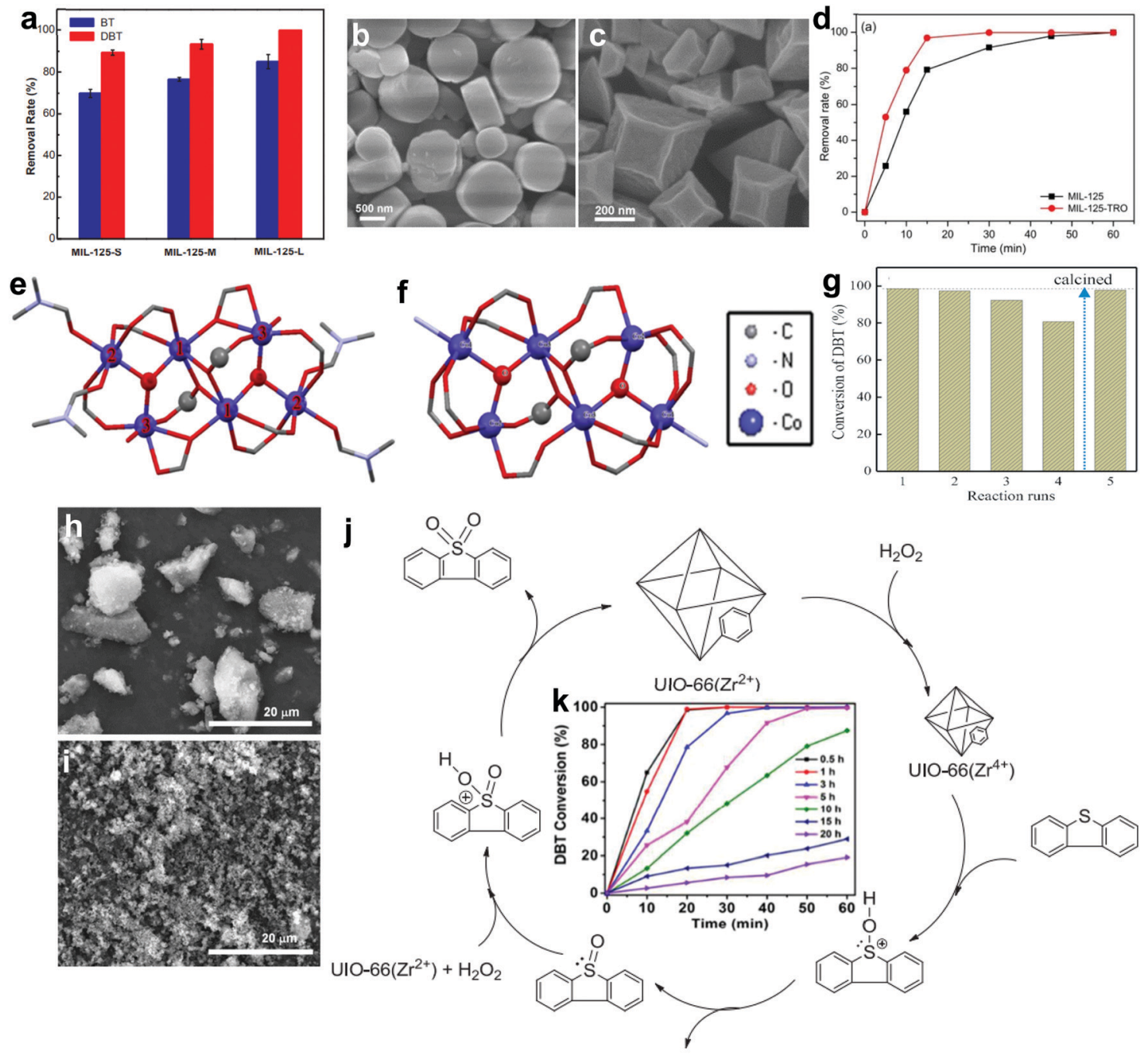

$\mathrm{UIO}-66\left(\mathrm{Zr}^{2+}\right)$

Fig. 15 (a) Removal rate of BT and DBT over various MIL-125, namely MIL-125-S, MIL-125-M and MIL-125-L, with $3.6 \mathrm{mmol}, 3 \mathrm{mmol}$ and $1.5 \mathrm{mmol}$ $\mathrm{Ti}\left(\mathrm{OC}_{4} \mathrm{H}_{9}\right)_{4}$, respectively, as Ti precursor. Reprinted with permission. ${ }^{179}$ Copyright 2018, Elsevier Ltd. SEM images of (b) MIL-125 and (c) MIL-125-TRO (truncated octahedral shape) and (d) their DBT removal in ODS at $60{ }^{\circ} \mathrm{C}$ using $\mathrm{H}_{2} \mathrm{O}_{2}$. Reprinted with permission. ${ }^{180}$ Copyright 2020 , Royal Society of Chemistry. Ball and stick model for the SBUs of (e) TMU-10 and (f) TMU-12. Reprinted with permission. ${ }^{182}$ Copyright 2015, American Chemical Society. (g) DBT conversion over hierarchical Ti-beta zeolite for five ODS cycles with a duration of $0.5 \mathrm{~h}$ per cycle at $60^{\circ} \mathrm{C}$ in the presence of TBHP. Reprinted with permission. ${ }^{183}$ Copyright 2021, Elsevier Inc. SEM images of (h) UiO-66-S and (i) UiO-66-MW. Reprinted with permission. ${ }^{184}$ Copyright 2019 , Multidisciplinary Digital Publishing Institute. (j) ODS mechanism of DBT when utilizing UiO-66 in the presence of $\mathrm{H}_{2} \mathrm{O}_{2}$. Reprinted with permission. ${ }^{185}$ Copyright 2017, Elsevier Ltd. (k) DBT conversion at $60{ }^{\circ} \mathrm{C}$ with $\mathrm{H}_{2} \mathrm{O}_{2}$ over several UiO-66 with synthesis times of $0.5 \mathrm{~h}, 1 \mathrm{~h}, 3 \mathrm{~h}, 5 \mathrm{~h}, 10 \mathrm{~h}, 15 \mathrm{~h}$ and $20 \mathrm{~h}$. Reprinted with permission. ${ }^{186}$ Copyright 2018, Royal Society of Chemistry.

acceptors for $\mathrm{H}_{2} \mathrm{O}_{2}$ activation to create $\mathrm{Zr}$-peroxo complexes. ${ }^{185}$ After the adsorption of DBT on the active site, it was converted to DBT sulfoxide and DBT sulfone, followed by its desorption from UiO-66. A similar synthesis duration effect on ODS activity was also substantiated by Xiao and colleagues, who revealed that the decrease of reaction time in the solvothermal method enhanced the DBT conversion by UiO-66 (Fig. 15k). ${ }^{186}$ Therefore, it can be concluded that the synthesis time and the morphologies of MOFs, including particle sizes and the number of defect sites, can be tuned and become more favorable toward ODS.

In a recent study, activation of UiO-66 was performed by incorporating anions into the framework via simple mixing with the respective salts, including $\mathrm{TiCl}_{4}, \mathrm{ZrCl}_{4}$ and $\mathrm{TiBr}_{4} \cdot{ }^{187}$ Unfortunately, the introduction of $\mathrm{Br}$ anions engendered the deactivation of UiO-66, leading to a poorer desulfurization efficiency than pristine UiO-66 in the ODS system with $\mathrm{H}_{2} \mathrm{O}_{2}$ at $50{ }^{\circ} \mathrm{C}$ (Fig. 16a). On the other hand, $\mathrm{Cl}$ anions successfully constructed more defect sites in the framework of UiO-66 and contributed to an essential ODS activity improvement. Despite this work manifesting the capability of $\mathrm{Cl}$ anions to elevate the catalytic activity of MOF in ODS, the ODS reaction pathways and the reason for the activity loss after the incorporation of $\mathrm{Br}$ anions have not been comprehensively investigated, which is crucial for improving this modification method in the future. 

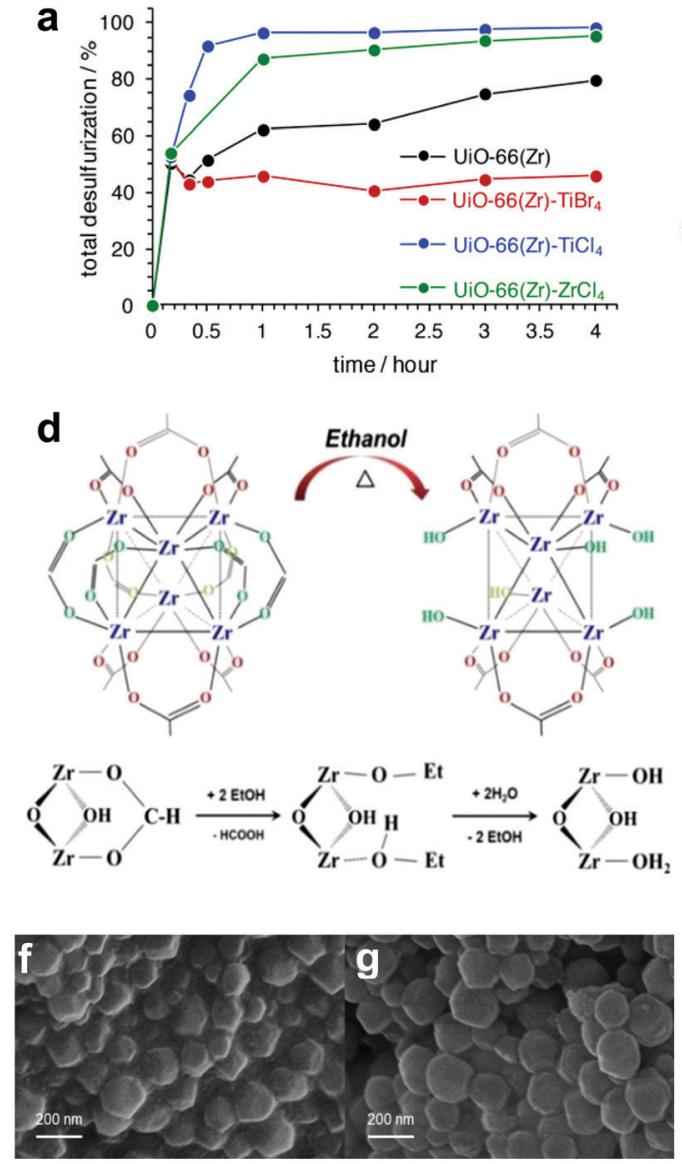
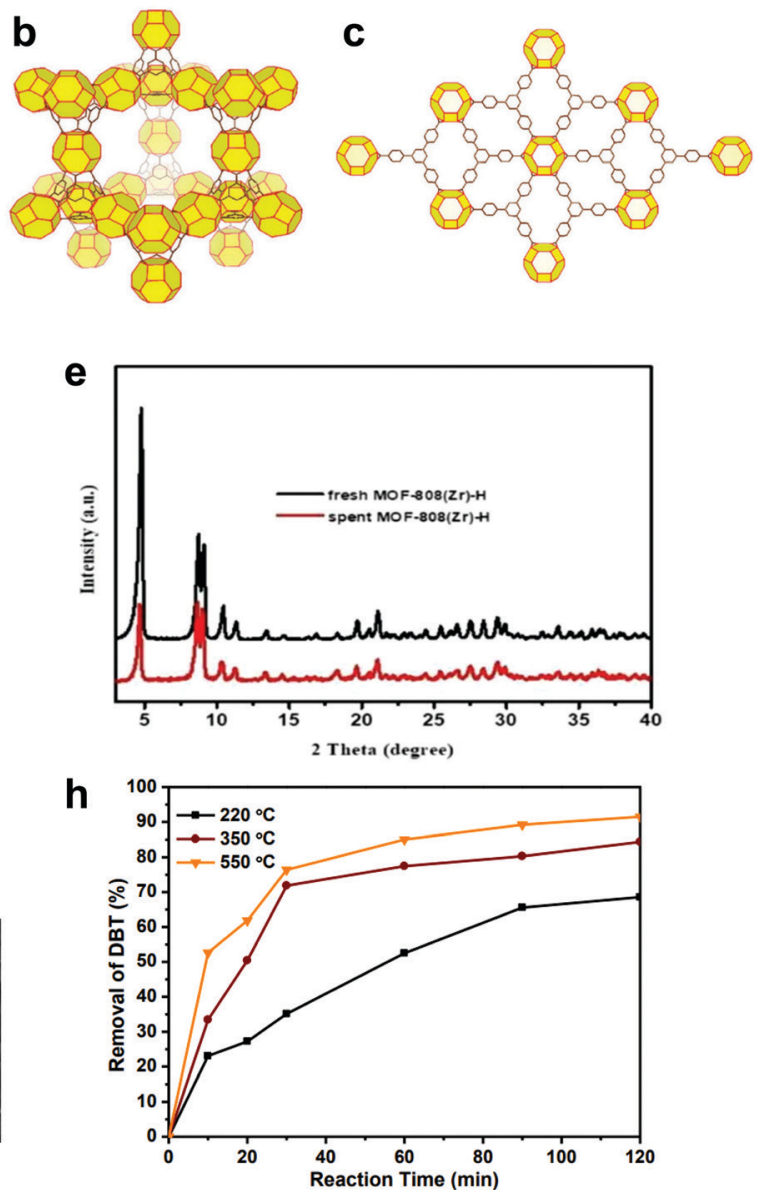

Fig. 16 (a) Desulfurization efficiency in ODS with $\mathrm{H}_{2} \mathrm{O}_{2}$ at $50{ }^{\circ} \mathrm{C}$ using pristine UiO-66( $\mathrm{Zr}$ ) and post-treated UiO-66( $\mathrm{Zr}$ ) with various salts, including TiBr ${ }_{4}$, $\mathrm{TiCl}_{4}$ and $\mathrm{ZrCl}_{4}$. Reprinted with permission. ${ }^{187}$ Copyright 2021, Elsevier B.V. Structures of (b) MOF-808 and (c) UMCM-309. Reprinted with permission. ${ }^{188}$ Copyright 2018, Wiley-VCH. (d) Mechanism of the hot ethanol treatment in MOF-808. (e) XRD analysis of the modified MOF-808 before and after the ODS reaction. The SEM images of modified MOF-808 (f) before and (g) after the ODS reaction. Reprinted with permission. ${ }^{190} \mathrm{Copyright} 2020$, Wiley-VCH. (h) DBT conversion at $60{ }^{\circ} \mathrm{C}$ using Ti-modified MIL-101 and CHP synthesized at different calcination temperatures. Reprinted with permission. ${ }^{191}$ Copyright 2020, Multidisciplinary Digital Publishing Institute.

In another modification route, $\mathrm{Fu}$ and fellows carried out postsynthetic ligand exchange (PSLE) to enhance the catalytic activity of Zr-based MOFs, namely MOF-808 and UMCM-309 in ODS. ${ }^{188}$ In PSLE, the original structural linkers in MOFs are substituted with new linkers to modify the topologies and morphologies. ${ }^{189}$ In this research, the formate ligands in MOF-808 and UMCM-309 were removed by reacting with methanol to induce more unoccupied $\mathrm{Zr}$ open sites for ODS. The increment of missing formate ions in the structure of the MOFs is notably conducive to the conversion of sulfur pollutants. However, UMCM-309 with fewer formate ions achieved a lower conversion rate of BT (18\%) than did MOF-808 (60\%) after $8 \mathrm{~h}$. The deviation stemmed from the fact that the 3D structured MOF-808 (Fig. 16b) possessed a greater specific surface area, aperture size and number of Lewis acid sites compared to UMCM-309 with its 2D layered structure (Fig. 16c). This accelerated the diffusion of BT into the internal surfaces of MOFs, thereby boosting the reaction between sulfur compounds and $\mathrm{Zr}$ active sites. Future work on the application of UMCM-309 in ODS can be strengthened by reconstructing the 2D layered structure into 2D ultrathin sheets through intercalation or exfoliation to unravel the upper limit of ODS activity. Owing to the time-consuming drawback of PSLE, Gu and co-workers amended the strategy by treating MOF-808 with hot ethanol for $4 \mathrm{~h}$ instead of methanol for $2 \mathrm{~d}$ to detach the formate ligands from the structure (Fig. 16d). ${ }^{190}$ This action offered crucial enhancement in the ODS activity of MOF- 808 by creating more defect $\mathrm{Zr}$ sites. The reformed MOF-808 oxidized $99 \%$ of DBT after 20 min with CHP, which was significantly beyond the performance of original MOF-808 (20\%). In addition, the modified MOF-808 with superior robustness exhibited identical morphologies before and after ODS, proving the absence of leaching (Fig. 16e-g). Therefore, the removal of ligands from the structure of MOFs is essential and efficacious for achieving ultradeep ODS via increasing the number of open boundaries and defect sites for the adsorption and oxidation of reactants.

Li et al. modified Cr-based MOF MIL-101 with Ti via IWI and calcination method to increase the catalytic sites of MIL-101. ${ }^{191}$ 
Fascinatingly, $\mathrm{TiO}_{2}$ and $\mathrm{Cr}_{2} \mathrm{O}_{3}$ nanoparticles were created in the pores of MIL-101 during the calcination process. The increase of calcination temperature also led to the enhancement of DBT conversion utilizing $\mathrm{CHP}$ at $60{ }^{\circ} \mathrm{C}$ (Fig. 16h). This was attributed to the increment of metal oxides with outstanding catalytic activity in the pores of MIL-101. Unfortunately, the catalyst exhibited poor stability and its activity fell significantly after the second run due to loss of active sites. Therefore, the low stability of the nanocomposite requires the development of strong interactions between the host and guest particles to prolong its durability in ODS.

In MOFs, the Lewis acid sites in the internal structure and their pore size are the major decisive factors for ODS activity. In spite of the fact that the direct application of MOFs in the ODS of fuels is viable, only a few species of MOFs are capable of achieving impressive desulfurization and becoming candidates for industrial application. Moreover, most of the MOFs possess microporous characteristics which hinder the accessibility of the unsaturated active sites inside the pores to reactants and requires structural modification before use. On that account, previous researchers have attempted to immobilize or hybridize porous MOFs with massive surface area as supports for various types of materials, including metal oxides and POMs, which possess extraordinary catalytic activity in ODS. Table 5 presents the ODS performances of various MOFs with different operating parameters.

\subsection{Application of metal-free nanomaterials in ODS}

Regardless of their spectacular performances in ODS, the inescapable drawbacks of metal-based catalysts, like high toxicity and leaching risk, which are inimical to the environment and fuel oil quality, have induced a significant reduction in the confidence of the petrochemical industry to invest in and upscale ODS. ${ }^{193}$ The challenges in sustainability and economic and environmental concerns have urged research communities to seek metal-free catalysts which are environmentally friendly and low priced. For their intrinsic properties of large surface area, excellent robustness and high susceptibility to redox reactions, carbonaceous materials stand out as the major species in the metal-free materials field and are deemed to be key for approaching complete desulfurization of diesel fuels in the coming decades. ${ }^{194,195}$

3.6.1 Carbon-based nanomaterials. Generally speaking, graphite is the paramount member of the nanocarbon family and is a building block for constructing other nanocarbon materials with distinct physico-chemical properties, such as 0D fullerene, 1D carbon nanotubes, 2D graphene sheets and 3D carbon materials. ${ }^{194}$ In the fabrication of graphene, several effective strategies have been carried out to exfoliate bulkstructured graphite into graphene by breaking the van der Waals interactions within the structure. The oxidation of graphite is one of the most economical and common routes to generate sheet-structured graphene oxide (GO). ${ }^{196}$ In the middle of the 19th

Table 5 Representative summary of the performances of MOF-based catalysts in thermal-driven ODS

\begin{tabular}{|c|c|c|c|c|c|c|c|}
\hline \multirow[b]{2}{*}{ Catalysts } & \multirow{2}{*}{$\begin{array}{l}\text { Reaction } \\
\text { temperature } \\
\left({ }^{\circ} \mathrm{C}\right)\end{array}$} & \multirow[b]{2}{*}{ Oxidant } & \multirow[b]{2}{*}{ Extractant } & \multicolumn{3}{|l|}{ Performances } & \multirow[b]{2}{*}{ Ref. } \\
\hline & & & & $\begin{array}{l}\text { Sulfur removal } \\
\text { (reactant) }\end{array}$ & $\begin{array}{l}\text { Reaction } \\
\text { time }(\mathrm{h})\end{array}$ & $\begin{array}{l}\text { Stability } \\
\text { (h) }\end{array}$ & \\
\hline MIL-125(Ti) & 80 & $\mathrm{CHP}$ & $\mathrm{N} / \mathrm{A}$ & $36 \%(\mathrm{DBT})$ & 6 & $\mathrm{~N} / \mathrm{A}$ & 176 \\
\hline $\mathrm{NH}_{2}$-MIL-125(Ti) & & & & $9 \%(\mathrm{DBT})$ & & & \\
\hline $\mathrm{NO}_{2}-\mathrm{MIL}-101(\mathrm{Cr})$ & 140 & $\mathrm{O}_{2}$ & N/A & $90 \%(\mathrm{DBT})$ & 4.5 & $>25$ & 177 \\
\hline UiO-66(Zr) & 60 & $\mathrm{H}_{2} \mathrm{O}_{2}(30 \mathrm{wt} \%)$ & N/A & 〜 69\% (DBT) & 2 & $\mathrm{~N} / \mathrm{A}$ & 178 \\
\hline Br-UiO-66(Zr) & & & & $\sim 77 \%(\mathrm{DBT})$ & & $\mathrm{N} / \mathrm{A}$ & \\
\hline $\mathrm{NH}_{2}$-UiO-66(Zr) & & & & $\sim 38 \%(\mathrm{DBT})$ & & N/A & \\
\hline $\mathrm{NO}_{2}-\mathrm{UiO}-66(\mathrm{Zr})$ & & & & 97\% (DBT) & & $>10$ & \\
\hline MIL-125(Ti) & 60 & $\mathrm{H}_{2} \mathrm{O}_{2}(30 \mathrm{wt} \%)$ & Methanol & $100 \%(\mathrm{DBT})$ & 4 & $>20$ & 179 \\
\hline $\mathrm{NH}_{2}-\mathrm{MIL}-125(\mathrm{Ti})$ & & & & $98 \%(\mathrm{DBT})$ & & $>20$ & \\
\hline MIL-125(Ti) & 60 & $\mathrm{H}_{2} \mathrm{O}_{2}(30 \mathrm{wt} \%)$ & Methanol & 〜 90\% (DBT) & 0.5 & $\mathrm{~N} / \mathrm{A}$ & 180 \\
\hline MIL-125-TRO(Ti) & & & & $100 \%(\mathrm{DBT})$ & & $>4.5$ & \\
\hline $\begin{array}{l}\text { Defect-rich porous titanium } \\
\text { terephthalate }\end{array}$ & Ambient & $\mathrm{CHP}$ & N/A & $100 \%(\mathrm{DBT})$ & 0.17 & $>0.83$ & 181 \\
\hline TMU-10(Co) & 60 & TBHP (70 wt\%) & N/A & $40.5 \%(\mathrm{DBT})$ & 8 & $<24$ & 182 \\
\hline TMU-12(Co) & & & & $75.2 \%(\mathrm{DBT})$ & & $>32$ & \\
\hline Hierarchical Ti-beta zeolite & 60 & TBHP (70 wt\%) & $\mathrm{N} / \mathrm{A}$ & $34.2 \%(\mathrm{DBT})$ & 0.5 & $>2$ & 183 \\
\hline $\begin{array}{l}\text { Hierarchical Ti-beta zeolite } \\
\text { with CTAB }\end{array}$ & & & & $98.5 \%(\mathrm{DBT})$ & & $>2$ & \\
\hline Ta-Beta-Re zeolite & 60 & $\mathrm{H}_{2} \mathrm{O}_{2}(30 \mathrm{wt} \%)$ & $\mathrm{N} / \mathrm{A}$ & $100 \%(\mathrm{DBT})$ & 2 & $<8$ & 192 \\
\hline UiO-66(Zr) & 50 & $\mathrm{H}_{2} \mathrm{O}_{2}(30 w t \%)$ & Acetonitrile & 99.5\% (DBT) & 3 & $<12$ & 184 \\
\hline UiO-66(Zr) & 60 & $\mathrm{H}_{2} \mathrm{O}_{2}(30 \mathrm{wt} \%)$ & Acetonitrile & $100 \%(\mathrm{DBT})$ & 0.33 & $<2$ & 186 \\
\hline UiO-66(Zr) & 50 & $\mathrm{H}_{2} \mathrm{O}_{2}(30 \mathrm{wt} \%)$ & Acetonitrile & $\sim 62 \%$ & 1 & $\mathrm{~N} / \mathrm{A}$ & 187 \\
\hline $\mathrm{UiO}-66(\mathrm{Zr})-\mathrm{TiBr}_{4}$ & & & & $\sim 45 \%$ & & $\mathrm{~N} / \mathrm{A}$ & \\
\hline $\mathrm{UiO}-66(\mathrm{Zr})-\mathrm{TiCl}_{4}$ & & & & $\sim 96 \%$ & & $>12$ & \\
\hline $\mathrm{UiO}-66(\mathrm{Zr})-\mathrm{ZrCl}_{4}$ & & & & $\sim 86 \%$ & & $\mathrm{~N} / \mathrm{A}$ & \\
\hline MOF-808(Zr) & 60 & TBHP (70 wt\%) & N/A & $88 \%(\mathrm{DBT})$ & 8 & $<32$ & 188 \\
\hline UMCM-309(Zr) & & & & $59 \%(\mathrm{DBT})$ & & N/A & \\
\hline MOF-808(Zr) & 50 & CHP & N/A & $>99 \%(\mathrm{DBT})$ & 0.33 & $<2$ & 190 \\
\hline Ti-Modified MIL-101 & 60 & CHP (70 wt\%) & $\mathrm{N} / \mathrm{A}$ & $90 \%(\mathrm{DBT})$ & 0.5 & $<6$ & 191 \\
\hline
\end{tabular}

CHP: cumene hydroperoxide; TBHP: tert-butyl hydroperoxide. 
century, Hummers and Offeman discovered a swift route (Hummers' method) to oxidize graphite by reacting with sulfuric acid, sodium nitrate and potassium permanganate to harvest GO. ${ }^{197}$ Through this process, GO layers are endowed with hydrophilic property and become susceptible to the intercalation of water molecules, thereby forming GO nanosheets. ${ }^{198}$ However, Hummers' method does not meet the goal of green chemistry because toxic gaseous like $\mathrm{NO}_{2}$ and $\mathrm{N}_{2} \mathrm{O}_{4}$ are released during the process. In 2010, Marcano's group developed a modified Hummers' method by replacing sodium nitrate with phosphorus acid to ameliorate this drawback. ${ }^{196}$ Surprisingly, additional oxygen-containing groups were introduced into the structure of graphene during the modified Hummers' method and were advantageous to oxidation reactions. Since then, the modified Hummers' method has served as the template for researchers in the area of materials science to synthesize GO.

To address environmental friendliness and sustainability, He et al. reported a creative and sustainable technique to derive N,O-doped porous graphene (N,O-PG) from the coke waste of the petroleum refinery industry. ${ }^{199}$ Basically, a ball-milling process was first conducted in the presence of coke and urea, accompanied by annealing to activate the catalyst and decompose the layered structure graphene into an ultrathin nanosheet structure (Fig. 17a). The auspicious morphology of N,O-PG nanosheets led to $98.5 \%$ DBT removal with $\mathrm{O}_{2}$ in $5 \mathrm{~h}$ reaction, a value markedly higher than that of commercial graphite (Fig. 17b). Significantly, the presence of nitrogen atoms increased the electron density of porous graphene and enriched the porous graphene surface with electrons, thus directly enhancing the activation of $\mathrm{O}_{2}$ and the ODS performance.
Similarly, the significant role of $\mathrm{N}$ was also discovered in $\mathrm{N}$-doped porous carbon transformed from waste air-aid paper. ${ }^{200}$ High specific surface area was another crucial feature that successfully promoted catalytic activity and stability in ODS, as N-doped porous carbon demonstrated complete conversion of $\mathrm{H}_{2} \mathrm{~S}$ with $\mathrm{O}_{2}$ at $190{ }^{\circ} \mathrm{C}$ and sustained outstanding ODS activity for more than $40 \mathrm{~h}$. Indeed, the doping of $\mathrm{N}$ is a promising strategy to tailor the electronic structure of metal-free nanomaterials with the aim of catalytic activity improvement in ODS.

In regard to $\mathrm{GO}$, the emergence of rich oxygen-containing functional groups like hydroxyl groups and carboxyl groups on the surface, which are valuable reaction sites for catalysis, has inspired numerous researchers to investigate its activity in ODS. ${ }^{201}$ For example, Abdi and co-workers prepared GO using the modified Hummers' method and studied its catalytic activity in oxidizing sulfides to sulfones with $\mathrm{H}_{2} \mathrm{O}_{2} \cdot{ }^{202}$ In the absence of extractive solvent, GO achieved 95\% conversion of thioanisole in $20 \mathrm{~min}$ owing to its amphiphilic property that allowed uniform dispersion in the organic phase. Apart from $\mathrm{H}_{2} \mathrm{O}_{2}$ activation, the hydroxyl groups on the surface of GO also acted as the adsorption platform for sulfone to separate sulfur compounds from the fuels. In another work, Abdi et al. comprehensively revealed the function of different oxygencontaining functional groups on the surface of GO grafted with acetic acid moieties in the ODS mechanism (Fig. 17c). ${ }^{203}$ First, the activation of $\mathrm{H}_{2} \mathrm{O}_{2}$ was stimulated by the carboxyl groups at the edge of GO. After DBT oxidation, the produced polar DBT sulfone strongly chemisorbed on the basal plane of GO, which contained hydroxyl groups, via hydrogen bonding and $\pi-\pi$ interactions, thus eliminating the need for solvent to separate
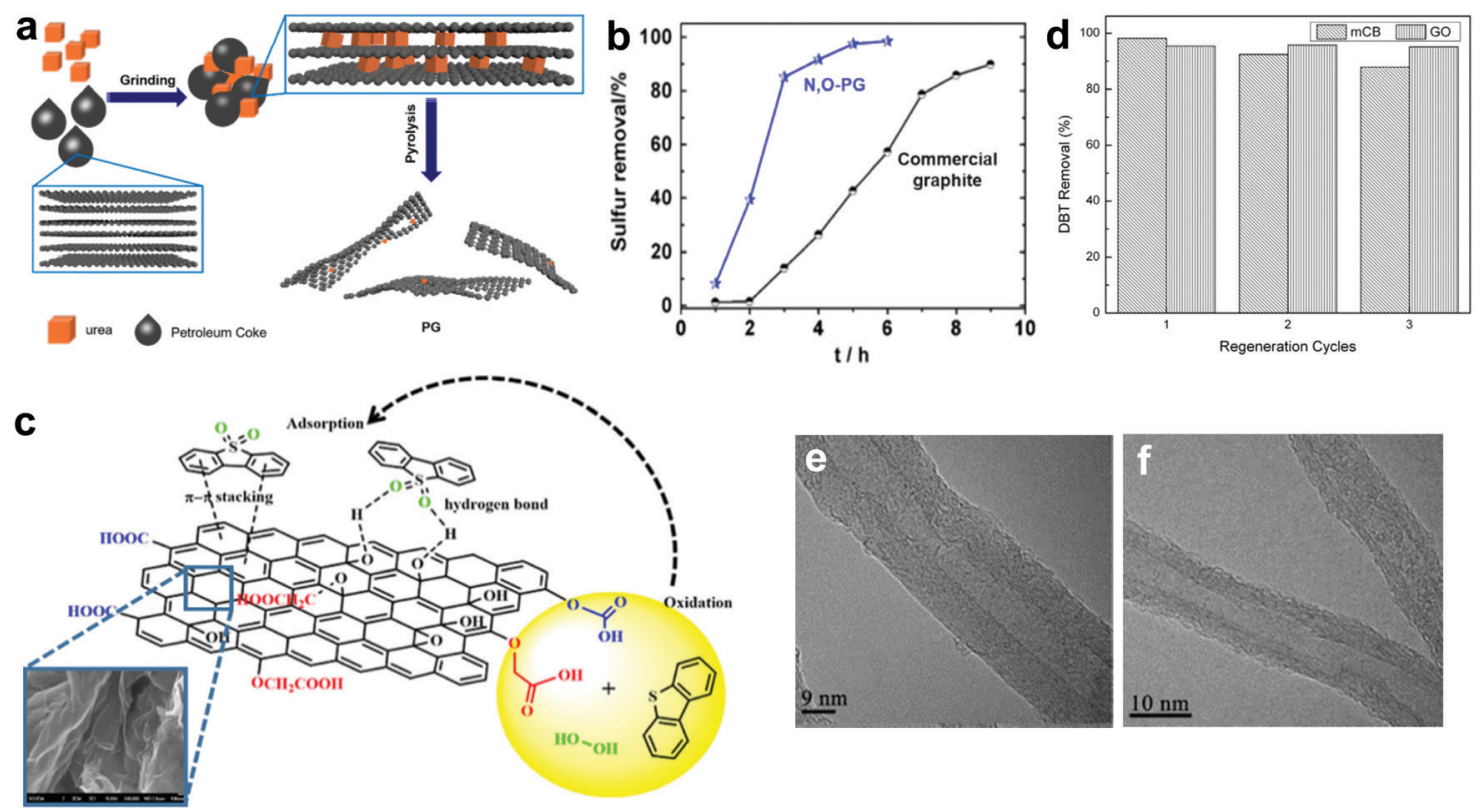

Fig. 17 (a) Synthesis pathway of N,O-doped porous graphene. (b) Catalytic activity of N,O-doped porous graphene and commercial graphite in removing DBT using $\mathrm{O}_{2}$ at $120{ }^{\circ} \mathrm{C}$. Reprinted with permission. ${ }^{199}$ Copyright 2019 , American Chemical Society. (c) Proposed route for the oxidation of DBT with $\mathrm{H}_{2} \mathrm{O}_{2}$ by GO with a SEM image of $\mathrm{GO}$. Reproduced with permission. ${ }^{203}$ Copyright 2017, Elsevier Ltd. (d) DBT removal by $\mathrm{mCB}$ and $\mathrm{GO}$ at $60{ }^{\circ} \mathrm{C}$ in the presence of $\mathrm{O}_{2}$ for three regeneration cycles at $5 \mathrm{~h}$ per cycle. Reprinted with permission. ${ }^{204}$ Copyright 2017, Elsevier B.V. HRTEM images of (e) CNT and (f) oxidized CNT. Reprinted with permission. ${ }^{206}$ Copyright 2019, Elsevier B.V. 
the DBT sulfone from the organic phase. Taken together, these works underlined the significant dual roles of GO in the desulfurization of fuels.

To compare the ODS activities of various nanocarbon materials, carbon black, modified carbon black (mCB), GO, activated carbon, carbon nanotubes (CNTs) and activated carbon fiber were synthesized by Zhang and Wang and employed in ODS with $\mathrm{O}_{2} \cdot{ }^{204}$ The results disclosed that $\mathrm{MCB}$ and GO attained the highest DBT conversion (97\%). Despite possessing identical ODS activity, mCB exhibited poorer recyclability than GO (Fig. 17d). This reflects the deficient robustness of mCB against catalyst deactivation stemming from the inefficient removal of sulfone compounds from adsorption sites on the surface. The lack of oxygen-containing functional groups on the surface of mCB was another critical factor, causing notable activity depletion after recovery. Obviously, the presence of oxygencontaining functional groups on the surface of carbon materials is conducive to the maximization of ODS activity and durability.

The role of the GO derivative reduced GO (rGO) in oxidizing various aromatic sulfur compounds with $\mathrm{O}_{2}$ was investigated by Gu and fellows. ${ }^{205}$ The rGO took $6 \mathrm{~h}$ to reach above $90 \%$ sulfur removal at $140{ }^{\circ} \mathrm{C}$. The sluggish ODS reaction rate stemmed from the shortage of oxygen-containing functional groups on the rGO surface. Accordingly, the authors proposed a gas-phase oxidative treatment to increase the oxygen content and the number of unstable defect sites (carbonyl groups) in the structure of rGO. As a result, the oxidized rGO accomplished $100 \%$ desulfurization in $2 \mathrm{~h}$ under the same operating conditions. In another work, $\mathrm{Gu}$ et al. functionalized CNTs with oxygen-containing functional groups by means of nitric acid and sulfuric acid treatment. ${ }^{206}$ The oxidized CNTs achieved complete desulfurization, compared to $34.8 \%$ by CNTs, with $\mathrm{H}_{2} \mathrm{O}_{2}$ as oxidant and ILs as extractant. The outstanding ODS performance arose from the formation of more carbonyl groups on the surface of CNTs without compromising the original textural properties (Fig. 17e and f). Similarly, Kampouraki et al. tailored the surface chemistry of commercial activated carbon (SX PLUS) via oxidation reaction with sulfuric acid and nitric acid. ${ }^{207}$ Profiting from the oxidation treatment, the number of acidic functional groups (carboxyl group) on the surface of SX PLUS was increased, which also denoted the enrichment of active sites. On the other hand, the other decisive factors in catalytic ODS, including the porosity and specific surface area of SX PLUS, experienced a significant diminution. Nonetheless, the catalytic activity of modified SX PLUS in oxidizing 4,6-dimethyldibenzothiophene (4,6-DMDBT) still drastically improved by $25 \%$ over pristine SX PLUS. These cases shed light on the significance of oxygen-functional groups on the surface of carbon materials for boosting the activity in ODS.

In view of the poor defect sites in graphene, a novel carbonbased material, carbon nitride $\left(\mathrm{C}_{3} \mathrm{~N}_{4}\right)$, which is produced by bridging heptazine units together, has gained much attention in the field of catalysis owing to its facile synthesis approach, plentiful surface chemistry and excellent chemical stability. ${ }^{208,209}$ A few years ago, Shen and colleagues reported the use of thermal polymerization to produce polymeric $\mathrm{C}_{3} \mathrm{~N}_{4}$ nanomesh from trithiocyanuric acid with a continuous supply of air at different heating temperatures. ${ }^{210}$ Interestingly, the heating temperature crucially affected the morphology of $\mathrm{C}_{3} \mathrm{~N}_{4}$, as exemplified in Fig. 18a and b. At elevated temperatures, the dissociation of $\mathrm{C}_{3} \mathrm{~N}_{4}$ with stacked layer structure was induced by the large supply of thermal energy. The surface energy between every layer was thermodynamically reduced, leading to the generation of ultrathin sheets of $1.1 \mathrm{~nm}$ thickness (Fig. 18c and d). Owing to the 2D ultrathin structure of $\mathrm{C}_{3} \mathrm{~N}_{4}$ with a gigantic specific surface area, the oxidation of $\mathrm{H}_{2} \mathrm{~S}$ was substantially strengthened. A similar phenomenon was also highlighted in the work of Lei et al., who shaped a graphitic $\mathrm{C}_{3} \mathrm{~N}_{4}\left(\mathrm{~g}-\mathrm{C}_{3} \mathrm{~N}_{4}\right)$ nanosheet from urea through thermal polymerization accompanied by a calcination process at a different temperature to exfoliate the bulk structure into ultrathin sheets (Fig. 18e). ${ }^{211}$ With greater exposure of surface active sites, the $\mathrm{g}-\mathrm{C}_{3} \mathrm{~N}_{4}$ nanosheet calcined at $600{ }^{\circ} \mathrm{C}$ exhibited the highest $\mathrm{H}_{2} \mathrm{~S}$ conversion with air compared to the other $\mathrm{g}-\mathrm{C}_{3} \mathrm{~N}_{4}$ at lower calcination temperatures (Fig. 18f). It also sustained strong ODS activity for more than six successive runs without severe deactivation. Thus, a higher calcination temperature favors the structural decomposition of $\mathrm{g}-\mathrm{C}_{3} \mathrm{~N}_{4}$, resulting in formation of ultrathin sheets with massive surface area. However, the necessity of a high oxidation temperature $\left(>150{ }^{\circ} \mathrm{C}\right)$ during $\mathrm{ODS}$ by $\mathrm{g}-\mathrm{C}_{3} \mathrm{~N}_{4}$ to provide ample activation energy to dissociate the powerful covalent bond in $\mathrm{O}_{2}$ exacerbated the energy consumption and the risk of diesel vaporization, resulting in enormous economic losses.

To surmount the unavoidable high energy barrier, Jia et al. attempted to intensify the Lewis acidity of $\mathrm{g}-\mathrm{C}_{3} \mathrm{~N}_{4}$ by doping with boron atoms to increase its catalytic activity. ${ }^{212}$ Aside from the improvement of the interfacial electronic properties, the boron-doped g- $\mathrm{C}_{3} \mathrm{~N}_{4}\left(\mathrm{~B}-\mathrm{C}_{3} \mathrm{~N}_{4}\right)$, synthesized from a deep eutectic solvent and urea via annealing (Fig. 18g), was endowed with a higher porosity compared to pristine $\mathrm{g}-\mathrm{C}_{3} \mathrm{~N}_{4}$ (Fig. 18h). This effectively created more active sites on $\mathrm{g}-\mathrm{C}_{3} \mathrm{~N}_{4}$ for ODS. Improved by the morphological changes, the oxidation of 4,6-DMDBT in the presence of air exhibited a sharp increase from $33.6 \%$ to $94.1 \%$ at only $120{ }^{\circ} \mathrm{C}$. In order to reveal the impact of boron doping, the proposed reaction mechanism for B- $\mathrm{C}_{3} \mathrm{~N}_{4}$ oxidizing 4,6-DMDBT is shown in Fig. 18j. With its Lewis acid feature, $\mathrm{B}-\mathrm{C}_{3} \mathrm{~N}_{4}$ attracted 4,6-DMDBT and $\mathrm{O}_{2}$ by creating a vigorous Lewis acid-base interaction. After that, the $\mathrm{O}_{2}$ was activated and catalysis proceeded to the oxidation of 4,6-DMDBT to generate 4,6-DMDBT sulfone. Wei et al. also reported the application of $\mathrm{B}-\mathrm{C}_{3} \mathrm{~N}_{4}$ in the ODS of model diesel, but their $\mathrm{B}-\mathrm{C}_{3} \mathrm{~N}_{4}$ was fabricated from a ternary deep eutectic solvent under calcination and spinodal decomposition. ${ }^{213}$ As expected, $\mathrm{B}^{-} \mathrm{C}_{3} \mathrm{~N}_{4}$ required only $125{ }^{\circ} \mathrm{C}$ to achieve $98.4 \%$ DBT removal with $\mathrm{O}_{2}$ due to the amelioration of reduction potential in the parent boron nitride that could be observed from the cyclic voltammetry curves (Fig. 18i). In other words, B- $\mathrm{C}_{3} \mathrm{~N}_{4}$ gained a greater ability to donate electrons to $\mathrm{O}_{2}$ and led to rapid oxygen reduction, forming reactive oxygen species for the oxidation of DBT. Thus, the reaction temperature for activating $\mathrm{O}_{2}$ can be reduced by modifying the electronic property of $\mathrm{g}-\mathrm{C}_{3} \mathrm{~N}_{4}$ through boron doping. During the ODS process, the boron atom was presumed to be the active site 

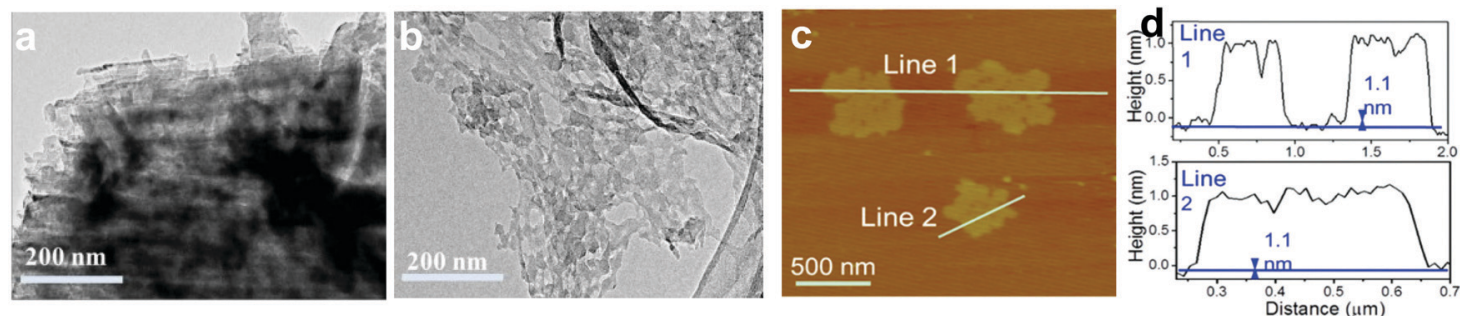

e

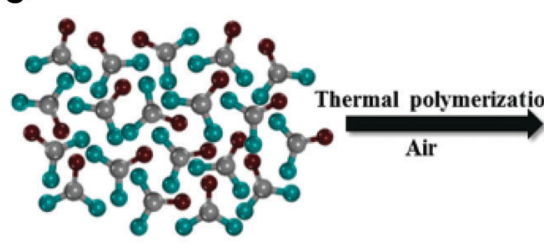

Urea
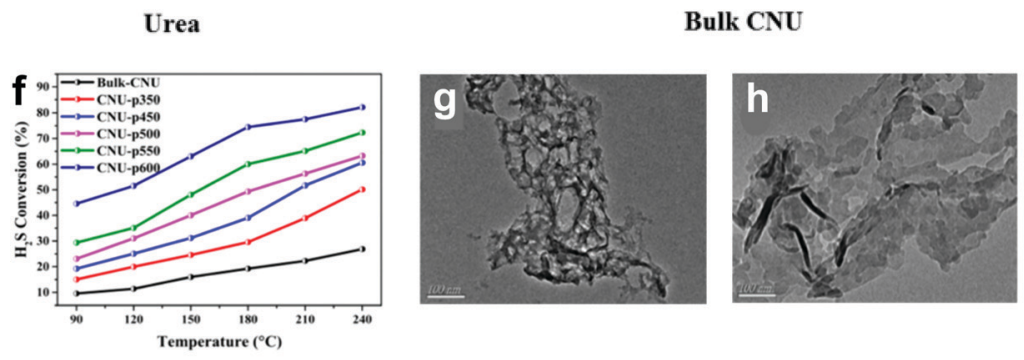

Bulk CNU
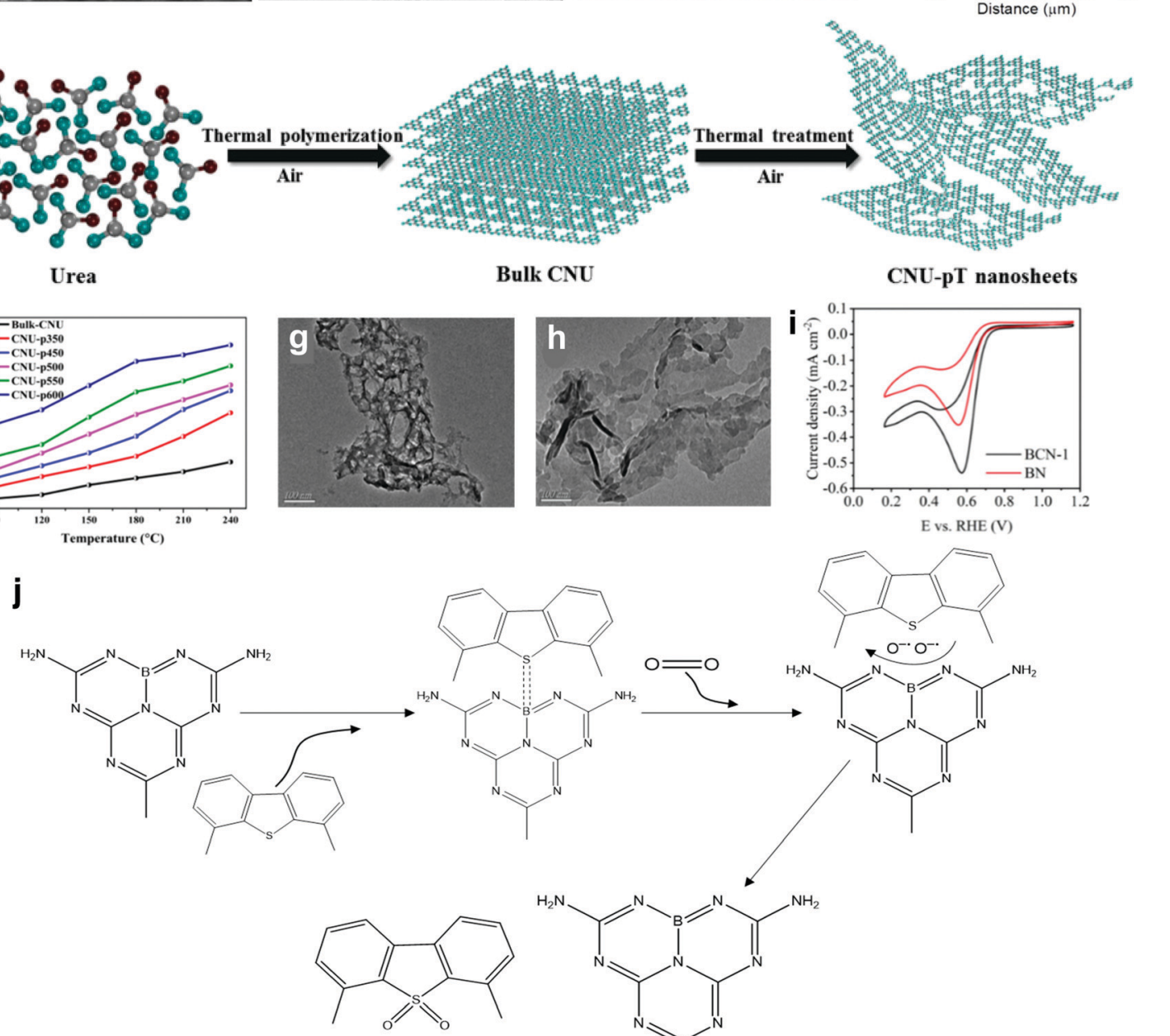

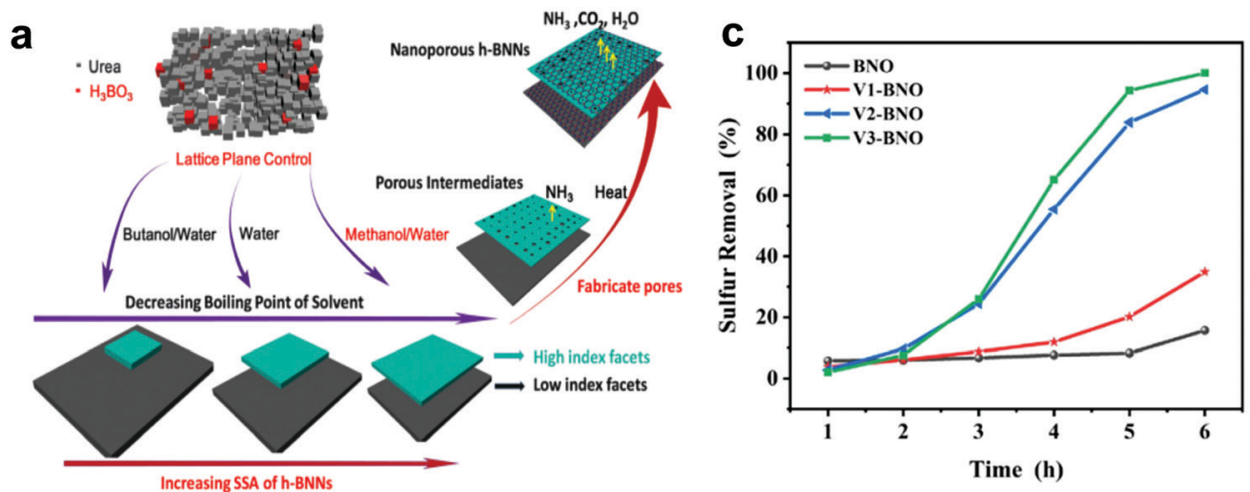
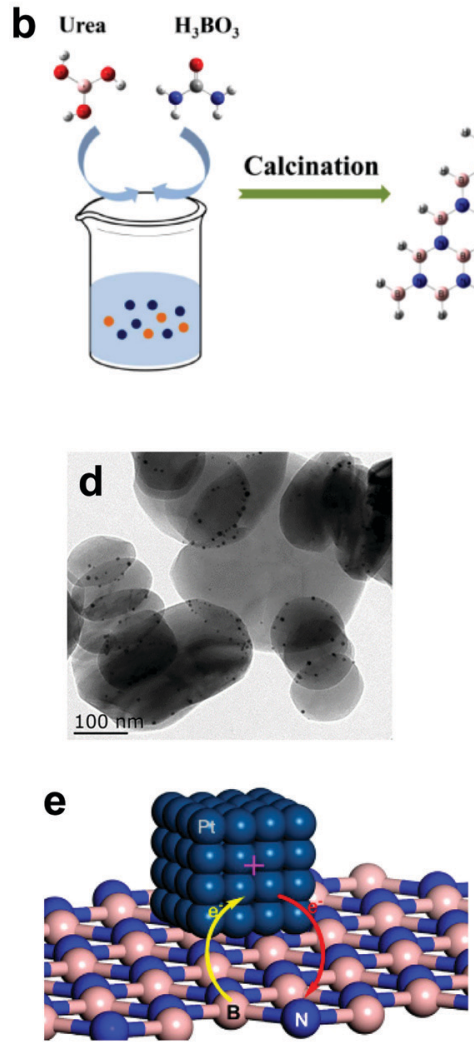

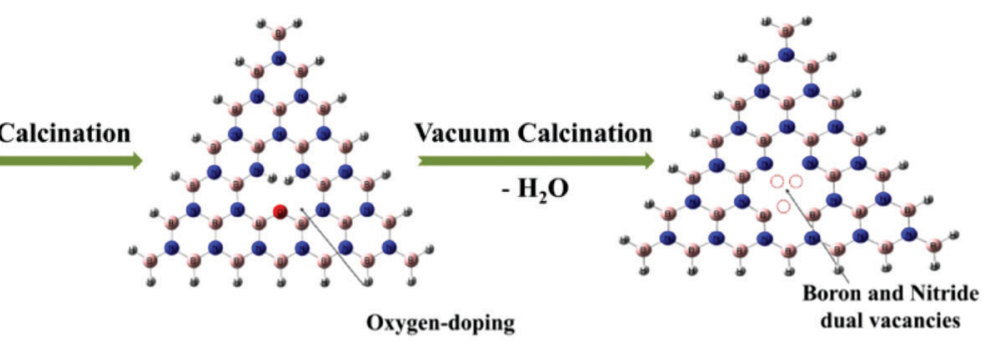

BNO
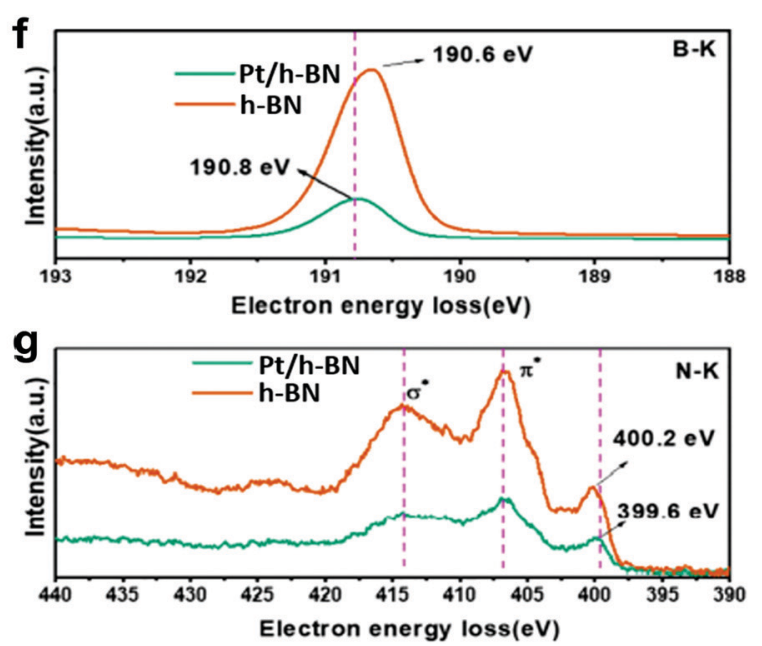

Fig. 19 (a) Effects of solvents with different boiling points on the morphology of $h$-BN. Reprinted with permission. ${ }^{215}$ Copyright 2016 , Royal Society of Chemistry. (b) The route for the fabrication of $\mathrm{V}$-BNO. (c) DBT removal at $125^{\circ} \mathrm{C}$ in the presence of $\mathrm{O}_{2}$ over original BNO and $\mathrm{V}$-BNO calcined for $1 \mathrm{~h}$ (V1-BNO), 2 h (V2-BNO) and 3 h (V3-BNO). Reprinted with permission. ${ }^{219}$ Copyright 2020, Wiley-VCH. (d) TEM image and (e) schematic of Pt/h-BN. Electron energy loss spectroscopy (EELS) spectra of Pt/h-BN and bare $\mathrm{h}-\mathrm{BN}$ for (f) $\mathrm{B}-\mathrm{K}$ edge and (g) N-K edge. Reprinted with permission. ${ }^{220}$ Copyright 2020, Elsevier B.V.

solvent's boiling point resulted in enlargement of the specific surface area of h-BN due to the increased rate of solvent evaporation (Fig. 19a). Notably, this also induced an increase in the recrystallization rate and the growth rate of precursors. Because the rapid recrystallization rate inhibited the growth of crystals, h-BN with a high-index-facet layered structure and high density of low-coordinated atoms was created. ${ }^{216}$ The produced h-BN attained $98.8 \%$ DBT conversion at $150{ }^{\circ} \mathrm{C}$ after $180 \mathrm{~min}$. In contrast to previous works, ball-milling and thermal treatment were recently utilized by $\mathrm{Wu}$ and co-workers to construct h-BN. ${ }^{217}$ The prepared h-BN exhibited a lower porosity and specific surface area compared to previous reports owing to the absence of a solvent to function as the pore builder during the pyrolysis stage. Even so, $99.4 \%$ of DBT was converted to its oxidized form in the ODS test within $180 \mathrm{~min}$ at $80^{\circ} \mathrm{C}$. The impressive ODS performance could be attributed to the use of the reactive oxidant $\mathrm{H}_{2} \mathrm{O}_{2}$ instead of stable $\mathrm{O}_{2}$ molecules. of note, the solvent recrystallization method is more favorable to produce h-BN with a pore-rich morphology that offers plentiful active sites for ODS.

Owing to the complexity of the defect sites in BN, Lv et al. revealed the ODS performances and mechanisms of the five 
major defect sites using $\mathrm{O}_{2} \cdot{ }^{218}$ According to the calculated Gibbs free energies, the activation of $\mathrm{O}_{2}$ decreased in the order of zigzag-B $>\mathrm{N}$-vacancy $>$ zigzag-N $>$ armchair $>$ B-vacancy. With respect to the oxidative activity, zigzag- $\mathrm{N}$ was preferable due to its lower energy barrier and exothermic property which promoted the transfer of oxygen radicals to Th. Although previous findings indicated the poor activities of the B-vacancy and $\mathrm{N}$-vacancy, attributed to the blockage of vacant sites by oxygen species, Dai et al. incorporated both $\mathrm{B}$ and $\mathrm{N}$ vacancies into the structure of oxygen-doped BN (BNO) by detaching some of the hydrogen and oxygen atoms through calcination under vacuum (Fig. 19b). ${ }^{219}$ The defective BNO (V-BNO) successfully acted as a catalytic promoter to facilitate the activation of $\mathrm{O}_{2}$ in ODS and contributed to the $100 \%$ DBT removal. This phenomenon stemmed from the effect of bivacancy sites which enlarge the aperture size of BNO, resolving the blockage of vacant sites by oxygen species. Furthermore, with the increase of the calcination period, more $\mathrm{B}$ and $\mathrm{N}$ vacancies were constructed in the morphology of BNO and improved the sulfur removal (Fig. 19c). Despite the outstanding ODS performance by V-BNO, profound studies on ameliorating the slow reaction rate are urgently needed to accelerate progress toward industrial application in the future.

In addition to serving as a catalyst, $2 \mathrm{D} \mathrm{BN}$, with outstanding stability, very large specific surface area and favorable surface properties, has also become an interesting support to disperse metal nanoparticles in ODS. For instance, Wu et al. supported Pt nanoparticles on 2D h-BN with the objective of improving the catalytic activity in ODS. ${ }^{220}$ Notably, Pt nanoparticles were immobilized at the edges of h-BN (Fig. 19d) instead of in the center, which is ascribed to the existence of higher electron density at the h-BN edges. The energetic edge interactions stemming from the electron exchange between Pt and h-BN were confirmed by electron energy loss spectroscopy (EELS). The reduction of electron energy loss at the B atom (Fig. 19f) and the increase of electron energy loss at the $\mathrm{N}$ atom (Fig. 19g) signified the donation of electrons from the $\mathrm{B}$ atom to $\mathrm{Pt}$ and the acceptance of electrons at the $\mathrm{N}$ atom from Pt (Fig. 19e). In the ODS experiment, Pt/h-BN achieved above $90 \%$ sulfur removal with $\mathrm{O}_{2}$ after five cycles. Likewise, $\mathrm{He}$ et al. grew $\mathrm{PtCu}$ alloy on BN nanosheets via solvothermal method and examined the ability to catalyze the ODS of model fuel. ${ }^{221}$ Thanks to the robust substrate-support interactions, the aggregation of metal nanoparticles was hindered, resulting in prominent ODS activity. Compared with commercial bulk BN, BN nanosheets provided a larger dispersion platform for $\mathrm{PtCu}$ nanoparticles and led to a higher exposure of catalytic sites for ODS. PtCu/BN nanosheets attained $96.1 \%$ DBT conversion at $110{ }^{\circ} \mathrm{C}$ in $7 \mathrm{~h}$ using $\mathrm{O}_{2}$, a result which was substantially better than that of $\mathrm{PtCu} /$ commercial BN (51.7\%). Overall, BN is a promising support to stabilize metal nanoparticles to achieve outstanding ODS performances.

In summary, metal-free nanomaterials have demonstrated their impressive potential to desulfurize fuels via ODS, but higher reaction temperatures and longer reaction times are required. Accordingly, appropriate modification of the physicochemical properties must be performed to enhance the catalytic activity of metal-free nanomaterials in ODS to establish a sustainable and rapid ODS process. Table 6 lists representative performances of diverse metal-free nanomaterials in ODS under different operating conditions.

\section{Photocatalyst design and mechanisms for light-driven ODS}

As a state-of-the-art route in ODS, light-driven ODS is seen as a promising approach to actualize green and zero-sulfur fuels in the coming years owing to its direct consumption of free and abundant solar light to degrade hazardous sulfur pollutants. However, the search for appropriate materials with the desired photocatalytic properties, including a broad light absorption range, low electron-hole recombination rate, high surface area and exceptional stability, is a challenge. Researchers have concentrated on the structure-property relation to assist the engineering of photocatalysts with advantageous properties that boost the photocatalytic activity.

\subsection{Metal oxide-based photocatalysts}

Because of its outstanding photoactivity, $\mathrm{TiO}_{2}$ has been utilized as a photocatalyst in the ODS of model oil, but its performance was below expectations. ${ }^{224,225}$ This circumstance stems from the fast electron-hole recombination rate, limited spectral responsive range and aggregation of the $\mathrm{TiO}_{2}$ nanoparticles which diminished the active surface area for light absorption. ${ }^{226}$ Therefore, several countermeasures have been adopted to ameliorate the shortcomings. Kalantari et al. adopted an ultrasonic-assisted impregnation method to graft nitrogen atoms on $\mathrm{TiO}_{2}$ in order to enhance its photoactivity in ODS. $^{227}$ Although there was no crucial difference in the surface structure, the $\mathrm{N}$-doped $\mathrm{TiO}_{2}$ showed an enlarged surface area and reduced band gap (Fig. 20b) compared to pristine $\mathrm{TiO}_{2}$. $\mathrm{N}$-doped $\mathrm{TiO}_{2}$ exhibited an extended light absorption ability within the visible light spectrum (Fig. 20a) and a lower energy requirement to excite electrons from the VB to $\mathrm{CB}$ for $\mathrm{O}_{2}$ activation. Correspondingly, the DBT conversion by $\mathrm{N}$-doped $\mathrm{TiO}_{2}$ increased substantially (Fig. 20c). However, the ODS performance of $\mathrm{N}$-doped $\mathrm{TiO}_{2}$ still remains insufficient for fulfilling the basic requirement of ultra-deep ODS owing to the paucity of active sites.

On account of that, the incorporation of $\mathrm{TiO}_{2}$ with various supports has been intensely studied in ODS by previous scholars. By the impregnation method, $\mathrm{TiO}_{2}$ was embedded onto $\mathrm{g}-\mathrm{C}_{3} \mathrm{~N}_{4}$ with large specific surface area and utilized as the photocatalyst for ODS in the presence of $\mathrm{H}_{2} \mathrm{O}_{2} \cdot{ }^{228}$ The resulting $\mathrm{TiO}_{2} / \mathrm{g}-\mathrm{C}_{3} \mathrm{~N}_{4}$ possessed a $2 \mathrm{D}$ structure with a uniform dispersion of $\mathrm{TiO}_{2}$ (Fig. 20d) which significantly elevated the exposure of $\mathrm{TiO}_{2}$ to the light source. Since $\mathrm{g}-\mathrm{C}_{3} \mathrm{~N}_{4}$ has a narrower band gap, g- $\mathrm{C}_{3} \mathrm{~N}_{4}$ was more prone to photo-activation compared to $\mathrm{TiO}_{2}$, which triggered the migration of excited electrons and holes across the heterojunction interface following the mechanism in Fig. 20e. In this way, the charge recombination was effectively hampered, preserving more active electrons in the 
Table 6 Representative summary of the performances of metal-free catalysts in thermal-driven ODS

\begin{tabular}{|c|c|c|c|c|c|c|c|}
\hline \multirow[b]{2}{*}{ Catalysts } & \multirow{2}{*}{$\begin{array}{l}\text { Reaction } \\
\text { temperature } \\
\left({ }^{\circ} \mathrm{C}\right)\end{array}$} & \multirow[b]{2}{*}{ Oxidant } & \multirow[b]{2}{*}{ Extractant } & \multicolumn{3}{|l|}{ Performances } & \multirow[b]{2}{*}{ Ref. } \\
\hline & & & & $\begin{array}{l}\text { Sulfur removal } \\
\text { (reactant) }\end{array}$ & $\begin{array}{l}\text { Reaction } \\
\text { time (h) }\end{array}$ & $\begin{array}{l}\text { Stability } \\
\text { (h) }\end{array}$ & \\
\hline $\mathrm{BN}$ & 80 & $\mathrm{H}_{2} \mathrm{O}_{2}(30 \mathrm{wt} \%)$ & N/A & $99.4 \%(\mathrm{DBT})$ & 3 & $>24$ & 217 \\
\hline $\mathrm{B}_{4} \mathrm{C}$ & 130 & $\mathrm{O}_{2}$ & N/A & $99.5 \%(\mathrm{DBT})$ & 8 & $>136$ & 222 \\
\hline N,O-Doped graphene & 120 & $\mathrm{O}_{2}$ & $\mathrm{~N} / \mathrm{A}$ & $98.5 \%(\mathrm{DBT})$ & 5 & $<48$ & 199 \\
\hline N-Doped porous carbon & 190 & $\mathrm{O}_{2}$ & $\mathrm{~N} / \mathrm{A}$ & $100 \%\left(\mathrm{H}_{2} \mathrm{~S}\right)$ & $0.6 \mathrm{~h}^{-1}$ (WHSV) & $>40$ & 200 \\
\hline Acidic GO & 25 & $\mathrm{H}_{2} \mathrm{O}_{2}(30 \mathrm{wt} \%)$ & N/A & 95\% (thioanisole) & 0.33 & $<4$ & 202 \\
\hline $\mathrm{GO} / \mathrm{COOH}$ & 40 & $\mathrm{H}_{2} \mathrm{O}_{2}(30 w t \%)$ & $\mathrm{N} / \mathrm{A}$ & $95 \%(\mathrm{DBT})$ & 5 & $\mathrm{~N} / \mathrm{A}$ & 203 \\
\hline GO & 60 & $\mathrm{O}_{2}$ & $\mathrm{~N} / \mathrm{A}$ & $96 \%(\mathrm{DBT})$ & 2 & $>15$ & 204 \\
\hline Modified CB & & & & 97\% (DBT) & & $<15$ & \\
\hline $\mathrm{CB}$ & & & & $90 \%(\mathrm{DBT})$ & & N/A & \\
\hline $\mathrm{AC}$ & & & & $78 \%(\mathrm{DBT})$ & & $\mathrm{N} / \mathrm{A}$ & \\
\hline AC fiber & & & & $71 \%(\mathrm{DBT})$ & & $\mathrm{N} / \mathrm{A}$ & \\
\hline CNTs & & & & $70 \%(\mathrm{DBT})$ & & $\mathrm{N} / \mathrm{A}$ & \\
\hline rGO & 140 & $\mathrm{O}_{2}$ & N/A & 100\% (DBT) & 6 & $>10$ & 205 \\
\hline Oxidized CNTs & 70 & $\mathrm{H}_{2} \mathrm{O}_{2}(30 w t \%)$ & {$[\mathrm{Omim}] \mathrm{PF}_{6}$} & $100 \%(\mathrm{DBT})$ & 1 & $>3.33$ & 206 \\
\hline CNTs/MOF-199-Mo ${ }_{16} V_{2}$ & 60 & $\mathrm{O}_{2}$ & $\mathrm{~N} / \mathrm{A}$ & $92.25 \%(\mathrm{DBT})$ & 3 & $>28$ & 223 \\
\hline SX PLUS & 60 & $\mathrm{H}_{2} \mathrm{O}_{2}(30 w t \%)$ & N/A & $76 \%(4,6-\mathrm{DMDBT})$ & 24 & $<144$ & 207 \\
\hline SX-PLUS-Nox & & & & $100 \%(4,6-\mathrm{DMDBT})$ & & N/A & \\
\hline SX-PLUS-Sox & & & & $100 \%_{200}(4,6-\mathrm{DMDBT})$ & & $\mathrm{N} / \mathrm{A}$ & \\
\hline $\mathrm{g}-\mathrm{C}_{3} \mathrm{~N}_{4}$ nanomesh & 180 & $\mathrm{O}_{2}$ & N/A & $\sim 98 \%\left(\mathrm{H}_{2} \mathrm{~S}\right)$ & 4 & $>24$ & 210 \\
\hline $\mathrm{N}$-Doped g- $\mathrm{C}_{3} \mathrm{~N}_{4}$ & & & & $\sim 88 \%\left(\mathrm{H}_{2} \mathrm{~S}\right)$ & & $<16$ & \\
\hline Bulk g- $\mathrm{C}_{3} \mathrm{~N}_{4}$ & & & & $\sim 72 \%\left(\mathrm{H}_{2} \mathrm{~S}\right)$ & & $\mathrm{N} / \mathrm{A}$ & \\
\hline $\mathrm{g}-\mathrm{C}_{3} \mathrm{~N}_{4}$ nanosheet & 180 & $\mathrm{O}_{2}$ & N/A & $\sim 75 \%\left(\mathrm{H}_{2} \mathrm{~S}\right)$ & 4 & $>24$ & 211 \\
\hline Bulk g- $\mathrm{C}_{3} \mathrm{~N}_{4}$ & & & & $\sim 15 \%\left(\mathrm{H}_{2} \mathrm{~S}\right)$ & & $\mathrm{N} / \mathrm{A}$ & \\
\hline$g-\mathrm{C}_{3} \mathrm{~N}_{4}$ & 120 & $\mathrm{O}_{2}$ & $\mathrm{~N} / \mathrm{A}$ & $33.6 \%(4,6-\mathrm{DMDBT})$ & 2 & $\mathrm{~N} / \mathrm{A}$ & 212 \\
\hline $\mathrm{B}-\mathrm{C}_{3} \mathrm{~N}_{4}$ & & & & $94.1 \%(4,6-\mathrm{DMDBT})$ & & $>30$ & \\
\hline $\mathrm{B}-\mathrm{C}_{3} \mathrm{~N}_{4}$ & 125 & $\mathrm{O}_{2}$ & $\mathrm{~N} / \mathrm{A}$ & $98.2 \%(\mathrm{DBT})$ & 4 & $>40$ & 213 \\
\hline $\mathrm{BN}$ & & & & $64.5 \%(\mathrm{DBT})$ & & N/A & \\
\hline $\mathrm{BN}$ & 100 & $\mathrm{O}_{2}$ & N/A & $40 \%(\mathrm{DBT})$ & 6 & $\mathrm{~N} / \mathrm{A}$ & 214 \\
\hline B- $\mathrm{C}_{3} \mathrm{~N}_{4}$ nanosheet & & & & $100 \%(\mathrm{DBT})$ & & $>30$ & \\
\hline h-BN & 150 & $\mathrm{O}_{2}$ & $\mathrm{~N} / \mathrm{A}$ & $28 \%(\mathrm{DBT})$ & 1 & N/A & 215 \\
\hline h-BN nanosheet & & & & $98.8 \%(\mathrm{DBT})$ & & $>10$ & \\
\hline O-Doped BN & 125 & $\mathrm{O}_{2}$ & N/A & 15\% (DBT) & 6 & $\mathrm{~N} / \mathrm{A}$ & 219 \\
\hline $\mathrm{B}, \mathrm{N}$ vacancies $\mathrm{O}$-doped $\mathrm{BN}$ & & & & $100 \%(\mathrm{DBT})$ & & $>36$ & \\
\hline $\mathrm{Pt} / \mathrm{h}-\mathrm{BN}$ & 130 & $\mathrm{O}_{2}$ & $\mathrm{~N} / \mathrm{A}$ & $98.3 \%(\mathrm{DBT})$ & 6 & $>30$ & 220 \\
\hline $\mathrm{Pt} / \mathrm{BN}$ nanosheet & 110 & $\mathrm{O}_{2}$ & N/A & $22.7 \%(\mathrm{DBT})$ & 7 & $\mathrm{~N} / \mathrm{A}$ & 221 \\
\hline $\mathrm{PtCu} /$ commercial BN & & & & $51.7 \%(\mathrm{DBT})$ & & $\mathrm{N} / \mathrm{A}$ & \\
\hline $\mathrm{PtCu} / \mathrm{BN}$ nanosheet & & & & 96.1\% (DBT) & & $>63$ & \\
\hline
\end{tabular}

BN: boron nitride; WHSV: weight hourly space velocity; GO: graphene oxide; GO/COOH: acetic acid moiety modified graphene oxide; CB: carbon black; AC: activated carbon; rGO: reduced graphene oxide; CNTs: carbon nanotubes [Omim] $\mathrm{PF}_{6}$ : 1-methyl-3-octylimidazolium hexafluorophosphate; SX-PLUS: commercial activated carbon; g- $\mathrm{C}_{3} \mathrm{~N}_{4}$ : graphitic carbon nitride; $\mathrm{B}^{-} \mathrm{C}_{3} \mathrm{~N}_{4}$ : boron-doped carbon nitride; h-BN: hexagonal boron nitride.

CB of $\mathrm{TiO}_{2}$ to reduce $\mathrm{H}_{2} \mathrm{O}_{2}$ into hydroxyl radicals for the oxidation of DBT. Eventually, $\mathrm{TiO}_{2} / \mathrm{g}-\mathrm{C}_{3} \mathrm{~N}_{4}$ brought about $98.9 \%$ DBT removal in $2 \mathrm{~h}$. Zhang's research group supported $\mathrm{TiO}_{2}$ on rGO via hydrothermal approach to fabricate sheet structured nanocomposites. ${ }^{229}$ The absence of $\mathrm{TiO}_{2}$ agglomeration (Fig. 20f) was ascribed to the strong interactions between $\mathrm{TiO}_{2}$ and rGO which inhibited the attraction between $\mathrm{TiO}_{2}$ nanoparticles as a result of their high surface energy. Under light irradiation, $\mathrm{TiO}_{2} /$ rGO achieved up to $94.3 \%$ Th conversion with $\mathrm{H}_{2} \mathrm{O}_{2}$ in $100 \mathrm{~min}$, a markedly higher value than that of pristine $\mathrm{TiO}_{2}$ (40\%) (Fig. 20g). Similar to g- $\mathrm{C}_{3} \mathrm{~N}_{4}$, the high electron mobility in rGO accelerated the migration of activated electrons from $\mathrm{TiO}_{2}$ to the rGO surface, suppressing the electron-hole recombination. Hence, the coupling of $\mathrm{TiO}_{2}$ with carbon materials as a photocatalyst not only overcomes the limited surface area issue, but also enhances the electronic property for excellent charge migration.

In another work, Zarrabi et al. employed a non-metal dopant and support to enhance the performance of $\mathrm{TiO}_{2}$ in light-driven
ODS. ${ }^{50}$ Notably, the doping of carbon intensified the visible light absorption and reduced the band gap of $\mathrm{TiO}_{2}$ by creating an interband between $\mathrm{CB}$ and VB (Fig. 20h) to reinforce the electron-hole separation. Impregnation on mesoporous MCM-41 also resolved the low specific surface area in $\mathrm{TiO}_{2}$. With these improvements, the obtained catalyst removed 95.6\% of DBT without oxidants in $5 \mathrm{~h}$. To discover how the oxidation of DBT can work without oxidants, the authors carried out experiments with several radical scavengers. The results elucidated that hydroxyl radicals and superoxide radicals produced by the breakdown of hydroxyl groups, $\mathrm{H}_{2} \mathrm{O}$ and $\mathrm{O}_{2}$ on the surface of the catalyst were the major source of oxygen for the ODS process. Likewise, Guo et al. modified $\mathrm{TiO}_{2}$ with organic dye 2,9-dichloroquinacridone (DCQ) and embedded it in SBA-15 molecular sieve through an impregnation-calcination technique to enhance its photoactivity in a biphasic ODS system. ${ }^{230}$ Owing to the sensitization of $\mathrm{TiO}_{2}$ by DCQ, the optical property in the visible light region was substantially strengthened 

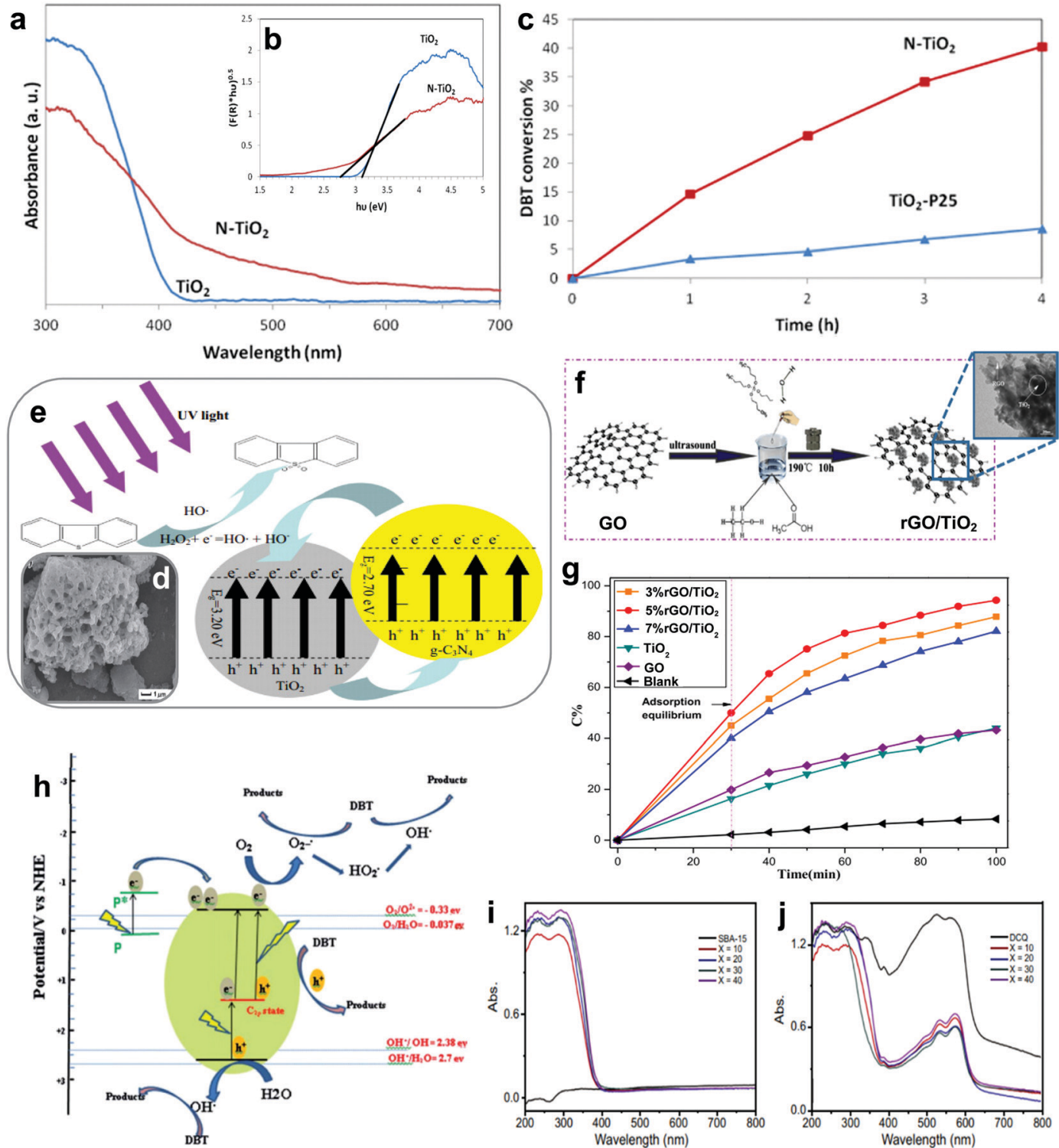

Fig. 20 (a) UV-Vis diffusion reflection spectra, (b) Kubelka-Munk function plot and (c) DBT conversion of $\mathrm{N}$-doped $\mathrm{TiO}_{2}$ and $\mathrm{TiO}_{2}$. Reprinted with permission. ${ }^{227}$ Copyright 2016, Elsevier Ltd. (d) SEM image of $\mathrm{TiO}_{2} / \mathrm{g}-\mathrm{C}_{3} \mathrm{~N}_{4}$ and (e) mechanism for DBT oxidation with $\mathrm{H}_{2} \mathrm{O}_{2}$. Reproduced with permission. 228 Copyright 2014, Elsevier Ltd. (f) Synthesis route of $\mathrm{rGO}^{2} / \mathrm{TiO}_{2}$ and (g) sulfur removal of $\mathrm{rGO} / \mathrm{TiO}_{2}$ with $3 \%, 5 \%$ and $7 \% \mathrm{rGO}, \mathrm{TiO}$, GO and a blank with $\mathrm{O}_{2}$ and $\mathrm{H}_{2} \mathrm{O}_{2}$. Reproduced with permission. ${ }^{229}$ Copyright 2019, Elsevier Inc. (h) Proposed mechanism of photo-driven ODS for C-doped TiO $\mathrm{O}_{2} /$ MCM-41 without oxidants. Reprinted with permission. ${ }^{50}$ Copyright 2015, Royal Society of Chemistry. UV-Vis diffusion reflection spectra of (i) SBA-15, $X \% \mathrm{TiO}_{2} / \mathrm{SBA}-15$ and (j) $\mathrm{DCQ}$ and $\mathrm{DCQ}-X \% \mathrm{TiO}_{2} / \mathrm{SBA}-15(X=10,20,30,40)$. Reprinted with permission. ${ }^{230}$ Copyright 2020 , Elsevier B.V.

(Fig. 20i and j), leading to better light absorption for the excitation of electrons. With abundant light absorption sites, DCQ-TiO $/$ /SBA-15 degraded $96.1 \%$ of DBT with $\mathrm{H}_{2} \mathrm{O}_{2}$ as oxidant within $90 \mathrm{~min}$. Hitam et al. developed ZnO on fibrous nanosilica KCC-1 via in situ microwave-assisted hydrothermal (HM) and impregnation (IM) methods to reveal the influence of the synthesis method on the catalyst properties. ${ }^{231}$ With respect to textural properties, $\mathrm{HM}$ enabled a higher dispersion of $\mathrm{ZnO}$ on KCC-1 than IM due to the generation of stronger interactions between $\mathrm{ZnO}$ and KCC-1 during the process. This was confirmed by the lower ZnO XRD intensity peaks in ZnO/KCC1(HM) (Fig. 21a), which indicated a lower concentration of $\mathrm{ZnO}$ on the surface of KCC-1. Moreover, the larger specific surface area and pore volume in $\mathrm{ZnO} / \mathrm{KCC}-1$ (IM), stemming from the poor anchoring of $\mathrm{ZnO}$, also evidenced this fact. With its auspicious structural properties, $\mathrm{ZnO} / \mathrm{KCC}-1(\mathrm{HM})$ achieved higher DBT conversion (88.9\%) in 60 min upon light irradiation due to the existence of more $\mathrm{ZnO}$ as light capturing sites. Therefore, the application of HM for immobilizing metal oxide on silica nanoparticles can crucially endow a morphological advantage for nanocomposites, leading to the enhancement of photocatalytic activity in ODS. Overall, the above reports signified that silica nanoparticles play a decisive role by supplying a massive surface area for the immobilization of metal oxides 

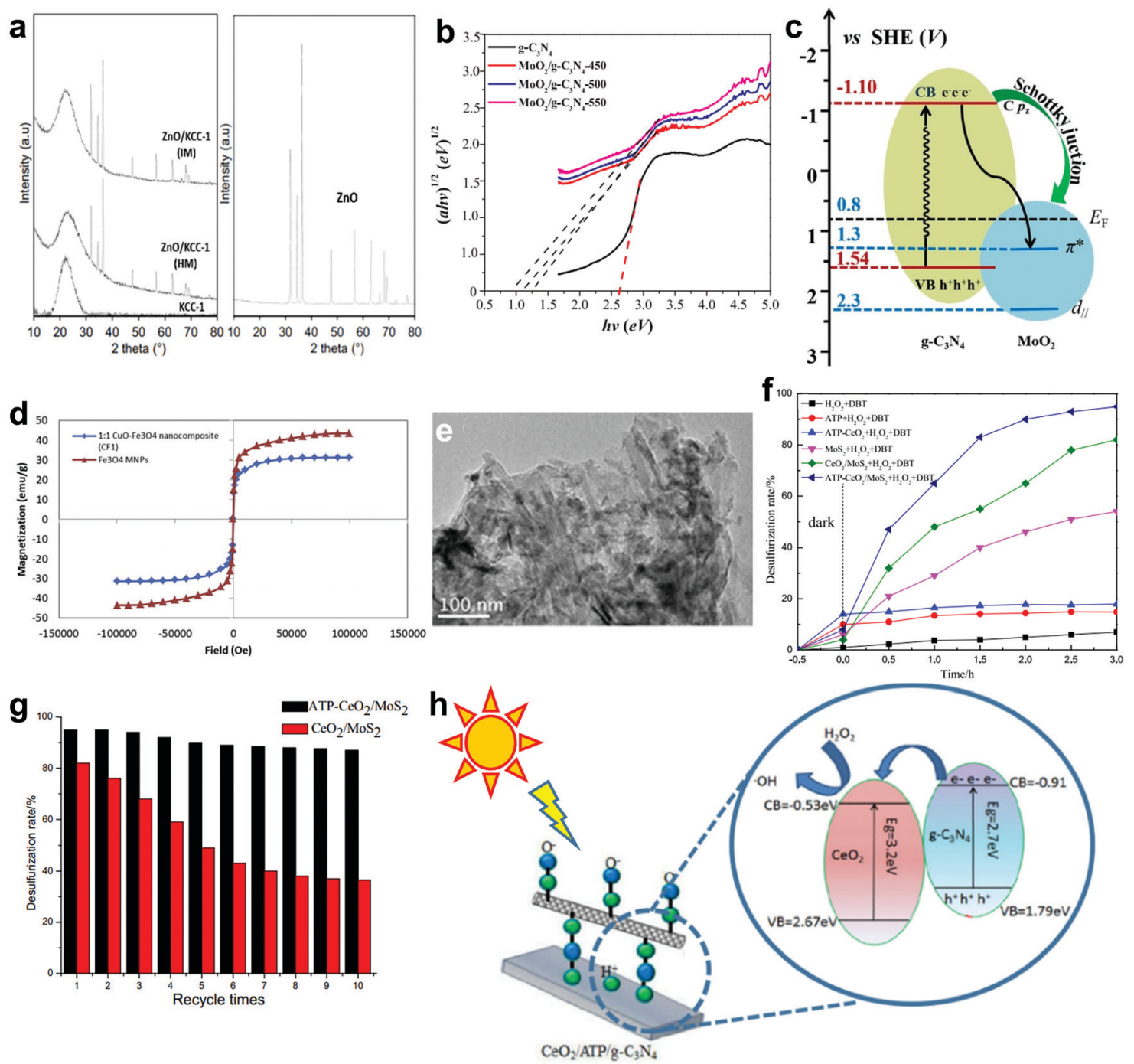

Fig. 21 (a) XRD spectra of ZnO/KCC-1(IM), ZnO/KCC-1(HM), KCC-1 and ZnO. Reprinted with permission. ${ }^{231}$ Copyright 2020, Springer Nature. (b) Graph of $(a h v)_{1 / 2}$ versus photon energy for $\mathrm{g}-\mathrm{C}_{3} \mathrm{~N}_{4}$ and $\mathrm{MoO}_{2} / \mathrm{g}-\mathrm{C}_{3} \mathrm{~N}_{4}$ with different synthesis temperatures. (c) Electronic structure of $\mathrm{MoO}_{2} / \mathrm{g}-\mathrm{C}_{3} \mathrm{~N}_{4}$ with the electron movement. Reprinted with permission. ${ }^{232}$ Copyright 2018, Elsevier B.V. (d) Magnetic hysteresis loops of $\mathrm{CuO}_{-} \mathrm{Fe}_{3} \mathrm{O}_{4}$ and $\mathrm{Fe}_{3} \mathrm{O}_{4}$. Reprinted with permission. ${ }^{233}$ Copyright 2018, Elsevier Ltd. (e) TEM image of ATP- $\mathrm{CeO}_{2} / \mathrm{MoS}_{2}$ ( f) DBT oxidation of various catalysts and (g) the recyclability test for ATP$\mathrm{CeO}_{2} / \mathrm{MoS}_{2}$ and $\mathrm{CeO}_{2} / \mathrm{MoS}_{2}$ using $\mathrm{H}_{2} \mathrm{O}_{2}$. Reprinted with permission. ${ }^{235}$ Copyright 2016, Elsevier B.V. (h) Reaction pathway of photocatalytic ODS using ATP- $-\mathrm{CeO}_{2} / \mathrm{g}-\mathrm{C}_{3} \mathrm{~N}_{4}$ and $\mathrm{H}_{2} \mathrm{O}_{2}$ under visible light irradiation. Reproduced with permission. ${ }^{237}$ Copyright 2017, Elsevier B.V.

rather than being involved in the light-driven ODS because of their broad band gap and weak light-harvesting property.

Recently, Chen et al. investigated the electronic structure of $\mathrm{MoO}_{2} / \mathrm{g}-\mathrm{C}_{3} \mathrm{~N}_{4}$ synthesized by impregnation method. ${ }^{232}$ The decrease of the band gap (Fig. 21b) after the immobilization of $\mathrm{MoO}_{2}$ implied the establishment of a heterojunction structure in $\mathrm{MoO}_{2} / \mathrm{g}-\mathrm{C}_{3} \mathrm{~N}_{4}$. The unmatched band gap promoted the movement of excited electrons from $\mathrm{g}-\mathrm{C}_{3} \mathrm{~N}_{4}$ to $\mathrm{MoO}_{2}$ (Fig. 21c) and resulted in rapid charge carrier separation. Although the authors did not examine the photocatalytic activity of $\mathrm{MoO}_{2} /$ g- $\mathrm{C}_{3} \mathrm{~N}_{4}$ in ODS, the discovery of the remarkable light-harvesting property of $\mathrm{MoO}_{2} / \mathrm{g}-\mathrm{C}_{3} \mathrm{~N}_{4}$ sheds new light on its potential to be a promising photocatalyst in the coming years. For easy catalyst recovery, light-responsive $\mathrm{CuO}$ was coupled with magnetic $\mathrm{Fe}_{3} \mathrm{O}_{4}$ via impregnation method in the work of Ammar et al. ${ }^{233}$
As anticipated, the $\mathrm{CuO}-\mathrm{Fe}_{3} \mathrm{O}_{4}$ nanomaterial inherited the magnetic property of the parent $\mathrm{Fe}_{3} \mathrm{O}_{4}$ with negligible loss of magnetization, as detected by magnetometer (Fig. 21d). Thanks to its strong photoactivity and intrinsic DBT adsorption ability, CuO- $\mathrm{Fe}_{3} \mathrm{O}_{4}$ converted $95 \%$ of DBT into DBT sulfone with $\mathrm{H}_{2} \mathrm{O}_{2}$ after $2 \mathrm{~h}$. This study successfully lays the groundwork for future research into the magnetization of nanomaterials to substitute for the cumbersome and environmentally unfriendly chemical extraction methods in ODS for separating the spent catalyst from fuels.

The rare-earth metal oxide $\mathrm{CeO}_{2}$, with semiconductor properties analogous to $\mathrm{TiO}_{2}$, has emerged as an alternative for traditional metal oxides in the photocatalytic decomposition of organic pollutants. ${ }^{234}$ In this context, Li and co-workers developed a ternary $\mathrm{CeO}_{2}$-based composite $\left(\mathrm{ATP}-\mathrm{CeO}_{2} / \mathrm{MoS}_{2}\right)$ 
by microwave assisted hydrothermal route to unravel its activity in light-driven ODS. ${ }^{235}$ Through hybridization with 2D structured molybdenum disulfide $\left(\mathrm{MoS}_{2}\right)$, the undesirable rapid electron-hole recombination in pristine $\mathrm{CeO}_{2}$ was addressed. Furthermore, attributed to the support of the 1D needlestructured attapulgite (ATP) with robust surface area, $\mathrm{CeO}_{2}$ was homogenously distributed in the micropores of ATP (Fig. 21e), prompting the increment of both active sites and thermal mechanical stability. Despite the fact that ATP does not possess any photocatalytic activity, its amazing adsorption tendency facilitated the interaction between DBT and oxygen radicals by gathering them within the catalyst pores. ${ }^{236}$ Gaining from the above modifications, ATP- $\mathrm{CeO}_{2} / \mathrm{MoS}_{2}$ oxidized $98 \%$ of DBT with $\mathrm{H}_{2} \mathrm{O}_{2}$ in $3 \mathrm{~h}$ (Fig. 21f) and demonstrated excellent reusability for ten cycles in contrast to $\mathrm{CeO}_{2} / \mathrm{MoS}_{2}$ (Fig. 21g). A similar synergistic effect and remarkable performance in ODS was described in another work of Li et al., wherein the $\mathrm{MoS}_{2}$ support was substituted by metal-free $\mathrm{g}-\mathrm{C}_{3} \mathrm{~N}_{4}$ through an identical synthesis method. ${ }^{237}$ In regard to the structure-activity interaction, the photocatalytic route in ODS using ATP-CeO $/ g-\mathrm{C}_{3} \mathrm{~N}_{4}$ is illustrated in Fig. 21h. As g- $\mathrm{C}_{3} \mathrm{~N}_{4}$ exhibited a narrower band gap compared to $\mathrm{CeO}_{2}, \mathrm{~g}-\mathrm{C}_{3} \mathrm{~N}_{4}$ served as the engine to initiate the oxidation process upon visible light irradiation, whereas $\mathrm{CeO}_{2}$ played the roles of storage for the excited electrons and the site for $\mathrm{H}_{2} \mathrm{O}_{2}$ degradation. Notably, $\mathrm{CeO}_{2}$ is unable to perform photocatalysis alone due to its huge band gap and, hence, a semiconductor with outstanding light-responsive property is imperative for forming a heterojunction structure with $\mathrm{CeO}_{2}$ to accomplish excellent sulfur removal in ODS.

Most recently, $\mathrm{BiVO}_{4}$ was supported on bentonite (BTT) and coupled with $\mathrm{CuO}$ to impede the agglomeration of $\mathrm{BiVO}_{4}$ nanoparticles and enhance the photocatalytic activity in ODS. $^{238}$ Upon $3.5 \mathrm{~h}$ of visible light irradiation, CuO-BiVO 4 BTT achieved 91.3\% DBT oxidation, which was far higher than pristine $\mathrm{BiVO}_{4}$ and $\mathrm{BiVO}_{4} / \mathrm{BTT}$. The notable activity improvement was ascribed to the uniform dispersion of $\mathrm{BiVO}_{4}$ on BTT which enormously elevated the exposure of active sites for ODS. Moreover, the formation of a $\mathrm{p}-\mathrm{n}$ heterojunction by $\mathrm{BiVO}_{4}$ and $\mathrm{CuO}$ efficiently promoted the separation of charge carriers and resulted in a higher rate of ODS (Fig. 22a). The photoexcited electrons were transferred from $\mathrm{CuO}$ to $\mathrm{BiVO}_{4}$ for the activation of $\mathrm{O}_{2}$, while the generated holes in $\mathrm{BiVO}_{4}$ were transported across the interface to $\mathrm{CuO}$ for the oxidation of aromatic sulfur compounds. Aside from introducing a support, the fact that sonication is able to address the agglomeration issue during the synthesis of $\mathrm{Cu}_{2} \mathrm{O}-\mathrm{CeO}_{2}$ nanocomposites has been discovered recently. ${ }^{239}$ With the presence of a powerful ultrasonic field, $\mathrm{Cu}_{2} \mathrm{O}$ was created instead of $\mathrm{CuO}$, due to the reduction of $\mathrm{Cu}^{2+}$ ions to $\mathrm{Cu}^{+}$, and possessed a better light-harvesting property within the visible light range. Moreover, the ultrasound radiation also incurred the shrinkage of $\mathrm{Cu}_{2} \mathrm{O}-\mathrm{CeO}_{2}$ particles, leading to smaller particle sizes (Fig. 22b) than those of $\mathrm{CuO}-\mathrm{CeO}_{2}$ (Fig. 22c) and hence escalating the number of surface active sites. Meanwhile, the heterojunction of $\mathrm{Cu}_{2} \mathrm{O}$ and $\mathrm{CeO}_{2}$ also significantly hindered the swift electron-hole recombination and promoted the oxidation of sulfur compounds.
Benefitting from the synergistic effect, $\mathrm{Cu}_{2} \mathrm{O}-\mathrm{CeO}_{2}$ achieved a higher desulfurization efficiency (84\%) than $\mathrm{CuO}-\mathrm{CeO}_{2}(39 \%)$ under identical reaction conditions. Collectively, this research has revealed the feasibility of the sonochemical approach to fabricate nanocomposites with auspicious morphologies to enhance the photocatalytic activity in ODS.

\subsection{Metal-free nanomaterial-based photocatalysts}

From an economic and environmental point of view, metal-free nanomaterials, like $\mathrm{g}-\mathrm{C}_{3} \mathrm{~N}_{4}$ with its moderate band gap and considerable visible light absorption ${ }^{240-243}$ and GO with its plentiful oxygen-containing groups and tunable electrical properties, ${ }^{244}$ have been employed as emerging nanomaterials in photocatalysis. Besides supporting metallic nanomaterials, mesoporous $\mathrm{g}-\mathrm{C}_{3} \mathrm{~N}_{4}$ was applied as the photocatalyst to desulfurize stimulated fuel in the presence of $\mathrm{O}_{2}$ and visible light. ${ }^{245}$ Marvelously, g- $\mathrm{C}_{3} \mathrm{~N}_{4}$ oxidized all the DBT within $90 \mathrm{~min}$. This was ascribed to its enormous film-structured surface (Fig. 22d) and appropriate band gap for redox reactions. However, its poor resistance against irreversible deactivation due to the blockage of active sites by aromatic sulfur constituents substantially curtailed the reusability of $\mathrm{g}-\mathrm{C}_{3} \mathrm{~N}_{4}$, leading to a drastic reduction of sulfur removal efficiency starting from the second run (Fig. 22e). To bolster the robustness of g- $\mathrm{C}_{3} \mathrm{~N}_{4}$, Zhang's team grafted sodium into g- $\mathrm{C}_{3} \mathrm{~N}_{4}$ through simple mixing followed by calcination to form $\mathrm{Na} / \mathrm{g}-\mathrm{C}_{3} \mathrm{~N}_{4}$ composites. ${ }^{246}$ According to Fig. 22f, the reduction of $\mathrm{XRD}$ intensities resulted from the increase of $\mathrm{Na}$ loading, which prompted the formation of defect sites in the morphology of $\mathrm{g}-\mathrm{C}_{3} \mathrm{~N}_{4}$. Furthermore, the doping of $\mathrm{Na}$ promoted the preservation of electrons and holes, as confirmed by the lower photoluminescence peak intensity in $\mathrm{Na} / \mathrm{g}$ $\mathrm{C}_{3} \mathrm{~N}_{4}$ (Fig. 22g). With these improvements, the Th removal efficiency using $\mathrm{Na} / \mathrm{g}-\mathrm{C}_{3} \mathrm{~N}_{4}$ increased spectacularly upon light illumination compared to that using g- $\mathrm{C}_{3} \mathrm{~N}_{4}$ (Fig. 22h). Relatedly, the photoactivity of GO and its reaction mechanism in light-driven ODS were studied comprehensively by Zeng et al. ${ }^{247}$ Using DFT computations, the authors proposed the role of defect sites and the zigzag edge as electron suppliers for the generation of reactive oxygen species from $\mathrm{O}_{2}$, hydrogen ions and oxygen-containing functional groups on the surface of GO. With the help of acetonitrile, the transfer of DBT compounds from the organic phase to the polar phase compelled the interaction between oxygen radicals and DBT, resulting in 99.9\% DBT conversion under UV irradiation. Despite the exceptional photocatalytic activity demonstrated by metal-free materials, the salient challenges like poor reusability and sluggish reaction kinetics still remain.

\subsection{Layered double hydroxide (LDH)}

Over the past few years, layered double hydroxide (LDH) has gained copious attention in the field of photocatalysis for its unique 2D-layered structure, remarkable light-capturing ability and tailorable band gap. ${ }^{248}$ Huang et al. hybridized $\mathrm{ZnAl-}$ and $\mathrm{ZnCr}-\mathrm{LDH}$ with $\mathrm{g}-\mathrm{C}_{3} \mathrm{~N}_{4}$ nanosheets through an electrostatic selfassembly approach to establish a Z-scheme heterojunction to improve the efficiency in light-driven ODS. ${ }^{249}$ The Z-scheme 

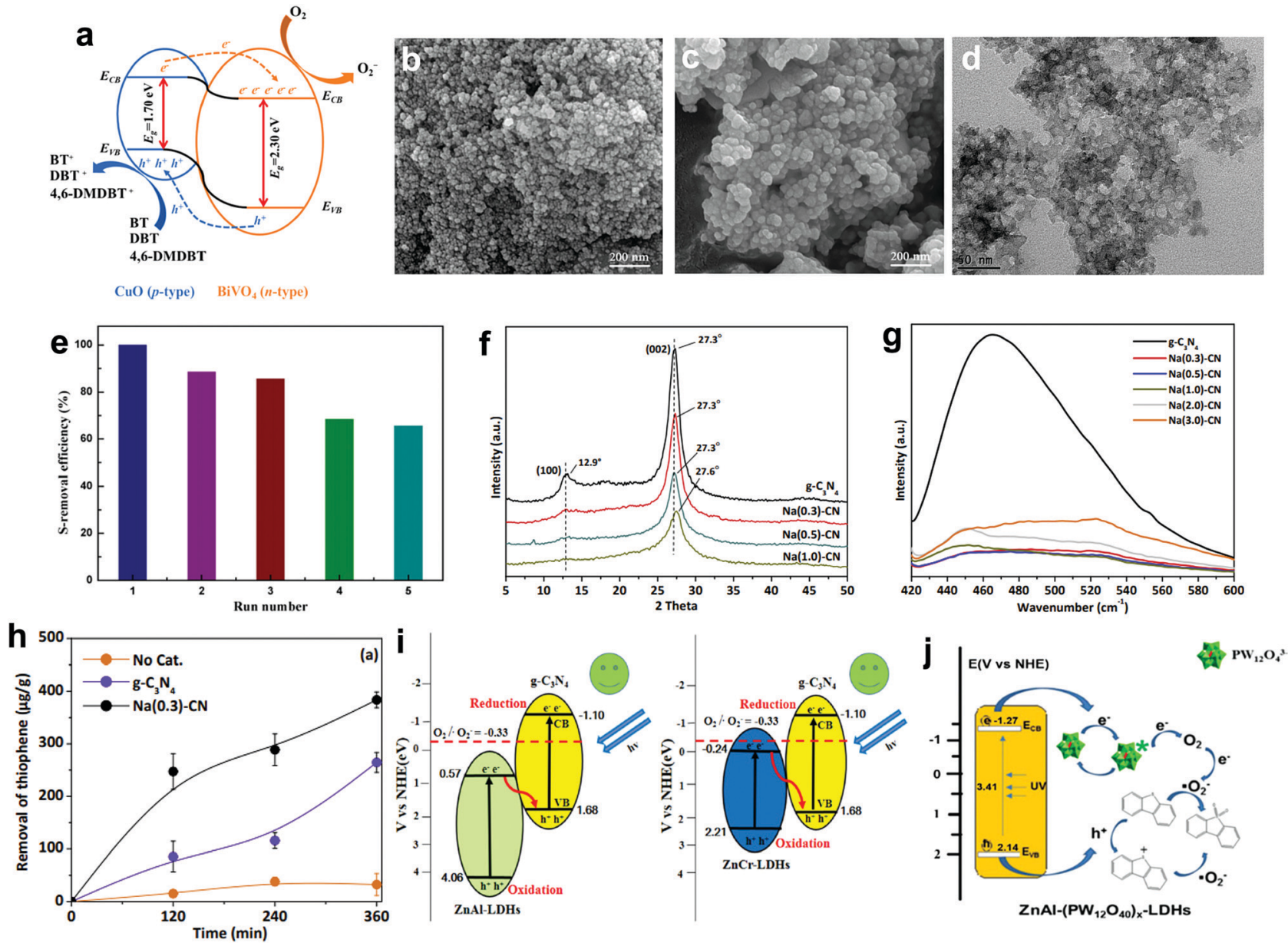

Fig. 22 (a) Plausible reaction pathway of photocatalytic ODS using $\mathrm{CuO}-\mathrm{BiVO}_{4} / \mathrm{BTT}$ in the presence of $\mathrm{O}_{2}$. Reprinted with the permission. ${ }^{238} \mathrm{Copyright}$ 2021, Elsevier Ltd. SEM images of (b) $\mathrm{Cu}_{2} \mathrm{O}-\mathrm{CeO}_{2}$ and (c) $\mathrm{CuO}-\mathrm{CeO}_{2}$. Reprinted with permission. ${ }^{239}$ Copyright 2020, Elsevier B.V. (d) TEM image and (e) the DBT removal efficiency for five runs at $1.5 \mathrm{~h}$ per run using $\mathrm{g}-\mathrm{C}_{3} \mathrm{~N}_{4}$ and $\mathrm{O}_{2}$ via light-driven ODS. Reprinted with permission. ${ }^{245}$ Copyright 2016 , Elsevier B.V. (f) XRD spectra and (g) photoluminescence of $\mathrm{g}-\mathrm{C}_{3} \mathrm{~N}_{4}$ and $\mathrm{Na}(X) / \mathrm{g}-\mathrm{C}_{3} \mathrm{~N}_{4}(X=0.3 \mathrm{M}, 0.5 \mathrm{M}, 1.0 \mathrm{M})$. (h) Th removal of $\mathrm{g}-\mathrm{C}_{3} \mathrm{~N}_{4}$ and $\mathrm{Na}(0.3) / \mathrm{g}-\mathrm{C}_{3} \mathrm{~N}_{4}$ in the presence of $\mathrm{O}_{2}$ under light irradiation. Reprinted with permission. ${ }^{246}$ Copyright 2019, Elsevier B.V. (i) Reaction route for light-driven ODS using ZnAl$\mathrm{LDH} / \mathrm{g}-\mathrm{C}_{3} \mathrm{~N}_{4}$ (left) and $\mathrm{ZnCr}-\mathrm{LDH} / \mathrm{g}-\mathrm{C}_{3} \mathrm{~N}_{4}$ (right). Reprinted with permission. ${ }^{249}$ Copyright 2020. American Chemical Society. (j) Photocatalytic conversion of DBT by $\mathrm{ZnAl}-\left(\mathrm{PW}_{12} \mathrm{O}_{40}\right)_{x}-\mathrm{LDH}$ in the presence of $\mathrm{O}_{2}$. Reprinted with permission. ${ }^{250}$ Copyright 2018 , Royal Society of Chemistry.

heterojunction recombined excited electrons from $\mathrm{LDH}$ and holes from $\mathrm{g}-\mathrm{C}_{3} \mathrm{~N}_{4}$, preserving the free reactive electrons and holes in the $\mathrm{CB}$ of $\mathrm{g}-\mathrm{C}_{3} \mathrm{~N}_{4}$ and the $\mathrm{VB}$ of $\mathrm{LDH}$, respectively, for redox reactions, which was greatly conducive to the ODS reaction rate (Fig. 22i). From the perspective of textural properties, $\mathrm{ZnCr}-\mathrm{LDH} / \mathrm{g}-\mathrm{C}_{3} \mathrm{~N}_{4}$ demonstrated comparably more severe aggregation than $\mathrm{ZnAl} / \mathrm{g}-\mathrm{C}_{3} \mathrm{~N}_{4}$. This phenomenon caused a slightly lower ODS activity in $\mathrm{ZnCr}-\mathrm{LDH} / \mathrm{g}-\mathrm{C}_{3} \mathrm{~N}_{4}$ (96.6\%) compared to $\mathrm{ZnAl}-\mathrm{LDH} / \mathrm{g}-\mathrm{C}_{3} \mathrm{~N}_{4}(99.8 \%)$ due to the emergence of fewer surface active sites. Cai et al. intercalated ZnAl-LDH with $\mathrm{PW}_{12} \mathrm{O}_{40}$ by exfoliation-reassembly method to enhance its photocatalytic activity in ODS. ${ }^{250}$ The robust interactions between $\mathrm{ZnAl}-\mathrm{LDH}$ and $\mathrm{PW}_{12} \mathrm{O}_{40}$ facilitated the electron transfer and electron-hole separation, which extended the lifetime of charge carriers. In the ODS process, $\mathrm{PW}_{12} \mathrm{O}_{40}$ acted as the excited electron storage site for the activation of $\mathrm{O}_{2}$ (Fig. 22j). As a result, $\mathrm{ZnAl}-\left(\mathrm{PW}_{12} \mathrm{O}_{40}\right)_{0.07}-\mathrm{LDH}$ converted $95.3 \%$ of DBT using $\mathrm{O}_{2}$ within $3 \mathrm{~h}$ of UV irradiation. To achieve an effortless photocatalyst recovery process, Masoumi and Hosseini fabricated magnetic $\mathrm{NiCo}_{2}-\mathrm{LDH} / \mathrm{Fe}_{3} \mathrm{O}_{4}$ and evaluated its photocatalytic performances in ODS. ${ }^{251}$ Advantageously, the anchoring of $\mathrm{NiCo}_{2}-\mathrm{LDH}$ on $\mathrm{Fe}_{3} \mathrm{O}_{4}$ contributed to a significant increment of specific surface area as well as comparably minor agglomeration. The higher number of surface catalytic sites brought about $74.6 \%$ DBT conversion in the presence of $\mathrm{O}_{2}$. These studies manifested LDH photocatalyst as an excellent candidate to catalyze light-driven ODS.

In summary, through doping and introducing heterojunctions, the performances of photocatalysts in ODS can be greatly enhanced by the improvement of charge carrier separation, light absorption range and light-capturing sites. Crucially, the previous studies are just the tip of iceberg, as only a few species of nanomaterials have been applied in light-driven ODS. Indeed, it is highly valuable to explore new nanomaterials with light-harvesting property to create a breakthrough in the efficiency of ODS using photon energy. Table 7 illustrates the 
Table 7 Representative summary of the performances of photocatalysts in light-driven ODS

\begin{tabular}{|c|c|c|c|c|c|c|c|}
\hline \multirow[b]{2}{*}{ Catalysts } & \multirow[b]{2}{*}{$\begin{array}{l}\text { Light source } \\
\text { (power) }\end{array}$} & \multirow[b]{2}{*}{ Oxidant } & \multirow[b]{2}{*}{ Extractant } & \multicolumn{3}{|l|}{ Performances } & \multirow[b]{2}{*}{ Ref. } \\
\hline & & & & $\begin{array}{l}\text { Sulfur removal } \\
\text { (reactant) }\end{array}$ & $\begin{array}{l}\text { Reaction } \\
\text { time }(\mathrm{h})\end{array}$ & $\begin{array}{l}\text { Stability } \\
\text { (h) }\end{array}$ & \\
\hline $\mathrm{TiO}_{2}$ & Hg lamp (250 W) & $\mathrm{H}_{2} \mathrm{O}_{2}(30 w t \%)$ & N/A & $65.2 \%(\mathrm{BT})$ & 2 & N/A & 224 \\
\hline $\mathrm{TiO}_{2}$ & Hg-Xe lamp (200 W) & $\mathrm{H}_{2} \mathrm{O}_{2}(30 w t \%)$ & Acetonitrile & $<40 \%(\mathrm{DBT})$ & 10 & N/A & 225 \\
\hline $\mathrm{TiO}_{2}$ & Xe lamp $(55 \mathrm{~W})$ & $\mathrm{O}_{2}$ & N/A & $8.6 \%(\mathrm{DBT})$ & 4 & $\mathrm{~N} / \mathrm{A}$ & 227 \\
\hline $\mathrm{N}$-Doped $\mathrm{TiO}_{2}$ & & & & $40.3 \%(\mathrm{DBT})$ & & $>12$ & \\
\hline $\mathrm{TiO}_{2}$ & Hg lamp (250 W) & $\mathrm{H}_{2} \mathrm{O}_{2}(30 \mathrm{wt} \%)$ & $\mathrm{N} / \mathrm{A}$ & $79.1 \%(\mathrm{DBT})$ & 2 & $\mathrm{~N} / \mathrm{A}$ & 228 \\
\hline $\mathrm{g}-\mathrm{C}_{3} \mathrm{~N}_{4}$ & & & & $1.3 \%(\mathrm{DBT})$ & & N/A & \\
\hline $\mathrm{TiO}_{2} / \mathrm{g}-\mathrm{C}_{3} \mathrm{~N}_{4}$ & & & & 98.9\% (DBT) & & $>8$ & \\
\hline $\mathrm{TiO}_{2}$ & Xe lamp & $\mathrm{H}_{2} \mathrm{O}_{2}(30 w \mathrm{t} \%)$ & $\mathrm{N} / \mathrm{A}$ & $42 \%(\mathrm{Th})$ & 1.67 & N/A & 229 \\
\hline $\mathrm{GO}$ & & & & $42 \%(\mathrm{Th})$ & & & \\
\hline $\mathrm{TiO}_{2} / \mathrm{rGO}$ & & & & $94.3 \%(\mathrm{Th})$ & & & \\
\hline $\mathrm{TiO}_{2} / \mathrm{SBA}-15$ & Xe lamp (300 W) & $\mathrm{H}_{2} \mathrm{O}_{2}(30 \mathrm{wt} \%)$ & Acetonitrile & 86\% (DBT) & 1.5 & N/A & 230 \\
\hline $\mathrm{DCQ}^{-\mathrm{TiO}_{2}} / \mathrm{SBA}-15$ & & & & 96.1\% (DBT) & & & \\
\hline $\mathrm{C} / \mathrm{TiO}_{2} / \mathrm{MCM}-41$ & W lamp (300 W) & $\mathrm{O}_{2}$ & N/A & $95.6 \%(\mathrm{DBT})$ & 5 & $>10$ & 50 \\
\hline $\mathrm{ZnO}$ & Halide lamp $(160 \mathrm{~W})$ & $\mathrm{O}_{2}$ & Acetonitrile & $44.4 \%$ (DBT) & 1 & N/A & 231 \\
\hline KCC-1 & & & & $53.9 \%(\mathrm{DBT})$ & & & \\
\hline $\mathrm{ZnO} / \mathrm{KCC}-1$ & & & & $88.9 \%(\mathrm{DBT})$ & & & \\
\hline $\mathrm{CuO}-\mathrm{Fe}_{3} \mathrm{O}_{4}$ & Hg lamp (350 W) & $\mathrm{H}_{2} \mathrm{O}_{2}(30 w t \%)$ & N/A & $95.2 \%(\mathrm{DBT})$ & 2 & $>10$ & 233 \\
\hline $\mathrm{CeO}_{2} / \mathrm{MoS}_{2}$ & Xe lamp $(300 \mathrm{~W})$ & $\mathrm{H}_{2} \mathrm{O}_{2}(30 w t \%)$ & Acetonitrile & $82 \%(\mathrm{DBT})$ & 3 & $<9$ & 235 \\
\hline $\mathrm{ATP}-\mathrm{CeO}_{2} / \mathrm{MoS}_{2}$ & & & & $98 \%(\mathrm{DBT})$ & & $>30$ & \\
\hline$g-\mathrm{C}_{3} \mathrm{~N}_{4}$ & Xe lamp $(300 \mathrm{~W})$ & $\mathrm{H}_{2} \mathrm{O}_{2}(30 w t \%)$ & $\mathrm{N} / \mathrm{A}$ & $42 \%(\mathrm{DBT})$ & 3 & N/A & 237 \\
\hline $\mathrm{CeO}_{2} / \mathrm{g}-\mathrm{C}_{3} \mathrm{~N}_{4}$ & & & & $83 \%(\mathrm{DBT})$ & & $<21$ & \\
\hline ATP-CeO ${ }_{2} / g-\mathrm{C}_{3} \mathrm{~N}_{4}$ & & & & $98 \%(\mathrm{DBT})$ & & $>24$ & \\
\hline $\mathrm{mpg}-\mathrm{C}_{3} \mathrm{~N}_{4}$ & Xe lamp $(300 \mathrm{~W})$ & $\mathrm{O}_{2}$ & $\mathrm{~N} / \mathrm{A}$ & $100 \%(\mathrm{DBT})$ & 1.5 & $<7.33$ & 245 \\
\hline $\mathrm{g}-\mathrm{C}_{3} \mathrm{~N}_{4}$ nanosheet & Xe lamp $(300 \mathrm{~W})$ & $\mathrm{O}_{2}$ & $\mathrm{~N} / \mathrm{A}$ & $52 \%(\mathrm{Th})$ & 6 & $\mathrm{~N} / \mathrm{A}$ & 246 \\
\hline $\begin{array}{l}\text { Na-Doped g- } \mathrm{C}_{3} \mathrm{~N}_{4} \\
\text { nanosheet }\end{array}$ & & & & $92.3 \%(\mathrm{Th})$ & & $>24$ & \\
\hline $\mathrm{GO}$ & Hg lamp (100 W) & $\mathrm{O}_{2}$ & $\begin{array}{l}\text { Acetonitrile } \\
\text { Formic acid }\end{array}$ & 99.9\% (DBT) & 2.33 & $<9.33$ & 247 \\
\hline $\mathrm{Ti}_{3} \mathrm{C}_{2}$ MXene & Xe lamp $(300 \mathrm{~W})$ & $\mathrm{O}_{2}$ & N/A & $29.6 \%(\mathrm{Th})$ & 3 & N/A & 252 \\
\hline$g-\mathrm{C}_{3} \mathrm{~N}_{4}$ & & & & $36.4 \%(\mathrm{Th})$ & & N/A & \\
\hline $\mathrm{Ti}_{3} \mathrm{C}_{2}$ MXene/g- $\mathrm{C}_{3} \mathrm{~N}_{4}$ & & & & $73.6 \%(\mathrm{Th})$ & & $>18$ & \\
\hline $\mathrm{BiVO}_{4}$ & W lamp (300 W) & $\mathrm{O}_{2}$ & N/A & 49.1\% (DBT) & 3.5 & $>35$ & 238 \\
\hline $\mathrm{BiVO}_{4} / \mathrm{BTT}$ & & & & $59.8 \%(\mathrm{DBT})$ & & $>35$ & \\
\hline CuO-BiVO 4 /bentonite & & & & $91.3 \%(\mathrm{DBT})$ & & $>35$ & \\
\hline $\mathrm{BiOCl}$ & Hg lamp (300 W) & $\mathrm{O}_{2}$ & Acetonitrile & 99.1\% (DBT) & 3 & $<18$ & 253 \\
\hline $\mathrm{CuO}-\mathrm{CeO}_{2}$ & Visible lamp (400 W) & $\mathrm{O}_{2}$ & DMF & $39 \%(\mathrm{Th})$ & 3 & N/A & 239 \\
\hline $\mathrm{Cu}_{2} \mathrm{O}-\mathrm{CeO}_{2}$ & & & & $84 \%(\mathrm{Th})$ & & $>12$ & \\
\hline $\mathrm{ZnAl}-\mathrm{LDH} / \mathrm{g}-\mathrm{C}_{3} \mathrm{~N}_{4}$ & Hg lamp (500 W) & $\mathrm{O}_{2}$ & Acetonitrile & $99.8 \%(\mathrm{DBT})$ & 3 & $>15$ & 249 \\
\hline $\mathrm{ZnCr}-\mathrm{LDH} / \mathrm{g}-\mathrm{C}_{3} \mathrm{~N}_{4}$ & & & & $96.6 \%(\mathrm{DBT})$ & & $>15$ & \\
\hline $\mathrm{ZnAl}-\mathrm{NO}_{3}-\mathrm{LDH}$ & Hg lamp (500 W) & $\mathrm{O}_{2}$ & Acetonitrile & $80.5 \%(\mathrm{DBT})$ & 3 & $\mathrm{~N} / \mathrm{A}$ & 250 \\
\hline $\mathrm{ZnAl}-\left(\mathrm{PW}_{12} \mathrm{O}_{40}\right)_{0.07}-\mathrm{LDH}$ & & & & $95.3 \%(\mathrm{DBT})$ & & $>15$ & \\
\hline $\mathrm{Ni}-\mathrm{Co}_{2}-\mathrm{LDH} / \mathrm{Fe}_{3} \mathrm{O}_{4}$ & W lamp (250 W) & $\mathrm{O}_{2}$ & $\mathrm{~N} / \mathrm{A}$ & $74.6 \%(\mathrm{DBT})$ & 3.7 & $\mathrm{~N} / \mathrm{A}$ & 251 \\
\hline
\end{tabular}

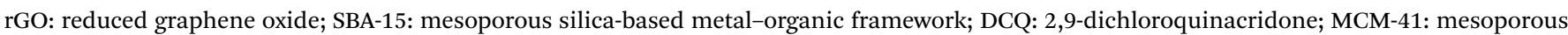

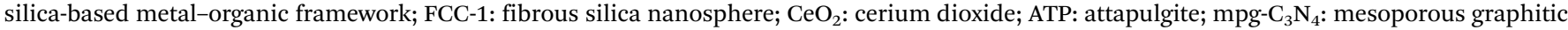
carbon nitride; GO: graphene oxide; DMF: dimethylformamide; LDH: layered double hydroxide.

performances of myriad nanomaterials in light-driven ODS systems with different operating parameters.

\section{Summary, challenges and future outlook}

Over the past few years, the desulfurization of fuels via ODS has gained traction and is anticipated to be the emerging technology in years to come to realize the milestone of environmentally friendly fuels, in contrast to conventional HDS. This has led to explosive interest in ODS in the field of environmental remediation. To this end, the many published works related to the application of catalysts, including metal oxides, ILs, DESs, POMs, MOFs, metal-free materials and their heterostructured composites, in the thermal-driven and light-driven ODS of fuel oils have been reviewed in individual sections and critically discussed in this comprehensive review. With the wide range of discovered ODS catalysts, this review is anticipated to deliver an instructive and interdisciplinary overview of the current progress in thermal-driven and light-driven ODS and methodically covers the intrinsic connections between their synthesis routes, modification approaches, physico-chemical properties, reaction pathways and catalytic performances in ODS. The relationships of the primary factors influencing the ODS processes with respect to different classes of catalysts is pictorially described in Fig. 23.

In light of the insufficient surface active sites in metal oxides, modification strategies, such as anchoring on a support, metal oxide doping and morphological tuning, have been carried 

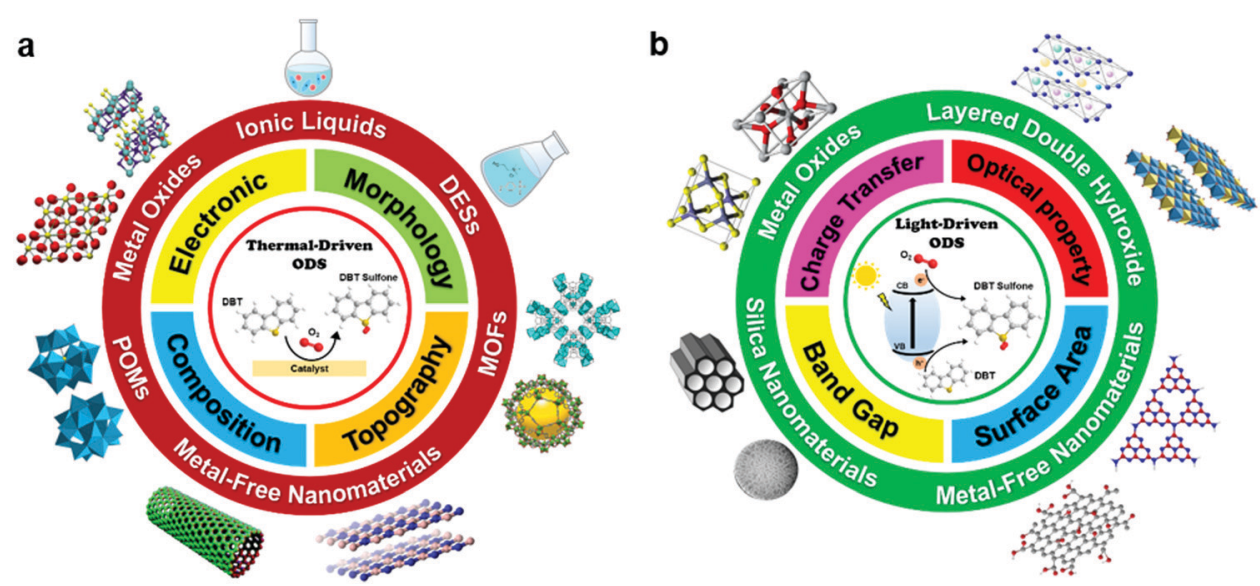

Fig. 23 A pictorial overview of (a) thermal-driven ODS and (b) light-driven ODS.

out to increase the electron density and specific surface area and improve their efficiency in catalyzing ODS. This has invigorated the exploration of POMs, which are capable of extraordinary mass transfer which facilitates the interactions between sulfur pollutants and the catalyst in ODS. However, the costly and intractable downstream separation process has tremendously restricted the further development of POMs until the emergence of various promising schemes, including precipitation with insoluble ions, immobilization on supports and hybridization, with the objective of increasing their heterogeneity in ODS systems. Bifunctional ILs and DESs have also widely served as the catalyst and extractant in ODS because of their facile recyclable properties, excellent catalytic activity and low thermal energy requirements. It is noted that DESs are more favorable than ILs because of their better environmental compatibility, higher biodegradability, cheaper raw materials and lower toxicity. In addition, MOFs have recently garnered considerable attention due to their large specific surface area, which is highly conducive to catalytic activity in ODS. Crucially, the accessibility of the active sites to sulfur compounds is substantially limited by the microporous structure in MOFs, resulting in relatively poor desulfurization rates in ODS. In addition to focusing on the Lewis active sites, the pore dimensions of MOFs are regarded as a pivotal property for attaining remarkable ODS activity. Of the metal-free nanomaterials, carbonaceous nanomaterials g- $\mathrm{C}_{3} \mathrm{~N}_{4}$ and BN have shown excellent results in ODS application, which are ascribed to their exceptional physico-chemical robustness and tailorable structures. However, their employment in ODS suffers from sluggish reaction kinetics which are far below the basic requirement for industrialization. In order to ameliorate the preceding shortfalls, MOFs and metal-free nanomaterials with robust surface area are often used as the anchoring sites for decoration with metal oxides and POMs. The hybridization of nanomaterials also exhibits an unprecedented synergistic influence on the catalytic performances in ODS. Embracing sustainable chemistry, solar energy as an inexhaustible driving force for ODS has been reported as a novel step toward zero-sulfur clean fuels. Though various explored semiconductors can effectively purify fuels, light-driven ODS is burdened with several daunting challenges, such as a swift charge carrier recombination rate and narrow light absorption range, which have not been entirely resolved.

On top of the foregoing challenges, there are still many issues which must be surmounted to formulate an efficacious and eco-friendly ODS process, thereby accelerating the commercialization progress of ODS. Since a catalyst is an essential booster for ODS, the engineering of nanomaterials is a momentous mission for the materials science community in the search for outstanding ODS activity and recyclability. Until now, knowledge of the optimal operating parameters, including temperature, reaction time, precursor species and others, for the fabrication of ODS catalysts has not been fully exploited, but is of vital importance for customizing favorable catalyst properties to pursue maximum ODS activity. In spite of the numerous studies that have reported successful formation of ODS catalysts, the reproducibility and scalability of the syntheses are still in their infancy. Additionally, some innovative methods like the sonochemical and microwave-assisted routes are not developed enough for the mass production of nanomaterials due to concerns about the safety and controllability of catalyst properties. Therefore, more emphasis should be placed on the optimization and upscaling of synthesis to reveal their exact feasibility and potential in industrial applications. Moreover, the search for relatively streamlined and energy-efficient process routes will work in the long run to replace energy-intensive synthesis techniques.

It is noteworthy that the stability of ODS catalysts remains an urgent hurdle for industrial scale ODS. In this regard, additional investigations must suppress catalytic deactivation to achieve a durable and effectual ODS catalyst. For instance, the reinforcement of substrate-support interactions in nanocomposites and the refinement of pore size are pragmatic practices to respectively hinder the leaching phenomenon and the blockage of pores by oxidized sulfur compounds which are the major root causes of catalytic deactivation in ODS. On the other hand, the critical effect of various hydrocarbons in commercial fuels on the robustness of as-designed ODS catalysts has not been unambiguously explored, as the aforementioned 
ODS studies were typically performed on a lab scale by employing model fuels. Researchers should grasp the opportunity to thoroughly examine the activity and stability of ODS catalysts in various real fuels with a wide range of olefins and aromatic sulfur compounds, which is essential for the development of state-ofthe-art ODS catalysts to adapt to real fuel conditions. Furthermore, it is an arduous task to alleviate the agglomeration of nanoscale particles as the total surface energy or the attraction force between particles increases with the reduction of particle size. To guarantee the highest exposure of catalytic site in ODS, surface functionalization, which ameliorates the vigorous surface charge by introducing appropriate functional groups, will be a fruitful procedure. Further study should be undertaken to shed more light on the effects of multifarious functional groups on the morphology, topography and catalytic performance of ODS catalysts, targeted at easing the functional group screening process to further comprehend the structure-activity relationship.

For green chemistry, a growing number of studies adopt lowpriced and hazard-free $\mathrm{O}_{2}$ as the oxidant in ODS. However, the utilization of $\mathrm{O}_{2}$ in ODS requires relatively more thermal or light energy, as well as a longer reaction time to accomplish ultra-deep desulfurization because of its stable molecular structure. As such, improvements are demanded to elevate the activity of ODS catalysts while reducing the energy consumption and boosting the efficiency of ODS systems using $\mathrm{O}_{2}$. Also, the existing separation technologies, such as solvent extraction, for removing the oxidized sulfur compounds from the clean fuels, possess a number of drawbacks, such as the generation of enormous amounts of wastewater and the high risk of fuel contamination, which are great and unceasing concerns for industrial ODS processes. A comparably facile, cost-effective and environmentally safe post-treatment process is pending discovery for its practical advantages and warrants a concerted effort from multidisciplinary researchers. It is also hugely challenging to curtail the competitive impact of the oxidation of hydrocarbons on the oxidation of sulfur compounds in ODS. This necessitates plausible countermeasures to promote the selectivity of ODS catalysts toward sulfur compounds to circumvent undesirable yield loss of fuels.

Given the challenges, there are boundless opportunities for further advancement of this fast-paced research field. On the road to practical ODS applications, a colossal amount of trial and error is mandatory for finding satisfactory materials with prominent catalytic properties, as well as developing viable catalyst modification techniques. To address the timeconsuming process, more attention should be paid to computational chemistry methods, namely DFT calculations and molecular dynamics, to assist in the interpretation of experimental data and contribute a mechanistic understanding of the structure-activity relationship, worthwhile information for the rational design of ODS catalysts. In addition, the molecular structure, properties and possible reaction mechanisms in ODS of newly discovered materials can be predicted via computational model or simulation to establish a plentiful material chemical data library. As the world moves into the information age, it is anticipated that the further incorporation of intelligence technology, including artificial intelligence (AI), big data technology, and the Internet of Things (IoTs), to perform in-depth analysis using available databases can prevent the waste of time and research capital in experimental work. Besides expediting the material screening process, encountered bottlenecks in the engineering of ODS catalysts would be addressed by applying these frontline technologies. The growth of 3D and 4D printing has opened a window to the prospective synthesis of ODS catalysts in the future. By means of design software, the properties and geometries of material can be facilely controlled to configure an ODS catalyst with outstanding catalytic activity. More significantly, 3D and 4D printing would be a promising tool to replace existing intricate synthesis techniques and could be a great leap forward for the advancement of ODS. The synergy between computational study, experimental work and smart technologies can constitute useful guidance for the research direction in this trending area and effectively drive the commercialization of ODS.

In the catalysis world, noticeable effort has been directed toward the development of multifunctional catalysts which can carry out multiple catalytic reactions concurrently. It is envisaged that the coupling of thermal and light-harvesting properties into a single catalyst to drive ODS will be very helpful in balancing energy consumption and reaction efficiency, as well as essentially enhancing the industrial practicality of ODS. As an example, a multifunctional ODS catalyst allows an effortless shift from light-driven ODS to thermal-driven ODS to maintain a high ODS reaction rate in poor light intensity conditions. In another stratagem, adsorption capability can be endowed to the ODS catalyst to capture the oxidized sulfur compounds and streamline the post-treatment process. In other words, the oxidized sulfone can be removed together with the ODS catalyst from the fuel through a simple filtration process instead of an environmentally harmful chemical separation process. Moreover, the hybridization of different materials to create ODS catalysts with the ability to simultaneously perform ODS and oxidative denitrogenation (ODN) will establish a new frontier in the arena of fuel purification. ${ }^{254}$ The one-step degradation of sulfur and nitrogen-containing compounds in fuels kills two birds with one stone, offers enormous economic benefit, and diminishes the deleterious impacts on both the environment and the efficiency of oil processing. The design of multipurpose ODS catalysts is not solely limited to the abovementioned applications, but many opportunities are still waiting to be uncovered, such as the fusion of different oil refinery processes with the ODS reaction. In summary, a diagrammatic synopsis for the future perspectives of ODS is shown in Fig. 24.

The achievement of zero-sulfur fuels via ODS still demands strenuous endeavors from cross-disciplinary researchers all around the world to engineer materials with superlative ODS catalytic performance, controllable and scalable synthesis, and high affordability and availability. Last but not least, collaborative action between local governments, industrial players and scholars is of paramount significance to transform the ODS process from laboratory scale to industrial scale, thereby mitigating the environmental crisis stemming from the combustion 


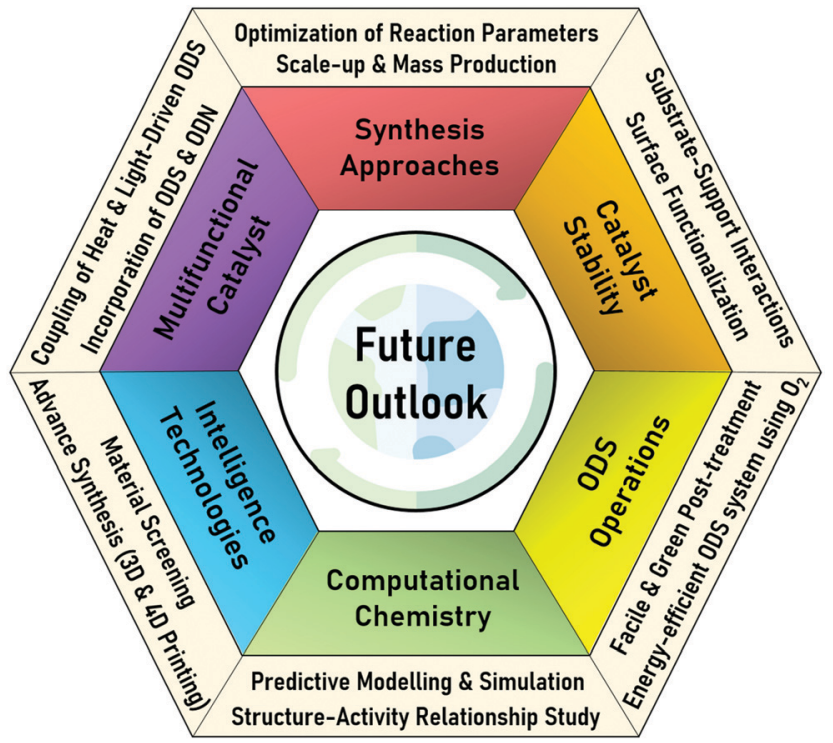

Fig. 24 Summary of the future outlook for ODS in the areas of synthesis approaches, improvement of catalyst stability, fine-tuning of operations, integration of computational chemistry, employment of intelligence technologies and engineering of multifunctional catalysts.

of fossil fuel. With such sustainable and efficacious desulfurization technology, we strongly believe that the dawn of a decent and clean environment is no longer out of reach.

\section{Author contributions}

X. B. L. was involved in project conceptualization, investigation, writing - original draft and writing - review and editing. W.-J. O. was involved in project administration, resources, supervision, writing - review and editing, as well as funding acquisition.

\section{Conflicts of interest}

There are no conflicts of interests to declare.

\section{Acknowledgements}

The authors would like to acknowledge the financial support provided by the Ministry of Higher Education (MOHE) Malaysia under the Fundamental Research Grant Scheme (FRGS) (Ref no. FRGS/1/2020/TK0/XMU/02/1). This work is also funded by Hengyuan International Sdn. Bhd. (Grant no. EENG/0003), Xiamen University Malaysia Investigatorship Grant (Grant no. IENG/0038) and Xiamen University Malaysia Research Fund (XMUMRF/2019-C3/IENG/0013).

\section{Notes and references}

1 C. Nunez, What is acid rain? https://www.national geographic.com/environment/global-warming/acid-rain/, accessed 11 November, 2020.
2 U.S. Environmental Protection Agency, Sulfur Dioxide $\left(\mathrm{SO}_{2}\right)$ Pollution, https://www.epa.gov/so2-pollution/sulfur-dioxidebasics\#: :text=What\%20are\%20the\%20environmental\% 20effects,which\%20can\%20harm\%20sensitive\%20ecosys tems, accessed 11 November, 2020.

3 U.S. Environmental Protection Agency, Particle Pollution Exposure, https://www.epa.gov/pmcourse/particle-pollutionexposure, accessed 10 November, 2020.

4 J. A. Rodriguez and J. Hrbek, Acc. Chem. Res., 1999, 32, 719-728.

5 D. E. Winterbone and A. Turan, in Advanced Thermodynamics for Engineers, ed. D. E. Winterbone and A. Turan, Butterworth-Heinemann, Boston, 2nd edn, 2015, pp. 307-322, DOI: 10.1016/B978-0-444-63373-6.00014-9.

6 U.S. Environmental Protection Agency, Diesel Fuel Standards and Rulemakings, https:/www.epa.gov/diesel-fuelstandards/diesel-fuel-standards-and-rulemakings, accessed 11 November, 2020.

7 X. Weng, L. Cao, G. Zhang, F. Chen, L. Zhao, Y. Zhang, J. Gao and C. Xu, Ind. Eng. Chem. Res., 2020, 59, 21261-21274.

8 A. Tanimu and K. Alhooshani, Energy Fuels, 2019, 33, 2810-2838.

9 R. A. Sánchez-Delgado, Organometallic Modeling of the Hydrodesulfurization and Hydrodenitrogenation Reactions, Springer, Netherlands, Dordrecht, 2002, pp. 1-34, DOI: 10.1007/0-306-47619-3_1.

10 W. Lai, Z. Chen, J. Zhu, L. Yang, J. Zheng, X. Yi and W. Fang, Nanoscale, 2016, 8, 3823-3833.

11 M. A. Betiha, A. M. Rabie, H. S. Ahmed, A. A. Abdelrahman and M. F. El-Shahat, Egypt. J. Pet., 2018, 27, 715-730.

12 X. Ma, K. Sakanishi and I. Mochida, Ind. Eng. Chem. Res., 1994, 33, 218-222.

13 W. Nabgan, M. Rashidzadeh and B. Nabgan, Environ. Chem. Lett., 2018, 16, 507-522.

14 I. Shafiq, S. Shafique, P. Akhter, W. Yang and M. Hussain, Catal. Rev., 2020, 1-86, DOI: 10.1080/01614940.2020. 1780824.

15 P. Tan, Y. Jiang, L.-B. Sun, X.-Q. Liu, K. AlBahily, U. Ravon and A. Vinu, J. Mater. Chem. A, 2018, 6, 23978-24012.

16 K. X. Lee and J. A. Valla, React. Chem. Eng., 2019, 4, 1357-1386.

17 I. Ahmed and S. H. Jhung, J. Hazard. Mater., 2016, 301, 259-276.

18 G. Mohebali and A. S. Ball, Int. Biodeterior. Biodegrad., 2016, 110, 163-180.

19 S. Kumar, V. C. Srivastava and S. M. Nanoti, Sep. Purif. Rev., 2017, 46, 319-347.

20 M. F. Majid, H. F. Mohd Zaid, C. F. Kait, K. Jumbri, L. C. Yuan and S. Rajasuriyan, J. Mol. Liq., 2020, 306, 112870.

21 P. Sikarwar, V. Gosu and V. Subbaramaiah, Rev. Chem. Eng., 2019, 35, 669-705.

22 Z. Ismagilov, S. Yashnik, M. Kerzhentsev, V. Parmon, A. Bourane, F. M. Al-Shahrani, A. A. Hajji and O. R. Koseoglu, Catal. Rev.: Sci. Eng., 2011, 53, 199-255.

23 M. M. H. Mondol, B. N. Bhadra and S. H. Jhung, Appl. Catal., B, 2021, 119988, DOI: 10.1016/j.apcatb.2021. 119988. 
24 J. He, P. Wu, L. Chen, H. Li, M. Hua, L. Lu, Y. Wei, Y. Chao, S. Zhou, W. Zhu and H. Li, Chem. Eng. J., 2021, 129022, DOI: 10.1016/j.cej.2021.129022.

25 M. F. Ali, A. Al-Malki, B. El-Ali, G. Martinie and M. N. Siddiqui, Fuel, 2006, 85, 1354-1363.

26 A. Rajendran, T.-y. Cui, H.-x. Fan, Z.-f. Yang, J. Feng and W.-y. Li, J. Mater. Chem. A, 2020, 8, 2246-2285.

27 X. Zhou, T. Wang, H. Liu, X. Gao, C. Wang and G. Wang, ChemSusChem, 2020, 14, 492-511.

28 M. Haghighi and S. Gooneh-Farahani, Environ. Sci. Pollut. Res., 2020, 27, 39923-39945.

29 M. N. Hossain, H. C. Park and H. S. Choi, Catalysts, 2019, 9, 229.

30 I. Shafiq, S. Shafique, P. Akhter, M. Ishaq, W. Yang and M. Hussain, J. Cleaner Prod., 2020, 125731, DOI: 10.1016/ j.jclepro.2020.125731.

31 M. H. Ibrahim, M. Hayyan, M. A. Hashim and A. Hayyan, Renewable Sustainable Energy Rev., 2017, 76, 1534-1549.

32 F. Liu, J. Yu, A. B. Qazi, L. Zhang and X. Liu, Environ. Sci. Technol., 2021, 55, 1419-1435.

33 H. Zhao and G. A. Baker, Front. Chem. Sci. Eng., 2015, 9, 262-279.

34 J. Li, Z. Yang, S. Li, Q. Jin and J. Zhao, J. Ind. Eng. Chem., 2020, 82, 1-16.

35 C. G. Piscopo, C. M. Granadeiro, S. S. Balula and D. Bošković, ChemCatChem, 2020, 12, 4721-4731.

36 L. Hao, M. J. Hurlock, G. Ding and Q. Zhang, Top. Curr. Chem., 2020, 378, 17.

37 J. G. Martinez, Top 10 Emerging Technologies 2020, World Economic Forum, 2020.

38 S. Houda, C. Lancelot, P. Blanchard, L. Poinel and C. Lamonier, Catalysts, 2018, 8, 344.

39 G. L. Wu, Y. C. Yin, W. B. Chen, F. Xin, Y. T. Lu, K. Qin, L. Zhang, Y. X. Song and M. F. Li, Chem. Eng. Sci., 2020, 214, 115446.

40 B. Wang, C. K. Xiao, P. F. Li, Z. S. Zhao, C. M. Xu, Z. Zhao, Q. Meng, J. M. Li, A. J. Duan and Z. T. Chen, Ind. Eng. Chem. Res., 2018, 57, 11868-11882.

41 C. Peng, R. Guo, X. Feng and X. C. Fang, Chem. Eng. J., 2019, 377, 119706.

42 S. Dasgupta, P. Gupta, Aarti, A. Nanoti, A. N. Goswami, M. O. Garg, E. Tangstad, O. B. Vistad, A. Karlsson and M. Stocker, Fuel, 2013, 108, 184-189.

43 X. He and C. Zhang, J. Mater. Sci., 2019, 54, 8831-8851.

44 D. Ravelli, D. Dondi, M. Fagnoni and A. Albini, Chem. Soc. Rev., 2009, 38, 1999-2011.

45 X. Chen, N. Li, Z. Kong, W.-J. Ong and X. Zhao, Mater. Horiz., 2018, 5, 9-27.

46 W.-J. Ong, L. K. Putri and A. R. Mohamed, Chem. - Eur. J., 2020, 26, 9710-9748.

47 W. Zhang, A. R. Mohamed and W.-J. Ong, Angew. Chem., Int. Ed., 2020, 59, 22894-22915.

48 M. R. Hoffmann, S. T. Martin, W. Y. Choi and D. W. Bahnemann, Chem. Rev., 1995, 95, 69-96.

49 A. Samokhvalov, ChemPhysChem, 2011, 12, 2870-2885.

50 M. Zarrabi, M. H. Entezari and E. K. Goharshadi, RSC Adv., 2015, 5, 34652-34662.
51 W.-J. Ong and K. P. Y. Shak, Sol. RRL, 2020, 4, 2000132.

52 J. Peng, X. Chen, W.-J. Ong, X. Zhao and N. Li, Chem, 2019, $5,18-50$.

53 C. N. C. Hitam, A. A. Jalil and A. A. Abdulrasheed, J. Ind. Eng. Chem., 2019, 74, 172-186.

54 A. Samokhvalov, Catal. Rev.: Sci. Eng., 2012, 54, 281-343.

55 A. Bourane, O. Koseoglu, A. Al-Hajji, F. Adam and H. Muller, React. Kinet., Mech. Catal., 2019, 126, 365-382.

56 M. W. Wan, M. D. G. de Luna, L. R. Golosinda, C. M. Futalan, P. Phatai and M. C. Lu, Clean Technol. Environ. Policy, 2019, 21, 1459-1469.

57 D. Julião, F. Mirante, S. O. Ribeiro, A. C. Gomes, R. Valenca, J. C. Ribeiro, M. Pillinger, B. de Castro, I. S. Gonçalves and S. S. Balula, Fuel, 2019, 241, 616-624.

58 J. C. Vedrine, ChemSusChem, 2019, 12, 577-588.

59 S.-F. Ng, M. Y. L. Lau and W.-J. Ong, Adv. Mater., 2021, 2008654, DOI: 10.1002/adma.202008654.

60 A. A. Olajire, A. Kareem and A. Olaleke, J. Nanostruct. Chem., 2017, 7, 159-170.

61 M. Liu, J. He, P. Wu, L. Lu, C. Wang, L. Chen, M. Hua, W. Zhu and H. Li, Inorg. Chem. Front., 2020, 7, 1212-1219.

62 W. A. W. Abu Bakar, R. Ali, A. A. A. Kadir and W. N. A. W. Mokhtar, Fuel Process. Technol., 2012, 101, 78-84.

63 A. Akbari, M. Omidkhah and J. T. Darian, Ultrason. Sonochem., 2014, 21, 692-705.

64 L. Cedeno-Caero, H. Gomez-Bernal, A. Fraustro-Cuevas, H. D. Guerra-Gomez and R. Cuevas-Garcia, Catal. Today, 2008, 133, 244-254.

65 C. Deng, P. Wu, L. Zhu, J. He, D. Tao, L. Lu, M. He, M. Hua, H. Li and W. Zhu, Appl. Mater. Today, 2020, 20, 100680.

66 J. He, P. Wu, Y. Wu, H. Li, W. Jiang, S. Xun, M. Zhang, W. Zhu and H. Li, ACS Sustainable Chem. Eng., 2017, 5, 8930-8938.

67 W. Jin, Y. Tian, G. Wang, D. Zeng, Q. Xu and J. Cui, RSC Adv., 2017, 7, 48208-48213.

68 A. Liu, M. Zhu and B. Dai, Appl. Catal., A, 2019, 583, 117134.

69 J. Luis Garcia-Gutierrez, G. C. Laredo, P. Garcia-Gutierrez and F. Jimenez-Cruz, Fuel, 2014, 138, 118-125.

70 S. Xun, C. Hou, H. Li, M. He, R. Ma, M. Zhang, W. Zhu and H. Li, J. Mater. Sci., 2018, 53, 15927-15938.

71 J. T. Sampanthar, H. Xiao, H. Dou, T. Y. Nah, X. Rong and W. P. Kwan, Appl. Catal., B, 2006, 63, 85-93.

72 X. Carrier, S. Royer and E. Marceau, Metal Oxides, Metal Oxides in Heterogeneous Catalysis, 2018, ch. 43, p. 61.

73 W. R. K. Thalgaspitiya, T. Kankanam Kapuge, J. He, D. Rathnayake and S. L. Suib, Appl. Mater. Today, 2020, 19, 100616.

74 M. Zhang, W. Liao, Y. Wei, C. Wang, Y. Fu, Y. Gao, L. Zhu, W. Zhu and H. Li, ACS Appl. Nano Mater., 2021, 4, 1085-1093.

75 Q. Zhang, J. Zhang, H. Yang, Y. Dong, Y. Liu, L. Yang, D. Wei, W. Wang, L. Bai and H. Chen, Catal. Sci. Technol., 2019, 9, 2915-2922.

76 Y. Liu, L. Han, J. Zhang, R. Yao, H. Zhan, H. Yang, L. Bai, L. Yang, D. Wei and W. Wang, Ind. Eng. Chem. Res., 2020, 59, 6488-6496. 
77 Y. Dong, J. Zhang, Z. Ma, H. Xu, H. Yang, L. Yang, L. Bai, D. Wei, W. Wang and H. Chen, Chem. Commun., 2019, 55, 13995-13998.

78 Y. Jia, G. Li and G. Ning, Fuel Process. Technol., 2011, 92, 106-111.

79 W. N. A. W. Mokhtar, W. A. W. Abu Bakar, R. Ali and A. A. A. Kadir, Arabian J. Chem., 2018, 11, 1201-1208.

80 Z. E. A. Abdalla, B. Li and A. Tufail, J. Ind. Eng. Chem., 2009, 15, 780-783.

81 D. Wang, E. W. Qian, H. Amano, K. Okata, A. Ishihara and T. Kabe, Appl. Catal., A, 2003, 253, 91-99.

82 R. Sheldon, J. Mol. Catal., 1980, 7, 107-126.

83 O. Gonzalez-Garcia and L. Cedeno-Caero, Catal. Today, 2009, 148, 42-48.

84 M. Muñoz, L. J. Mendoza-Herrera, G. P. Romanelli, D. Gazzoli and C. I. Cabello, Catal. Today, 2020, DOI: 10.1016/j.cattod.2020.10.011.

85 X. W. Lv, C. C. Weng, Y. P. Zhu and Z. Y. Yuan, Small, 2021, 2005304, DOI: 10.1002/smll.202005304.

86 L. Chen, Z.-P. Hu, J.-T. Ren, Z. Wang and Z.-Y. Yuan, Microporous Mesoporous Mater., 2021, 315, 110921.

87 S. Xun, Q. Ti, Z. Jiao, L. Wu, M. He, L. Chen, L. Zhu, W. Zhu and H. Li, Ind. Eng. Chem. Res., 2020, 59, 18471-18479.

88 R. Zhao, X. Li, J. Su and X. Gao, Appl. Surf. Sci., 2017, 392, 810-816.

89 R. Ma, J. Guo, D. Wang, M. He, S. Xun, J. Gu, W. Zhu and H. Li, Colloids Surf., A, 2019, 572, 250-258.

90 C. Wang, Y. Qiu, H. Wu, W. Yang, Q. Zhu, Z. Chen, S. Xun, W. Zhu and H. Li, Fuel, 2020, 270, 117498.

91 S. Said and A. A. Abdelrahman, J. Sol-Gel Sci. Technol., 2020, 95, 308-320.

92 Y. Qin, S. Xun, L. Zhan, Q. Lu, M. He, W. Jiang, H. Li, M. Zhang, W. Zhu and H. Li, New J. Chem., 2017, 41, 569-578.

93 Y. Cao, H. Wang, R. Ding, L. Wang, Z. Liu and B. Lv, Appl. Catal., A, 2020, 589, 117308.

94 C. Wang, W. Jiang, H. Chen, L. Zhu, J. Luo, W. Yang, G. Chen, Z. Chen, W. Zhu and H. Li, Chin. J. Catal., 2021, 42, 557-562.

95 C. Wang, A. Li, J. Xu, J. Wen, H. Zhang and L. Zhang, J. Chem. Technol. Biotechnol., 2019, 94, 3403-3412.

96 S.-W. Li, W. Wang and J.-S. Zhao, Appl. Catal., A, 2020, 602, 117671.

97 Q. Luo, Q. Zhou, Y. Lin, S. Wu, H. Liu, C. Du, Y. Zhong and C. Yang, Catal. Sci. Technol., 2019, 9, 6166-6179.

98 L. Seifikar Gomi and M. Afsharpour, Appl. Organomet. Chem., 2019, 33, e4830.

99 S.-W. Li, W. Wang and J.-S. Zhao, Appl. Catal., B, 2020, 277, 119224.

100 S. K. Singh and A. W. Savoy, J. Mol. Liq., 2020, 297, 112038.

101 A. Bösmann, L. Datsevich, A. Jess, A. Lauter, C. Schmitz and P. Wasserscheid, Chem. Commun., 2001, 2494-2495, DOI: 10.1039/B108411A.

102 C. Dai, J. Zhang, C. Huang and Z. Lei, Chem. Rev., 2017, 117, 6929-6983.

103 X. Chen, H. Guo, A. A. Abdeltawab, Y. Guan, S. S. Al-Deyab, G. Yu and L. Yu, Energy Fuels, 2015, 29, 2998-3003.
104 Y.-F. Guo, C.-Y. Gao, K.-G. Yang, Z.-J. Wang, Y.-H. Duan, S.-X. Feng and H. Xu, Energy Fuels, 2019, 33, 10728-10733.

105 H. A. Elwan, M. T. Zaky, A. S. Farag, F. S. Soliman and M. Ezel Dean Hassan, J. Mol. Liq., 2017, 248, 549-555.

106 H. A. Elwan, M. T. Zaky, A. S. Farag, F. S. Soliman and M. E. D. Hassan, J. Mol. Liq., 2020, 310, 113146.

107 M. Zhang, J. Liu, H. Li, Y. Wei, Y. Fu, W. Liao, L. Zhu, G. Chen, W. Zhu and H. Li, Appl. Catal., B, 2020, 271, 118936.

108 M. Safa, B. Mokhtarani, H. R. Mortaheb and K. Tabar Heidar, Energy Fuels, 2016, 30, 10909-10916.

109 Y. Chen, H.-y. Song, Y.-z. Lu, H. Meng, C.-x. Li, Z.-g. Lei and B.-h. Chen, Ind. Eng. Chem. Res., 2016, 55, 10394-10403.

110 S. Xun, W. Jiang, T. Guo, M. He, R. Ma, M. Zhang, W. Zhu and H. Li, J. Colloid Interface Sci., 2019, 534, 239-247.

111 W. Jiang, H. Jia, X. Fan, L. Dong, T. Guo, L. Zhu, W. Zhu and H. Li, Appl. Surf. Sci., 2019, 484, 1027-1034.

112 L. Zhang, J. Wang, Y. Sun, B. Jiang and H. Yang, Chem. Eng. J., 2017, 328, 445-453.

113 A. P. Abbott, G. Capper, D. L. Davies, R. K. Rasheed and V. Tambyrajah, Chem. Commun., 2003, 70-71, DOI: 10.1039/B210714G.

114 D. Chandran, M. Khalid, R. Walvekar, N. M. Mubarak, S. Dharaskar, W. Y. Wong and T. C. S. M. Gupta, J. Mol. Liq., 2019, 275, 312-322.

115 E. L. Smith, A. P. Abbott and K. S. Ryder, Chem. Rev., 2014, 114, 11060-11082.

116 F. Lima, L. C. Branco, A. J. D. Silvestre and I. M. Marrucho, Fuel, 2021, 293, 120297.

117 Z. Zhu, H. Lü, M. Zhang and H. Yang, Phys. Chem. Chem. Phys., 2021, 23, 785-805.

118 J. Yin, J. Wang, Z. Li, D. Li, G. Yang, Y. Cui, A. Wang and C. Li, Green Chem., 2015, 17, 4552-4559.

119 L. Hao, M. Wang, W. Shan, C. Deng, W. Ren, Z. Shi and H. Lü, J. Hazard. Mater., 2017, 339, 216-222.

120 C.-f. Mao, R.-x. Zhao and X.-p. Li, $R S C A d v ., 2017$, 7, 42590-42596.

121 L. Hao, T. Su, D. Hao, C. Deng, W. Ren and H. Lü, Chin. J. Catal., 2018, 39, 1552-1559.

122 H. Lü, P. Li, C. Deng, W. Ren, S. Wang, P. Liu and H. Zhang, Chem. Commun., 2015, 51, 10703-10706.

123 W. Jiang, K. Zhu, H. Li, L. Zhu, M. Hua, J. Xiao, C. Wang, Z. Yang, G. Chen, W. Zhu, H. Li and S. Dai, Chem. Eng. J., 2020, 394, 124831.

124 W. Jiang, H. Jia, H. Li, L. Zhu, R. Tao, W. Zhu, H. Li and S. Dai, Green Chem., 2019, 21, 3074-3080.

125 W. Liu, T. Li, G. Yu, J. Wang, Z. Zhou and Z. Ren, Fuel, 2020, 265, 116967.

126 L. Sun, Z. Zhu, T. Su, W. Liao, D. Hao, Y. Chen, Y. Zhao, W. Ren, H. Ge and H. Lü, Appl. Catal., B, 2019, 255, 117747.

127 H. Xu, D. Zhang, F. Wu, X. Wei and J. Zhang, Fuel, 2018, 225, 104-110.

128 W. Zhu, P. Wu, Y. Chao, H. Li, F. Zou, S. Xun, F. Zhu and Z. Zhao, Ind. Eng. Chem. Res., 2013, 52, 17399-17406.

129 W. Jiang, L. Dong, W. Liu, T. Guo, H. Li, M. Zhang, W. Zhu and H. Li, RSC Adv., 2017, 7, 55318-55325. 
130 C. M. Granadeiro, P. M. C. Ferreira, D. Juliao, L. A. Ribeiro, R. Valenca, J. C. Ribeiro, I. S. Goncalves, B. de Castro, M. Pillinger, L. Cunha-Silva and S. S. Balula, Energies, 2018, 11, 1696.

131 B. Bertleff, J. Claussnitzer, W. Korth, P. Wasserscheid, A. Jess and J. Albert, ACS Sustainable Chem. Eng., 2017, 5, 4110-4118.

132 R. Wang, G. Zhang and H. Zhao, Catal. Today, 2010, 149, 117-121.

133 S. O. Ribeiro, C. M. Granadeiro, P. L. Almeida, J. Pires, M. C. Capel-Sanchez, J. M. Campos-Martin, S. Gago, B. de Castro and S. S. Balula, Catal. Today, 2019, 333, 226-236.

134 J. Xu, Z. Zhu, T. Su, W. Liao, C. Deng, D. Hao, Y. Zhao, W. Ren and H. Lu, Chin. J. Catal., 2020, 41, 868-876.

135 H. Li, C. Lian, L. Chen, J. Zhao and G.-Y. Yang, Nanoscale, 2020, 12, 16091-16101.

136 P. Deshlahra, Encyclopedia of Interfacial Chemistry, 2018, pp. 553-559, DOI: 10.1016/B978-0-12-409547-2.14126-5.

137 A. E. S. Choi, S. Roces, N. Dugos and M.-W. Wan, Fuel, 2016, 180, 127-136.

138 A. E. S. Choi, S. Roces, N. Dugos and M.-W. Wan, Sustainable Environ. Res., 2016, 26, 184-190.

139 W. Trakarnpruk and K. Rujiraworawut, Fuel Process. Technol., 2009, 90, 411-414.

140 M. Ammam, J. Mater. Chem. A, 2013, 1, 6291-6312.

141 A. Blazevic and A. Rompel, Coord. Chem. Rev., 2016, 307, 42-64.

142 C. Komintarachat and W. Trakarnpruk, Ind. Eng. Chem. Res., 2006, 45, 1853-1856.

143 M. Te, C. Fairbridge and Z. Ring, Appl. Catal., A, 2001, 219, 267-280.

144 N. Mizuno, K. Kamata and K. Yamaguchi, in Bifunctional Molecular Catalysis, ed. T. Ikariya and M. Shibasaki, 2011, vol. 37, pp. 127-160.

145 A. Akbari, M. Chamack and M. Omidkhah, J. Mater. Sci., 2020, 55, 6513-6524.

146 X. Li, P. Li, J. Liu, Z. Lin and C. Hu, RSC Adv., 2020, 10, 22515-22521.

147 F. Mirante, A. C. Alves, D. Juliao, P. L. Almeida, S. Gago, R. Valenca, J. C. Ribeiro, B. de Castro, C. M. Granadeiro and S. S. Balula, Fuel, 2020, 259, 116213.

148 A. Mojaverian Kermani, V. Mahmoodi, M. Ghahramaninezhad and A. Ahmadpour, Sep. Purif. Technol., 2021, 258, 117960.

149 J. Xiao, L. Wu, Y. Wu, B. Liu, L. Dai, Z. Li, Q. Xia and H. Xi, Appl. Energy, 2014, 113, 78-85.

150 X. Liao, Y. Huang, Y. Zhou, H. Liu, Y. Cai, S. Lu and Y. Yao, Appl. Surf. Sci., 2019, 484, 917-924.

151 A. K. Dizaji, B. Mokhtarani and H. R. Mortaheb, Fuel, 2019, 236, 717-729.

152 Y. Zhu, M. Zhu, L. Kang, F. Yu and B. Dai, Ind. Eng. Chem. Res., 2015, 54, 2040-2047.

153 Z. Shokri Aghbolagh, M. R. Khanmohammadi Khorrami and M. S. Rahmatyan, Energy Fuels, 2020, 34, 16366-16380.

154 Z. Yu, X. Huang, S. Xun, M. He, L. Zhu, L. Wu, M. Yuan, W. Zhu and H. Li, J. Mol. Liq., 2020, 308, 113059.
155 Z. Ma, J. Zhang, H. Zhan, M. Xu, H. Yang, L. Yang, L. Bai, H. Chen, D. Wei and W. Wang, Process Saf. Environ. Prot., 2020, 140, 26-33.

156 Y. L. Peng, J. Y. Liu, H. F. Zhang, D. Luo and D. Li, Inorg. Chem. Front., 2018, 5, 1563-1569.

157 R. Abazari, L. Esrafili, A. Morsali, Y. Wu and J. Gao, Appl. Catal., B, 2021, 283, 119582.

158 C. Wang, A.-R. Li and Y.-L. Ma, Fuel Process. Technol., 2021, 212, 106629.

159 P. P. Wei, Y. Yang, W. Z. Li and G. M. Li, Fuel, 2020, 274, 117834.

160 Y. Lu, C. Yue, B. Liu, M. Zhang, Y. Li, W. Yang, Y. Lin, Y. Pan, D. Sun and Y. Liu, Microporous Mesoporous Mater., 2021, 311, 110694.

161 L. Xu, Y. Wang, T. Xu, S. Liu, J. Tong, R. Chu, X. Hou and B. Liu, ChemCatChem, 2018, 10, 5386-5390.

162 S. W. Li, R. M. Gao, R. L. Zhang and J. S. Zhao, Fuel, 2016, 184, 18-27.

163 S. W. Li, Z. Yang, R. M. Gao, G. Zhang and J. S. Zhao, Appl. Catal., B, 2018, 221, 574-583.

164 S. W. Li, J. R. Li, Q. P. Jin, Z. Yang, R. L. Zhang, R. M. Gao and J. S. Zhao, J. Hazard. Mater., 2017, 337, 208-216.

165 H. W. Yang, B. Jiang, Y. L. Sun, L. H. Zhang, Z. H. Huang, Z. N. Sun and N. Yang, J. Hazard. Mater., 2017, 333, 63-72.

166 H. Liu, Z. Li, J. Dong, D. Liu, C. Liu, Y. Chi and C. Hu, Nanoscale, 2020, 12, 16586-16595.

167 H. Zhang, X. Xu, H. Lin, M. A. Ud Din, H. Wang and X. Wang, Nanoscale, 2017, 9, 13334-13340.

168 G. Ye, L. Hu, Y. Gu, C. Lancelot, A. Rives, C. Lamonier, N. Nuns, M. Marinova, W. Xu and Y. Sun, J. Mater. Chem. A, 2020, 8, 19396-19404.

169 U. Mueller, M. Schubert, F. Teich, H. Puetter, K. SchierleArndt and J. Pastré, J. Mater. Chem., 2006, 16, 626-636.

170 H. Furukawa, K. E. Cordova, M. O'Keeffe and O. M. Yaghi, Science, 2013, 341, 974.

171 H.-C. Zhou, J. R. Long and O. M. Yaghi, Chem. Rev., 2012, 112, 673-674.

172 B. N. Bhadra and S. H. Jhung, Nanoscale, 2018, 10, 15035-15047.

173 M. Safaei, M. M. Foroughi, N. Ebrahimpoor, S. Jahani, A. Omidi and M. Khatami, TrAC, Trends Anal. Chem., 2019, 118, 401-425.

174 O. K. Farha and J. T. Hupp, Acc. Chem. Res., 2010, 43, 1166-1175.

175 N. Stock and S. Biswas, Chem. Rev., 2012, 112, 933-969.

176 S.-N. Kim, J. Kim, H.-Y. Kim, H.-Y. Cho and W.-S. Ahn, Catal. Today, 2013, 204, 85-93.

177 C. Valles-Garcia, A. Santiago-Portillo, M. Alvaro, S. Navalon and H. Garcia, Appl. Catal., A, 2020, 590, 117340.

178 X. Liao, X. Wang, F. Wang, Y. Yao and S. Lu, J. Inorg. Organomet. Polym. Mater., 2020, 31, 756-762, DOI: 10.1007/ s10904-020-01808-y.

179 Y. Zhang, G. Li, L. Kong and H. Lu, Fuel, 2018, 219, 103-110.

180 P. Yang, Y. Huang, Z.-W. Zhang, N. Li and Y. Fan, Dalton Trans., 2020, 49, 10052-10057. 
181 G. Ye, Y. Gu, W. Zhou, W. Xu and Y. Sun, ACS Catal., 2020, 10, 2384-2394.

182 M. Y. Masoomi, M. Bagheri and A. Morsali, Inorg. Chem., 2015, 54, 11269-11275.

183 H. Ma, Z. Zhu, P. Tang, T. Su, P. Wu and H. Lü, Microporous Mesoporous Mater., 2021, 311, 110702.

184 A. M. Viana, S. O. Ribeiro, B. de Castro, S. S. Balula and L. Cunha-Silva, Materials, 2019, 12, 3009.

185 X. Zhang, P. Huang, A. Liu and M. Zhu, Fuel, 2017, 209, 417-423.

186 W. Xiao, Q. Dong, Y. Wang, Y. Li, S. Deng and N. Zhang, CrystEngComm, 2018, 20, 5658-5662.

187 A. M. Viana, D. Juliao, F. Mirante, R. G. Faria, B. de Castro, S. S. Balula and L. Cunha-Silva, Catal. Today, 2021, 362, 28-34.

188 G. Fu, B. Bueken and D. De Vos, Small Methods, 2018, 2, 1800203.

189 S. Lee and W. Choe, Elaboration and Applications of MetalOrganic Frameworks, 2018, pp. 143-182, DOI: 10.1142/ 9789813226739_0003.

190 Y. Gu, G. Ye, W. Xu, W. Zhou and Y. Sun, ChemistrySelect, 2020, 5, 244-251.

191 X. Li, L. Zhang and Y. Sun, Catalysts, 2020, 10, 1091.

192 Z. Zhu, H. Ma, H. Xu, B. Wang, P. Wu and H. Lü, J. Hazard. Mater., 2020, 393, 122458.

193 J. R. Ludwig and C. S. Schindler, Chem, 2017, 2, 313-316.

194 L. Dai, Y. Xue, L. Qu, H.-J. Choi and J.-B. Baek, Chem. Rev., 2015, 115, 4823-4892.

195 Q. Zhao, Q. Mao, Y. Zhou, J. Wei, X. Liu, J. Yang, L. Luo, J. Zhang, H. Chen, H. Chen and L. Tang, Chemosphere, 2017, 189, 224-238.

196 D. C. Marcano, D. V. Kosynkin, J. M. Berlin, A. Sinitskii, Z. Sun, A. Slesarev, L. B. Alemany, W. Lu and J. M. Tour, ACS Nano, 2010, 4, 4806-4814.

197 W. S. Hummers Jr and R. E. Offeman, J. Am. Chem. Soc., 1958, 80, 1339.

198 S. Stankovich, D. A. Dikin, R. D. Piner, K. A. Kohlhaas, A. Kleinhammes, Y. Jia, Y. Wu, S. T. Nguyen and R. S. Ruoff, Carbon, 2007, 45, 1558-1565.

199 J. He, P. Wu, L. Lu, H. Sun, Q. Jia, M. Hua, M. He, C. Xu, W. Zhu and H. Li, Energy Fuels, 2019, 33, 8302-8311.

200 C. Xu, J. Chen, S. Li, Q. Gu, D. Wang, C. Jiang and Y. Liu, J. Hazard. Mater., 2021, 403, 123806.

201 S. Navalón, W.-J. Ong and X. Duan, Processes, 2020, 8, 672.

202 G. Abdi, A. Alizadeh and M. M. Khodaei, Mater. Chem. Phys., 2017, 201, 323-330.

203 G. Abdi, M. Ashokkumar and A. Alizadeh, Fuel, 2017, 210, 639-645.

204 Y. Zhang and R. Wang, Diamond Relat. Mater., 2017, 73, 161-168.

205 Q. Gu, G. Wen, Y. Ding, K.-H. Wu, C. Chen and D. Su, Green Chem., 2017, 19, 1175-1181.

206 Q. Gu, Y. Ding, Z. Liu, Y. Lin, R. Schloegl, S. Heumann and D. Su, J. Energy Chem., 2019, 32, 131-137.

207 Z. C. Kampouraki, D. A. Giannakoudakis, K. S. Triantafyllidis and E. A. Deliyanni, Green Chem., 2019, 21, 6685-6698.
208 T. S. Miller, A. B. Jorge, T. M. Suter, A. Sella, F. Cora and P. F. McMillan, Phys. Chem. Chem. Phys., 2017, 19, 15613-15638.

209 W.-J. Ong, L.-L. Tan, Y. H. Ng, S.-T. Yong and S.-P. Chai, Chem. Rev., 2016, 116, 7159-7329.

210 L. Shen, G. Lei, Y. Fang, Y. Cao, X. Wang and L. Jiang, Chem. Commun., 2018, 54, 2475-2478.

211 G. Lei, Y. Cao, W. Zhao, Z. Dai, L. Shen, Y. Xiao and L. Jiang, ACS Sustainable Chem. Eng., 2019, 7, 4941-4950.

212 Q. Jia, J. He, P. Wu, J. Luo, Y. Wei, H. Li, S. Xun, W. Zhu and H. Li, Mol. Catal., 2019, 468, 100-108.

213 Y. Wei, P. Wu, J. Luo, L. Dai, H. Li, M. Zhang, L. Chen, L. Wang, W. Zhu and H. Li, Microporous Mesoporous Mater., 2020, 293, 109788.

214 L. Lu, J. He, P. Wu, Y. Wu, Y. Chao, H. Li, D. Tao, L. Fan, H. Li and W. Zhu, Green Chem., 2018, 20, 4453-4460.

215 P. Wu, W. Zhu, Y. Chao, J. Zhang, P. Zhang, H. Zhu, C. Li, Z. Chen, H. Li and S. Dai, Chem. Commun., 2016, 52, 144-147.

216 Z. Quan, Y. Wang and J. Fang, Acc. Chem. Res., 2013, 46, 191-202.

217 P. Wu, L. Lu, J. He, L. Chen, Y. Chao, M. He, F. Zhu, X. Chu, H. Li and W. Zhu, Green Energy Environ., 2020, 5, 166-172.

218 N. Lv, L. Sun, L. Chen, Y. Li, J. Zhang, P. Wu, H. Li, W. Zhu and H. Li, Phys. Chem. Chem. Phys., 2019, 21, 21867-21874.

219 L. Dai, Y. Wei, X. Xu, P. Wu, M. Zhang, C. Wang, H. Li, Q. Zhang, H. Li and W. Zhu, ChemCatChem, 2020, 12, 1734-1742.

220 P. Wu, Y. Wu, L. Chen, J. He, M. Hua, F. Zhu, X. Chu, J. Xiong, M. He, W. Zhu and H. Li, Chem. Eng. J., 2020, 380, 122526.

221 J. He, Y. Wu, P. Wu, L. Lu, C. Deng, H. Ji, M. He, W. Zhu and H.-m. Li, ACS Sustainable Chem. Eng., 2020, 8, 2032-2039.

222 P. Wu, Q. Jia, J. He, L. Lu, L. Chen, J. Zhu, C. Peng, M. He, J. Xiong, W. Zhu and H. Li, J. Hazard. Mater., 2020, 391, 122183.

223 Y. Gao, Z. Y. Lv, R. M. Gao, G. Zhang, Y. Zheng and J. S. Zhao, J. Hazard. Mater., 2018, 359, 258-265.

224 H. Song, N. Zhu, B. Chen, F. Wang, M. Bai and X. Wang, Russ. J. Appl. Chem., 2016, 89, 2076-2083.

225 S. Matsuzawa, J. Tanaka, S. Sato and T. Ibusuki, J. Photochem. Photobiol., A, 2002, 149, 183-189.

226 H. Dong, G. Zeng, L. Tang, C. Fan, C. Zhang, X. He and Y. He, Water Res., 2015, 79, 128-146.

227 K. Kalantari, M. Kalbasi, M. Sohrabi and S. J. Royaee, Ceram. Int., 2016, 42, 14834-14842.

228 C. Wang, W. Zhu, Y. Xu, H. Xu, M. Zhang, Y. Chao, S. Yin, H. Li and J. Wang, Ceram. Int., 2014, 40, 11627-11635.

229 G. Zhang, M. Gao, M. Tian and W. Zhao, J. Solid State Chem., 2019, 279, 120953.

230 G. Guo, H. Guo, F. Wang, L. J. France, W. Yang, Z. Mei and Y. Yu, Green Energy Environ., 2020, 5, 114-120.

231 C. N. C. Hitam, A. A. Jalil and Y. O. Raji, Top. Catal., 2020, 63, 1169-1181.

232 K. Chen, X.-M. Zhang, X.-F. Yang, M.-G. Jiao, Z. Zhou, M.-H. Zhang, D.-H. Wang and X.-H. Bu, Appl. Catal., B, 2018, 238, 263-273. 
233 S. H. Ammar, Y. S. Kareem and A. D. Ali, J. Environ. Chem. Eng., 2018, 6, 6780-6786.

234 R. Ma, S. Zhang, T. Wen, P. Gu, L. Li, G. Zhao, F. Niu, Q. Huang, Z. Tang and X. Wang, Catal. Today, 2019, 335, 20-30.

235 X. Li, Z. Zhang, C. Yao, X. Lu, X. Zhao and C. Ni, Appl. Surf. Sci., 2016, 364, 589-596.

236 W. L. Haden and I. A. Schwint, Ind. Eng. Chem., 1967, 59, 58-69.

237 X. Li, W. Zhu, X. Lu, S. Zuo, C. Yao and C. Ni, Chem. Eng. J., 2017, 326, 87-98.

238 J. Cui, G. Wang, W. Liu, P. Ke, Q. Tian, X. Li and Y. Tian, Fuel, 2021, 290, 120066.

239 M. Mousavi-Kamazani and S. Ashrafi, Ultrason. Sonochem., 2020, 63, 104948.

240 Y. Yang, M. Wu, X. Zhu, H. Xu, S. Ma, Y. Zhi, H. Xia, X. Liu, J. Pan, J.-Y. Tang, S.-P. Chai, L. Palmisano, F. Parrino, J. Liu, J. Ma, Z.-L. Wang, L. Tan, Y.-F. Zhao, Y.-F. Song, P. Singh, P. Raizada, D. Jiang, D. Li, R. A. Geioushy, J. Ma, J. Zhang, S. Hu, R. Feng, G. Liu, M. Liu, Z. Li, M. Shao, N. Li, J. Peng, W.-J. Ong, N. Kornienko, Z. Xing, X. Fan and J. Ma, Chin. Chem. Lett., 2019, 30, 2065-2088.

241 Y. Ren, D. Zeng and W.-J. Ong, Chin. J. Catal., 2019, 40, 289-319.
242 Y. Li, X. Li, H. Zhang and Q. Xiang, Nanoscale Horiz., 2020, 5, 765-786.

243 X. Yu, S.-F. Ng, L. K. Putri, L.-L. Tan, A. R. Mohamed and W.-J. Ong, Small, 2021, 2006851, DOI: 10.1002/smll.202006851.

244 L. K. Putri, L.-L. Tan, W.-J. Ong, W. S. Chang and S.-P. Chai, Appl. Mater. Today, 2016, 4, 9-16.

245 Y. Zhu, X. Li and M. Zhu, Catal. Commun., 2016, 85, 5-8.

246 X. Zhang, H. Song, C. Sun, C. Chen, F. Han and X. Li, Mater. Chem. Phys., 2019, 226, 34-43.

247 X. Zeng, X. Xiao, Y. Li, J. Chen and H. Wang, Appl. Catal., B, 2017, 209, 98-109.

248 S.-F. Ng, M. Y. L. Lau and W.-J. Ong, Sol. RRL, 2021, 2000535, DOI: 10.1002/solr.202000535.

249 Z. Huang, H. Song, A. Li, Z. An, K. Zhang, X. Xiang, X. Shu and J. He, Energy Fuels, 2020, 34, 14676-14687.

250 Y. Cai, H. Song, Z. An, X. Xiang, X. Shu and J. He, Green Chem., 2018, 20, 5509-5519.

251 S. Masoumi and S. A. Hosseini, Fuel, 2020, 277, 118137.

252 B. Li, H. Song, F. Han and L. Wei, Appl. Catal., B, 2020, 269, 118845.

253 X. Y. Zeng, X. Y. Xiao, J. Y. Chen, Y. Wang and H. L. Wang, J. Hazard. Mater., 2020, 391, 122198.

254 M. Ja'fari, S. L. Ebrahimi and M. R. Khosravi-Nikou, Ultrason. Sonochem., 2018, 40, 955-968. 